The copyright of this thesis vests in the author. No quotation from it or information derived from it is to be published without full acknowledgement of the source. The thesis is to be used for private study or noncommercial research purposes only.

Published by the University of Cape Town (UCT) in terms of the non-exclusive license granted to UCT by the author. 


\title{
The effect of grassland shifts on the avifauna of a South African savanna
}

\author{
Kristine Krook \\ Submitted in fulfilment of the requirements of a degree of \\ Masters of science \\ Supervisor: Prof. William J. Bond \\ Co-supervisor: Prof. Philip A.R. Hockey \\ Botany Department \\ University of Cape Town \\ Rondebosch 7701
}

March 2005 


\section{Acknowledgements}

I would like to thank the National Research Foundation of South Africa and the Andrew Mellon foundation for funding. I thank Ezvemvelo KZN wildlife for permission to work within the reserve and management staff of the Hluhluwe Research Centre. Erick Khumalo, Sipho Zulu, Mendi Shelembe, Phumlani Zwane and Vincent Mkhwanasi from the Zululand Grass Project were fantastic field assistants who not only helped me, but provided much laughter and entertainment in the early mornings and on those 'stinking' hot field days. My armed guards Abednigo Mkhwanasi and Makateni Xulu chased many buffalo and black rhino off my study sites and provided many hours of entertaining discussion and stories on the meaning of life. I thank William Bond and Phil Hockey my supervisors for all their technical assistance and encouragement. Joe Craine, Micaela Szykman, Toni Krook and Matthew Waldram for advice and support. Lastly I thank my husband Rya n Clark for continually insisting on going fishing to refresh my mind during the writing up stage. 


\section{Abstract}

Two distinct grassland types occur within Hluhluwe-iMfolozi Park (HiP); short stoloniferous grazing lawns and tall, tussock-like 'bunch' grasslands. Grazing lawns are maintained by grazing mammals, among which White Rhinoceros Ceratotherium simum is of major importance. By contrast, tall bunch grasslands are promoted by frequent burning. The extent of each grassland type within the park is highly dynamic and can be altered by changes in mammal numbers and/or fire regimes. Such changes may have cascading consequences on other components of the ecosystem if they show specialisation towards one or other grassland state. This study compared avifaunal assemblages of grazing lawns and bunch grasslands to assess how bird species of the park might change with shifts in the grassland mosaic. Distinct bird communities were associated with each grassland type, including several specialists, and bird distribution was linked to vegetation structure, rather than floristics. Post-fire bunch grasslands provided ephemeral habitats for short grass specialists. Outside HiP, domestic livestock produced structurally similar grasslands to grazing lawns and bunch grasslands, but heavy predation of birds by people reduced bird densities. Because $\mathrm{HiP}$ is surrounded by such communal grazing lands, the park is of key importance in conserving grassland birds on a regional scale, a factor that needs to be considered in managing the park's grassland mosaic. 


\section{Table of Contents}

Acknowledgements $i$

Abstract $\quad$ ii

Table of Contents

Chapter 1: Introduction $I$

Thesis Outline 3

Note to the reader

Chapter 2: Site Area $\quad 5$

Geology 5

Mammal fauna $\quad 5$

Vegetation 6

Avifauna 8

Fire 9

Chapter 3: Effect of vegetation structure on grassland bird community composition within Hluhluwe-iMfolozi Park 11

$\begin{array}{ll}\text { Introduction } & 11\end{array}$

$\begin{array}{lc}\text { Field Methods } & 13\end{array}$

$\begin{array}{ll}\text { Quantifying Bird populations } & 13\end{array}$

$\begin{array}{ll}\text { Characterising vegetation } & 19\end{array}$

$\begin{array}{lr}\text { Analytical methods } & 20\end{array}$

$\begin{array}{ll}\text { Results } & 23\end{array}$

Vegetation 23

Bird abundances in the different grassland states $\quad 24$

$\begin{array}{ll}\text { Discussion } & 33\end{array}$

Chapter 4: Post-fire vegetation change and bird responses in Hluhluwe-iMfolozi Park

$\begin{array}{ll}\text { Introduction } & 41\end{array}$

$\begin{array}{ll}\text { Methods } & 43\end{array}$

$\begin{array}{lr}\text { Results } & 44\end{array}$

Discussion $\quad 52$ 
Chapter 5: Comparing grassland avifauna within HiP with surrounding communal lands

Introduction

Methods 55

Quantifying bird populations 57

Characterising vegetation 57 Analytical methods

Results 58

Grass species composition 58

Vegetation structure 59

Bird species composition 60

Discussion

Chapter 6: Human predation on bird populations outside Hluhluwe-iMfolozi Park 64

Introduction 64

Methods

Results 67

Discussion

Chapter 7: The importance of large grazing lawns for grassland avifauna in HluhluweiMfolozi Park 74

Introduction 74

Methods 76

Field methods 76

Results 77

Discussion

Chapter 8: Conclusion 85

References 88

Appendix 95 


\section{Chapter 1: Introduction}

Hluhluwe-iMfolozi Park (HiP) has two distinct grassland types, tall tussock 'bunch' grasslands and short stoloniferous grazing lawns (Figure 1.1). These grasslands form an integral part of the park's continually changing landscape. From a conservation standpoint, it is important to understand not only how these grasslands are formed and maintained, but also how animals use them.
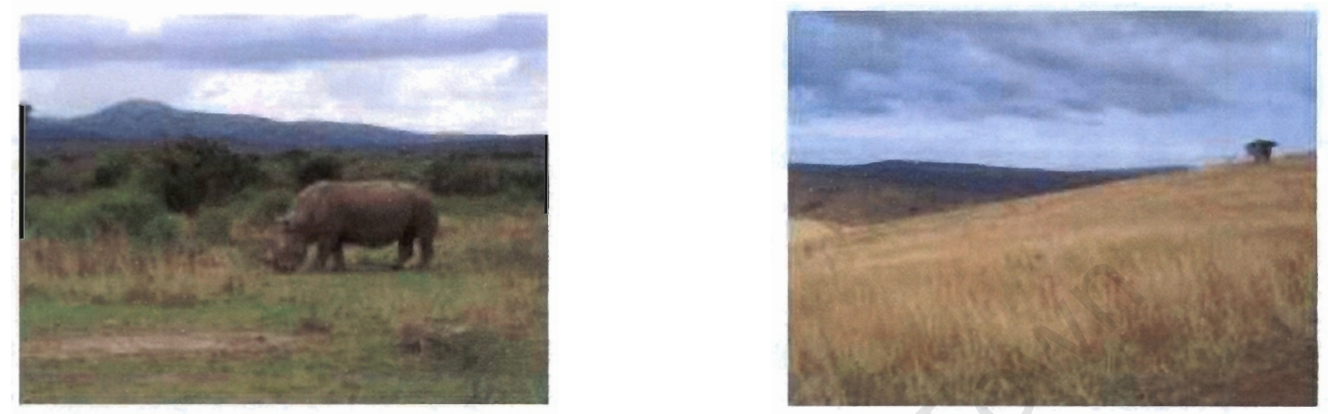

Figure 1.1: Illustrates grazing lawns on the left and bunch grasslands on the right.

Grazing lawns appear to be maintained by grazing mammals, while tall bunch grasslands are promoted by frequent fire. These grasslands are highly dynamic and the mosaic in which they occur is determined by grazing pressure and fire regimes(Archibald et al. 2005). They not only provide a valuable food source for many herbivores, but are also an important habitat for birds.

A comparison of avifauna of the 1970s with that of the area in historical times, found that a high proportion of grassland bird species had become locally extinct (Macdonald 1984), several of which frequented short-grass habitats. The majority of these species are known to be nomadic, migratory or on the edge of their range. However, their disappearance nonetheless strongly suggests that some change has taken place. It is possible that this change has occurred beyond the park boundaries, but it may equally well be a response to habitat changes within the park. If the latter is the case, an understanding of the processes responsible would be of great value to conservation managers and provide insight that may help prevent further biodiversity loss. 
In South Africa (and elsewhere) rangeland scientists have, in the past, perceived grazing lawns as products of overgrazing and mismanagement and considered tall Themeda triandra bunch grasslands as 'ideal veld'. The presence of 'overgrazed' patches prompted managers to reduce grazing pressure in an effort to convert short -grass areas to tall bunch grasslands. This was achieved by large-scale culling and game-capture operations. Recent studies (Zululand Grass Project, unpublished) have shown that grazing lawns are highly productive under intense grazing pressure. They are floristically different from tall bunch grasslands and support a high density and diversity of grazing herbivores. This suggests that they have a long evolutionary association with grazing herbivores and are a normal component of the African savanna. Evidence exists to suggest that drought, fire and mammal removal may have influenced the extent of grazing lawns in HiP since the 1960's (Bond et al. 2001). This is particularly evident in Hluhluwe, where long-term monitoring has shown dramatic changes from short grass in the late 1960's to tall grass swards in the 1980's. White Rhinoceroses Ceratotherium simum are primarily responsible for maintaining grazing lawns in the northern higher rainfall areas of HiP (MS Waldram pers. comm.). Thus, even though the rhinoceros population of the park is increasing (HiP park records), removal of many animals in the late 1970's and early 1980's resulted in low densities. Removal of rhinos and other grazers may have been responsible for the decrease and disappearance of grazing lawns in the northern part of the park.

Similarly, fire return intervals of less than fours year may reduce grazing lawn formation in HiP, by indirectly reducing the density and diversity of large mammal species on grazing lawns (Archibald et al. 2005). After a fire event, herbivores are attracted to the post-burn flush of new growth and consequently drawn off heavily grazed patches. Very small fires may concentrate grazers which might initiate a grazing patch but the normal large fires will pull grazers of $f$ grazing patches and cause the herbivores to spread out on the large burnt areas and thus have a less concentrating effect. In the long term, frequent large fires will indirectly reduce the density and diversity of large mammals species on grazing patches, and reduce lawn grass formation because grazers would not persist in a grazing patch long enough to cause a compositional shift from tall grass to lawn grass species. Consequently, the current high-frequency fire regime may have contributed to the decrease in grazing lawns.

This study compares the avifaunal assemblages associated with grazing lawns and bunch grasslands to assess how bird species composition within the park might change with 
changing proportions of the two grassland types. The study also compares the bird assemblages of post-burn bunch grasslands that resemble grazing lawns in the early stages of post-burn re-growth, and heavily grazed communally farmed areas outside the park. These may provide an alternate habitat to grazing lawns within the park.

The objectives of this study were:

1. To investigate which bird species characterise grazing lawns and bunch grasslands habitats within $\mathrm{HiP}$.

2. To investigate whether the incidence and abundance of grassland birds is a function of the physical structure of the vegetation or a response to its floral composition.

3. To investigate which bird species characterise post-burn bunch grasslands.

4. To investigate which bird species characterise communal lands surrounding HiP.

5. To use this information to recommend conservation strategies for grassland birds within the HiP.

\section{Thesis Outline}

In Chapter 2 I provide a detailed description of the study area from a geographical and management perspective. Chapter 3 reports on an analysis of grassland bird communities in the park. In this chapter, I identify grassland specialists by comparing the presence and abundance of birds not only in grassland habitats but also of other habitat types in the reserve. Chapter 4 is an investigation of bird species that make use of recently burnt grassland swards, since the post-burn condition of tall grasslands is structurally similar to grazing lawns. It is feasible that frequent burning might create the necessary habitat conditions to support "short grass" bird specialist species. Alternatively, the post-burn recovery might be too rapid to provide suitable habitat requirements for these birds. In Chapter 5 I compare birds in the grasslands outside the park and with those found inside the park. The areas outside the park are under communal tenure and typically heavily grazed by domestic livestock. It is therefore possible that, though rare within the park, short grass swards would be abundant outside the park, providing large areas of suitable habitats for grassland specialist birds. In Chapter 6, I report on bird predation by people. This followed, after finding very low bird abundances outside the park (from Chapter 5). I wished to explore whether predation could be a significant factor accounting for low bird 
abundance in the communal farming areas. In Chapter 7, I report an analysis of the distribution and size of grazing lawns in the park and their suitability for grassland bird conservation. I calculated species area requirements to explore the area of grassland necessary to support viable populations of specialist species and related these estimates to actual lawn distribution. The final chapter is a synthesis of the results with management recommendations

\section{Note to the reader}

Each chapter has been prepared as an individual report. Thus, some repetition was necessary to explain concepts and ideas in each Chapter. However in situations where the same survey techniques were used in different aspects of the study, they have not been redescribed. All scientific names for bird species are listed in Appendix A at the end of the thesis. 


\section{Chapter 2: Site Area}

Hluhluwe-iMfolozi Park (HiP) is located in northern KwaZulu-Natal, eastern South Africa $\left(28^{\circ} 00^{\prime}-28^{\circ} 10^{\prime} \mathrm{S}, 32^{\circ} 00^{\circ}-32^{\circ} 10^{\prime} \mathrm{E}\right)$. Once the exclusive royal hunting ground of King Shaka, and the former Hluhluwe and Umfolozi Game Reserves, this area is now enclosed by an electrified fence that separates it from the surrounding human population (Figure 2.1). It covers an area of $960 \mathrm{~km}^{2}$ and has a subtropical climate with variable topography, ranging from $40-580 \mathrm{~m}$ asl. The higher northern section of the park has an average annual rainfall of $985 \mathrm{~mm}$, decreasing to $650 \mathrm{~mm}$ p.a. in the southern section. The majority of the rain falls from October to March, with a daily mean minimum temperature of $13^{\circ} \mathrm{C}$ and a daily mean maximum of $35^{\circ} \mathrm{C}$ (Greyling $\&$ Huntley 1984).

\section{Geology}

The geological structure of the park is characterised by intense fracturing and faulting, which occurred during both the Gondwana break-up (180 mya) and the final drifting (140 mya). The rock strata is tilted, exposing the older rocks of 3200 my in the west. Most of the major rock series of Kwazulu Natal are represented, with Karoo sediments being most widespread. The varied topography, climate and geology has resulted in a wide variety of soil types (King 1970)

\section{Mammal fauna}

HiP supports a broad spectrum of mammals, including African Elephant Loxodonta afreiana, Black Rhinoceros Diceros bicornis, White Rhinoceros. Ceratotherium simum, Cape Buffalo Syncerus caffer, Lion Panthera leo and Leopard Panthera pardus, with a full compliment of other herbivores, carnivores and small mammals.

Herbivore numbers in particular have undergone great fluctuation since the park's proclamation in 1895 (Brooks \& Macdonald 1983). An outbreak of rinderpest Morbillivirus in the late 1800 s dramatically reduced game numbers which were reported to have only recovered in 1905 (Brooks \& Macdonald 1983). Similarly the 
anti-ngana Trypanosoma congolense campaign from 1916 to 1950 resulted in the extermination of 96000 animals (Brooks \& Macdonald 1983). The removal, either by shooting or capture, in the 1950s and late 1960s to early 1980 s also resulted in reductions in numbers of Burchell's Zebra Equus burchelli, Blue Wildebeest Connochaetes taurinus, Warthog Phacochoerus aethiopicus and White Rhinoceros, in an effort to revert 'overgrazed' areas into tall bunch grasslands (Brooks \& Macdonald 1983).

\section{Vegetation}

The vegetation is dominated by savanna woodlands, with some evergreen forests and grasslands (Whateley \& Porter 1983). Acocks (1988) classifies HiP into the Zululand Thornveld. Coastal Tropical Forest and Lowveld Tropical Bush and Savanna veld types. Low \& Rebelo (1996) classifies HiP into Afromontane Forest, Natal Central Bushveld, Natal Lowveld Bushveld and Coast-Hinterland Bushveld.

Qualitative and semi-quantitative accounts of the vegetation of the Hluhluwe-iMfolozi Park have indicated that gross structural changes have occurred since its proclamation as a protected area (see Bond et al. 2001; Brooks \& Macdonald 1983; Deane 1996; Downing 1980; Macdonald 1979; Macdonald 1983; Skowno et al. 1999; Vincent 1970; Watson \& Macdonald 1983a; Watson \& Macdonald 1983b). These include a progressive increase in both tree and shrub cover, at the expense of grassland and savanna areas, invasion by alien pla nt species such as Trifffid Weed Chromolaena odorata, and changing proportions of the two alternate grassland states (short stoloniferous grazing lawns and tall tussock like 'bunch' grasslands). These grassland shifts are particular evident in Hluhluwe, were where long-term monitoring has shown dramatic changes from short grass in the late 1960s to tall grass swards in the 1980s. For example, (Bond et al. 2001) noted that the dominant tree species in Hluhluwe, an area of over 30000 ha, had been replaced by different sapling species. This was thought to have been associated with a switch from short to tall grass because species with herbivore-tolerant saplings have been replaced by species with fire-tolerant saplings. 


\section{Hluhluwe-iMfolozi Park}

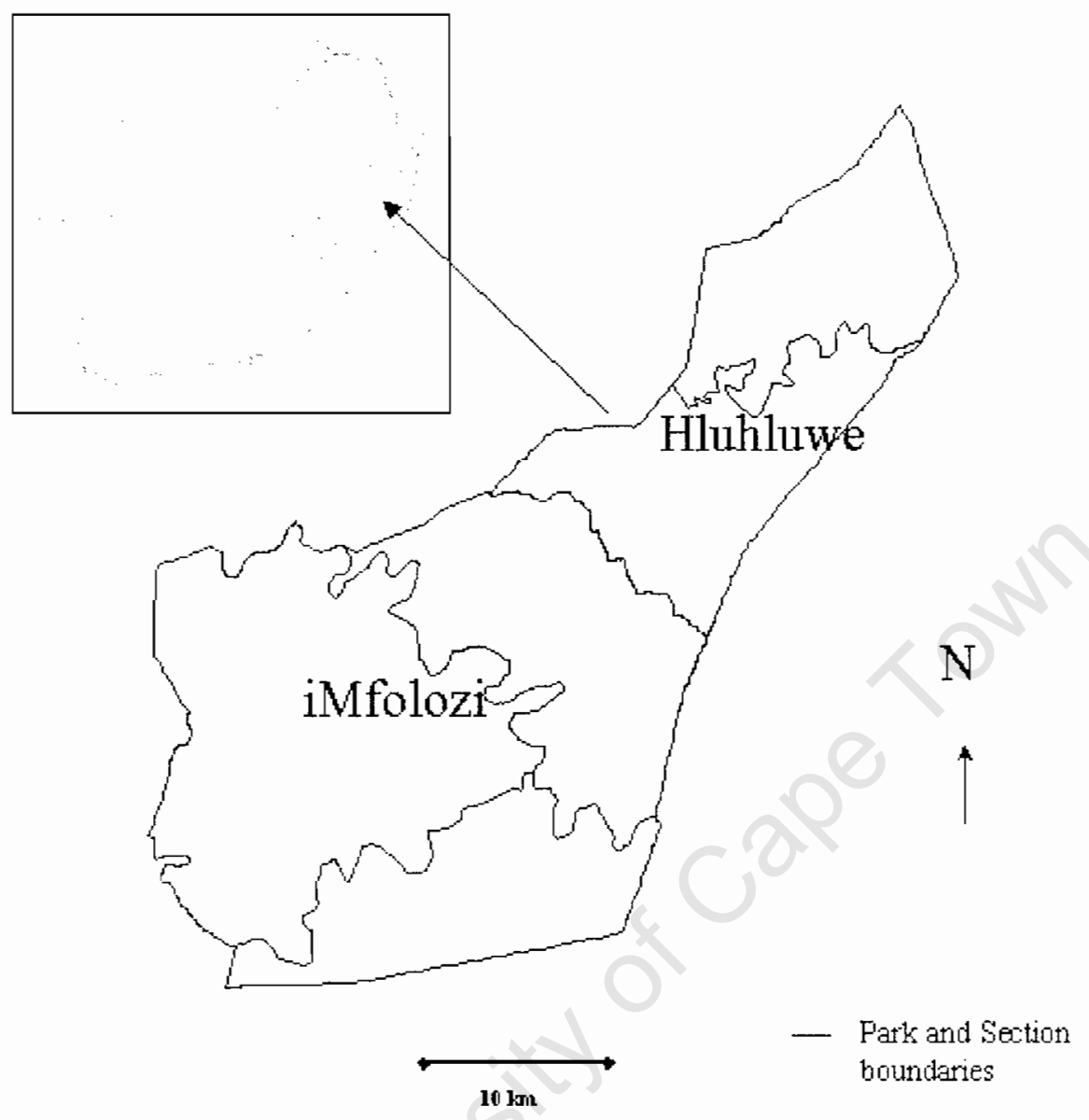

Figure 2.1: Map showing the location of Hluhluwe-iMfolozi Park and the different sections. 


\section{Avifauna}

According to Winterbottom's (1974) classification of avian zoogeographical regions. HiP falls within the Southern Sub-district of the East African Coastal District, but is close to the convergence point of four districts:

1). South Central Highlands District.

2). East African Coastal District - Mozambique Sub-district.

3). East African Coastal District - Southern Sub-district.

4). South Temperate District - Highveld Sub-district.

This convergence may explain the exceptionally high avifaunal diversity of more than 400 indigenous bird species that have been recorded in the Park, of which ca 326 species are considered to occur regularly (Macdonald \& Birkenstock 1980).

There is little avifaunal information about HiP prior to the 1960s, with the only records being unannotated checklists of park rangers. In the 1960s, Owen-Smith (1980) kept semi-quantitative records from iMfolozi. The best records stem from a study by Macdonald (1984). He compared birds recorded from 1970-1979 with those of previous years. His findings suggested that 54 species had become locally extinct by the 1970s. 25 of these were grassland species (Table 2.1). Many of the species that have apparently become locally extinct were formerly only present sporadically within HiP, or are known to be rare migrants, but the reason(s) for the disappearance of formerly resident species remains unknown. Macdonald (1984) suggests several possible reason for their extinction, none of which has been tested. Firstly, he suggested that the grassland habitats in the matrix surrounding the park have deteriorated and the losses are responses to these habitat changes outside the park boundaries Secondly, the extent of grassland habitat within HiP has always been small, and that the observed decrease in species diversity along with a further decrease in grassland area as a result of game management, is simply that predicted according to Island Biogeography Theory. Thirdly, a high proportion of the locally extinct species are ground nesters and it was thought that their eggs and offspring are being heavily depredated by the unusually high numbers of Vervet Monkey Cercopithecus aethiops, Chacma Baboon Papio ursinus and Pied Crow. Lastly, it 
was suggested that the 1970s was a wet period with above-average rainfall and that several of the species may return in drier years.

Subsequent to Macdonald's (1998) investigation, African Marsh-Harrier, Senegal Lapwing and Temminck's Courser have been recorded on rare occasions, but it is really only the African Pipit that has been regularly observed.

Table 2.1. A list of locally extinct grassland species in HiP, as judged by their absence over the period 1970-1979 (Macdonald 1984: Macdonald \& Birkenstock 1979). Resident species are highlighted.

\begin{tabular}{|c|c|c|c|}
\hline Common name & $\mathrm{Hab}$ & itat & Breeding status \\
\hline Abdim's Stork & Grassland & Savanna & Intra-African Migrant \\
\hline African Marsh-Harrier & Grassland & & Resident \\
\hline Pallid Harrier & Grassland & & Palaeartic Migrant \\
\hline Greater Kestrel & Grassland & Savanna & Nomad \\
\hline Harlequin Quail & Grassland & Savanna & Intra-African Migrant \\
\hline Blue Quail & Grassland & & Intra-African Migrant \\
\hline Corn Crake & Grassland & & Palaeartic Migrant \\
\hline Denham's Bustard & Grassland & Savanna & Intra-African Migrant \\
\hline Ludwig's Bustard & Grassland & Savanna & Nomad \\
\hline Senegal Lapwing & Grassland & Savanna & Intra-African Migrant \\
\hline Temminck's Courser & Grassland & Savanna & Nomad \\
\hline Black Coucal & Grassland & & Nomad \\
\hline African Grass-Owl & Grassland & & Nomad \\
\hline Marsh Owl & Grassland & & Nomad \\
\hline Red-capped Lark & Grassland & & Nomad \\
\hline Chestnut-backed Sparrowlark & Grassland & Savanna & Nomad \\
\hline Grey-rumped Swallow & Grassland & & Nomad \\
\hline Sentinel Rock Thrush & Grassland & & Resident \\
\hline Capped Wheatear & Grassland & Savanna & Nomad \\
\hline Broad-tailed Warbler & Grassland & & Nomad \\
\hline African pipit & Grassland & & Resident \\
\hline Lonq-billed Pipit & Grassland & & Resident \\
\hline Wattled Starling & Grassland & & Nomad \\
\hline Long-tailed Widowbird & Grassland & & Nomad \\
\hline Brimstone Canary & Grassland & & Nomad \\
\hline
\end{tabular}

Fire

The fire regimes of HiP have varied since the park's proclamation. The frequency and size of the fires have been affected by the variation in fuel loads during wet and dry rainfall periods and by fire management policies. In the 1930s and 1940s, fire was largely excluded from the iMfolozi area to prevent the wooden tsetse fly traps from burning (Vincent 1970), while elsewhere winter burning was implement to improve 
grass quality for grazers (Vincent 1970). In the 1950s, fire was used as a tool to control encroachment of several Acacia species (Brooks \& Macdonald 1983). From the 1960s onwards, burning frequency was determined by available fuel loads, with the primary aim to provide grazing for herbivores and reduce encroachment. These fires were initially implemented as block burns, but this changed in the 1980s to point ignition, as this would create a more heterogenous environment (Balfour \& Howison 2001).

The area of the park that burns in a year has ranged from 0 to 80000 ha $(90 \%$ of the park). In recent years there has been a general increase in area burnt and at present between 30 and 50 percent of the park is burnt in any one year (Archibald 2003). The mean fire return period for the park, over 41 years, is 3.8 years, and the median fire return period is considerably shorter at 1.3 years (Balfour \& Howison 2001) 


\section{Chapter 3: Effect of vegetation structure on grassland bird community composition within Hluhluwe-iMfolozi Park}

\section{Introduction}

Qualitative and semi-quantitative accounts of the vegetation of the Hluhluwe-iMfolozi Park have indicated that gross structural changes have occurred since the park's proclamation (see Bond et al. 2001; Brooks \& Macdonald 1983; Deane 1996; Downing 1980; Macdonald 1979; Macdonald 1983; Skowno et al. 1999; Vincent 1970; Watson \& Macdonald 1983a; Watson \& Macdonald 1983b). These include a progressive increase in both tree and shrub cover, at the expense of grassland and savanna areas, invasion by alien plant species such as Trifffid Weed Chromolaena odorata and changing proportions of the two alternate grassland states (short stoloniferous grazing lawns and tall tussock -like 'bunch' grasslands) (Macdonald 1983; Watson \& Macdonald 1983b). These grassland shift are particularly evident in Hluhluwe, where there have been dramatic changes from short grass in the late 1960s to tall grass swards by the 1980s (Bond et al. 2001).

Climatic changes, fire regimes and fluctuations in herbivore numbers may all contribute to changes in the spatial extent of the two grassland states (Archibald et al. 2005; Bond et al. 2001). Although conservation managers are unable to alter climatic fluctuations, fire and herbivore numbers can and have been used as tools to manipulate the landscape (Anderson 2003; Whateley \& Porter 1983). Low -frequency fire regimes and/or high herbivore number are thought to assist in the formation of grazing lawns. Conversely, frequent fires and/or low herbivore numbers retard the formation of grazing lawns and promote tall bunch grasslands (Archibald et al. 2005). If these grassland states are to be managed effectively to maintain biodiversity within the Park, it is important to document and interpret differences in the biodiversity characteristics of the two grassland states.

The physical structure of a habitat has long been considered an important niche dimension for birds (Folse 1982; Knopf et al. 1988; Wiens \& Rotenberry 1981). It provides nesting substrata, courtship and display stations, protection from predators 
and shelter from physiological stresses. It also provides potential cues to the availability and diversity of prey and other conditions necessary for successful reproduction (Hilden 1965; Wiens 1969).

Understanding habitat relationships of birds and how species assemble to form communities is a critical component of bird and habitat conservation. Numerous studies since the early 1960s have linked various aspects of vegetation structure with avian diversity and community organisation (MacArthur \& MacArthur 1961; MacArthur et al. 1962; Ralph 1985; Roth 1976; Wiens \& Rotenberry 1981; Willson 1974). In South Africa Jansen (2001) and Skowno \& Bond (2003) looked at the effect of habitat change on bird diversity. I wish to investigate changes in bird densities and assemblages within the alternate grassland states found in HiP, namely grazing lawns and bunch grasslands found in HiP.

Grazing lawns develop when tall bunch grasslands are heavily utilised by herbivores. Bunch grasslands are grazed down into a 'grazing patch', if grazing within such a patch persists, the grazing patch undergoes a compositional grass species shift from short grazing intolerant caespitose bunch-grass species to short, stoloniferous, grazing-tolerant species. This golf course like grassland is termed as a 'grazing lawn'. These two alternative grassland states (bunch grasslands and grazing lawns) are structurally and floristically very different, and may support different bird communities. Should this be the case, shifts in the grassland state may be beneficial to some taxa and detrimental to others.

This chapter sets out to identify:

1. Whether different bird species characterise grazing lawns and bunch grasslands within HiP.

2. Whether these bird species make use of other habitats, or if they are restricted to a particular grassland state.

3. Whether the incidence and abundance of grassland birds is a function of the physical structure of the vegetation or a response to its floristic composition, or both. 
These results will not only provide valuable insight into the grassland birds of HiP, but may provide guidance on the consequences, for this component of the Park's biodiversity, of management policies with regards to of fire regimes and herbivore removals.

\section{Field Methods}

\section{Quantifying Bird populations}

Several techniques exist to count terrestrial birds. These can be categorised into two main groups: methods that use counts as an index of relative abundance, and methods that use empirical modelling to estimate bird density directly. This study makes use of both.

Line transects are mainly used to collect data in large open areas because they tend to record more birds per unit time than point counts. In contrast, point counts are used in dense habitats as it is often difficult for an observer to detect birds while moving (Bibby et al. 2000). Line transects were used to quantify the grassland bird species, and point counts to identify which of the birds identified within the grasslands made use of other habitats.

\section{Birds in open grasslands}

Potential sampling sites were initially identified using a classification map of grass communities derived from a 1999 Landsat TM image (Archibald 2003). Whilst it was possible to distinguish between short and tall grasslands on this map, potential sites had to be ground-truthed in order to characterise them within the grassland continuum as some areas had undergone transformation since 1999. Sites heavily invaded by woody plants were not selected, primarily because such plants attract birds that are not true grassland species. Twenty-four open grassland sites (12 short grass and 12 tall grass sites), of varying size, were selected across the rainfall gradient to include the full range of grassland habitats within HiP. The location of the sites is shown in Figure 3.1. Surveys were started in August 2003 and took place every 2 months over a period of one year. This allowed for the monitoring of bird presence, absence and abundance with seasonal vegetation changes, and took into account seasonal migrants.

Chapter 3 : Effect of vegetation structure on grassland bird community composition within Hluhluwe-iMfolozi Park 


\section{Hluhluwe-iMfolozi Park}

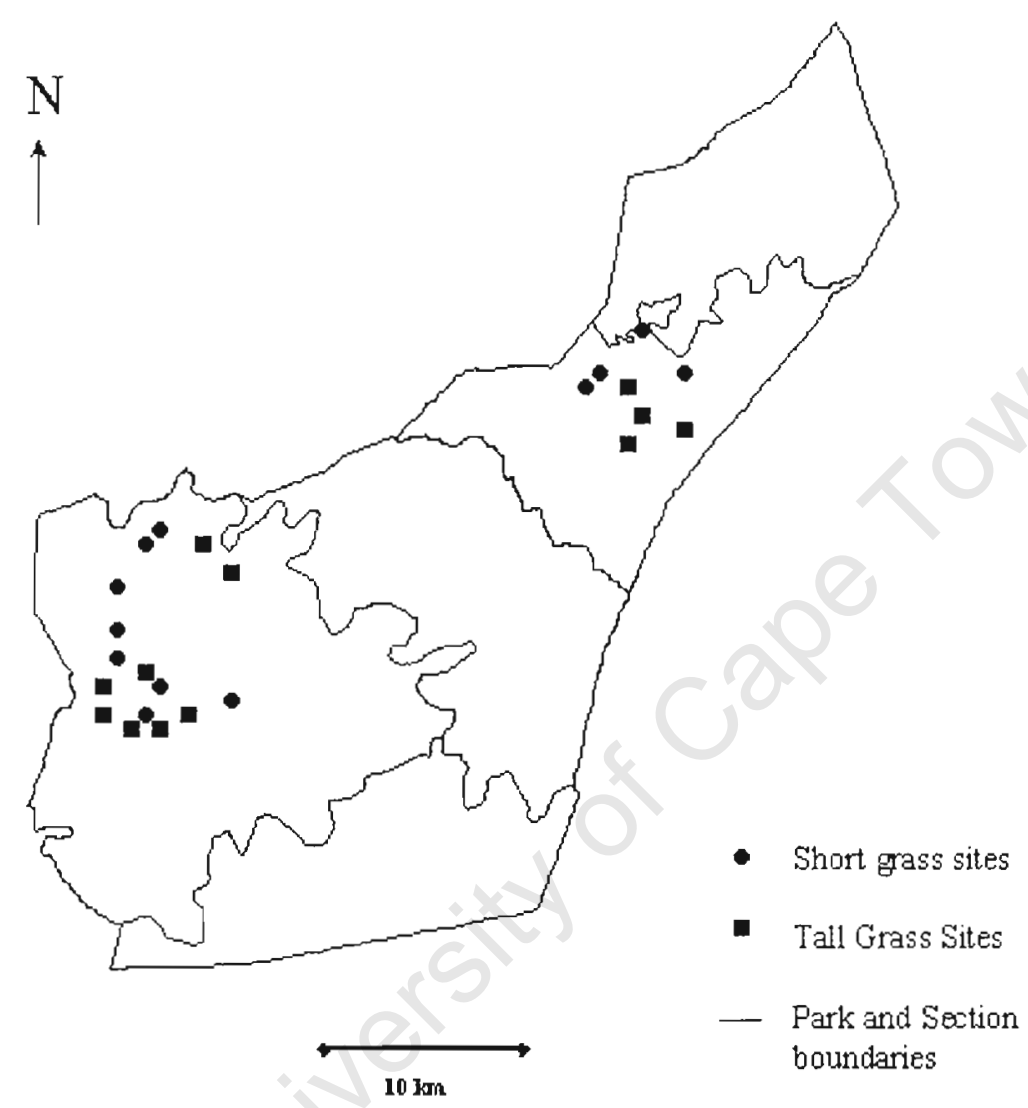

Figure. 3.1: Map of Hluhluwe-iMfolozi Park showing study sites, park boundary and section boundaries 
At each study site, a fixed transect that traversed the longest axis was marked. This transects varied in length from $100 \mathrm{~m}$ to $300 \mathrm{~m}$, depending on the size of the study patch. The beginning and end point of these transects were demarcated with metal pegs, to ensure the same route was traversed during each sampling period. Avian species accumulation curves were constructed during preliminary studies in July 2003: these indicated that each transect needed to be sampled a minimum of four times during each sampling period. Sites were therefore surveyed four times on two consecutive days. Sampling took place during the first two hours after sunrise and the last two hours before sunset. When rain or wind appeared to affect bird activity or detectability, sampling was terminated. Data from these temporal replicates were pooled and treated as a single sample for each site.

Bird survey techniques were modified to suit each grassland type:

a) Short grass swards

Bird density data were collected using the standard method for line-transect sampling (Buckland et al. 2001). A slow, steady pace was walked, all birds seen within the study area identified and the perpendicular distance from the transect line to the position of each bird when first detected was estimated (Figure 3.2). To improve the accuracy of the distance measurements, permanent markers were installed at known distances from the transect line. In situations in which species occurred in flocks, the distance to the centre of a group was estimated, and the number of individuals noted. Aerial feeders, such as swifts, swallows and martins, as well as raptors, were excluded.

\section{b) Tall grass swards}

The above technique was unsuitable in tall grass areas, because most birds were hidden within the grass. Densities were therefore assessed using a rope-drag transect of $30 \mathrm{~m}$ width, sited according to the same criteria used in lawn grass areas (Figure 3.3.). 


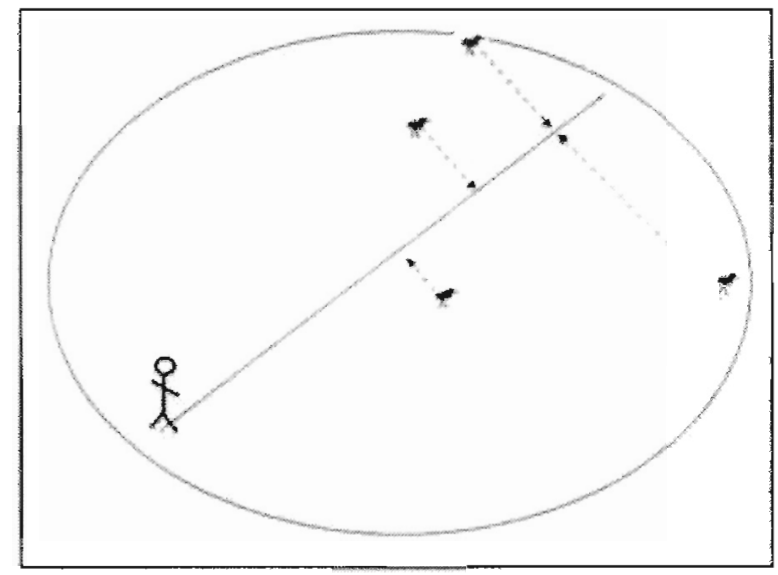

Figure 3.2: Line transect. All birds sighted within the study area are identified and the perpendicular distance to the transect line estimated.

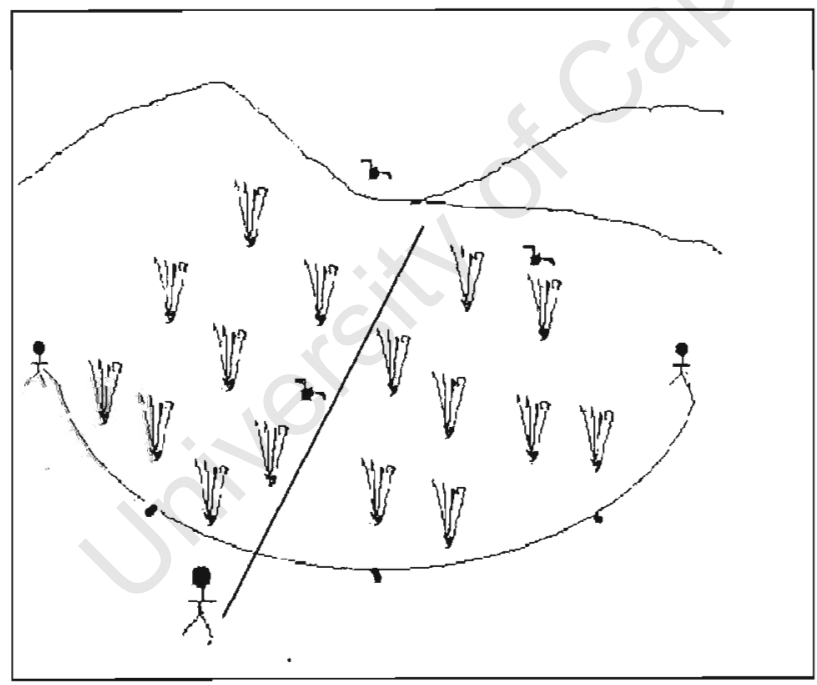

Figure 3.3: Rope-drag transect. A weighted $30 \mathrm{~m}$ rope was dragged through grass swards; flushed birds are identified and counted 


\section{Birds in other habitats}

In order to determine whether species observed in grassland sites were habitat specialists or used other, more wooded habitats, additional samples were taken in different habitat types. Using a vegetation map created by Whateley \& Porter (1983), woody vegetation types that support a grass layer were grouped into low-, medium and high-density woodlands, and thicket. Ten random sites within each of these habitat types were selected. A total of four, 10-minute point counts (Bibby et al. 2000) were conducted at each site and all birds seen and heard within a $100 \mathrm{~m}$ circular radius were recorded. This was done in the morning and afternoon of two consecutive days in January 2004 (Figure 3.4). Only presence/absence data were collected, because the purpose of this survey was solely to establish which of the birds observed in the grasslands were not grassland specialists. 


\section{Hluhluwe-iMfolozi Park}

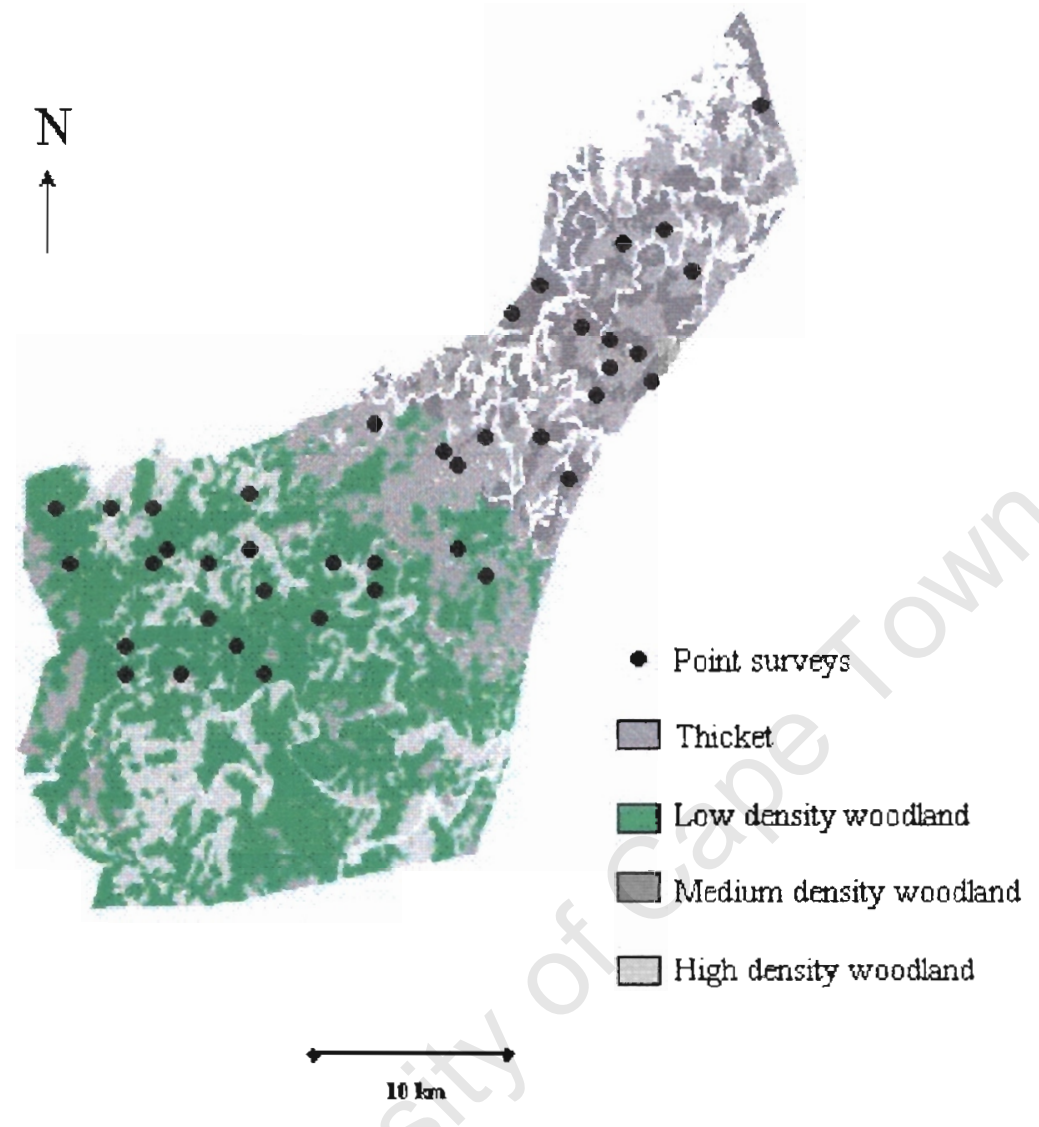

Figure 3.4: Map of Hluhluwe-iMfolozi Park showing point count bird survey sites in low, medium and high density woodlands and thicket habitats Adapted from Whateley \& Porter (1983) 


\section{Characterising vegetation}

The following information was collected for each grassland site:

1. Grass species composition

2. Tree species composition

3. Foliage biomass

4. Horizontal foliage diversity and the amount of bare ground

5. Foliage height profiles

Grass and tree species composition for each study site was determined once during the study. The dominant grass species were identified at $1 \mathrm{~m}$ intervals along the first 100 $\mathrm{m}$ of the transect used for the bird surveys. Preliminary species accumulation curves suggested $100 \mathrm{~m}$ was sufficient to identify common grass species within the study site. The primary purpose of this was to determine which grass species characterise the two grassland types, and to determine which of the short grass areas were grazing lawns or grazing patches. In patches that contained woody plants taller than the grass sward, the tree composition and density were determined using the Wandering Quarter technique (Catana 1953)

Structural diversity was assessed using three techniques, two quantitative (Disc Pasture Metre and Foliage Height Profiles) and one-semi quantitative (Intercept Method). An index of foliage biomass was obtained using a Disc Pasture Meter (DPM) (Bransby \& Tainton 1977). A total of 50 points were sampled per transect, at 2 $\mathrm{m}$ intervals along the first $100 \mathrm{~m}$ of the transect. Horizontal foliage diversity of vegetation height, density and amount of bare ground were determined using the Intercept Method, designed specifically for this study. This consisted of recording ground cover at $1 \mathrm{~m}$ intervals along the fixed transect as follows:0 = bare ground $1=$ grass $<50 \mathrm{~mm}$ high, $2=$ grass $50-200 \mathrm{~mm}$, and $3=$ grass $>200 \mathrm{~mm}$. The three grass layers were clearly distinct in the field. In all patches, the minimum number of sample points was 150 . Their relative percentages gave a spatial index of bare ground, short grass swards, medium grass swards and tall grass swards. Data using the Intercept Method and Foliage Biomass Index were collected every 2 months for a period of 1 year (August 2003 to July 2004) after each grassland bird sampling period. 
In addition. the amount of vegetation at different heights was assessed with foliage height profiles (MacArthur \& MacArthur 1961) along the fixed transects. The same method was used by Skowno \& Bond (2003) in HiP. I estimated the distance at which 50 percent of a $30 \mathrm{~cm} \times 30 \mathrm{~cm}$ white board was obscured by foliage at $0,0.25,0.5$, $0.75,1$ and $1,5 \mathrm{~m}$ above ground from the four cardinal directions. This was done every $10 \mathrm{~m}$ along the first $100 \mathrm{~m}$ of the transect. This technique was very time consuming and data were collected only in the middle of the dry season (August 2003 ) and the middle of the wet season (February 2004).

\section{Analytical methods}

In tall grass swards it was assumed that all birds within the strip were flushed by the rope-drag technique, hence calculations of density were simply a matter of dividing the total number of birds seen within the strip by the strip area. For short grass sward areas, the software DISTANCE (Laake et al. 1994) was used to calculate densities. This technique was favoured because it can account for difference in conspicuousness between species based on distance-incidence functions, and thus uses a detection function to calculate density. This is critical as not all birds were seen while walking the transect.

Buckland et al. (2001) prescribe the necessary exploratory analyses of the field data to look for evidence of evasive movement of birds before detection, rounding and heaping of data and to check if truncation is necessary for outlier observations. For example, the African Pipit data set showed evidence of evasive movement before detection, with highest detection at $10 \mathrm{~m}$ rather than at $0 \mathrm{~m}$. A Hazard Rate Model (Buckland et al. 2001) was employed to change the line of best fit from a third order to a second order best-fit curve, forcing the curve not to peak at $10 \mathrm{~m}$ but decrease slowly from $0 \mathrm{~m}$ (Figure 3.5).

Chapter 3: Fffect of vegetation structure on grassland bird community composition within Hluhluwe-iMfolozi Park 


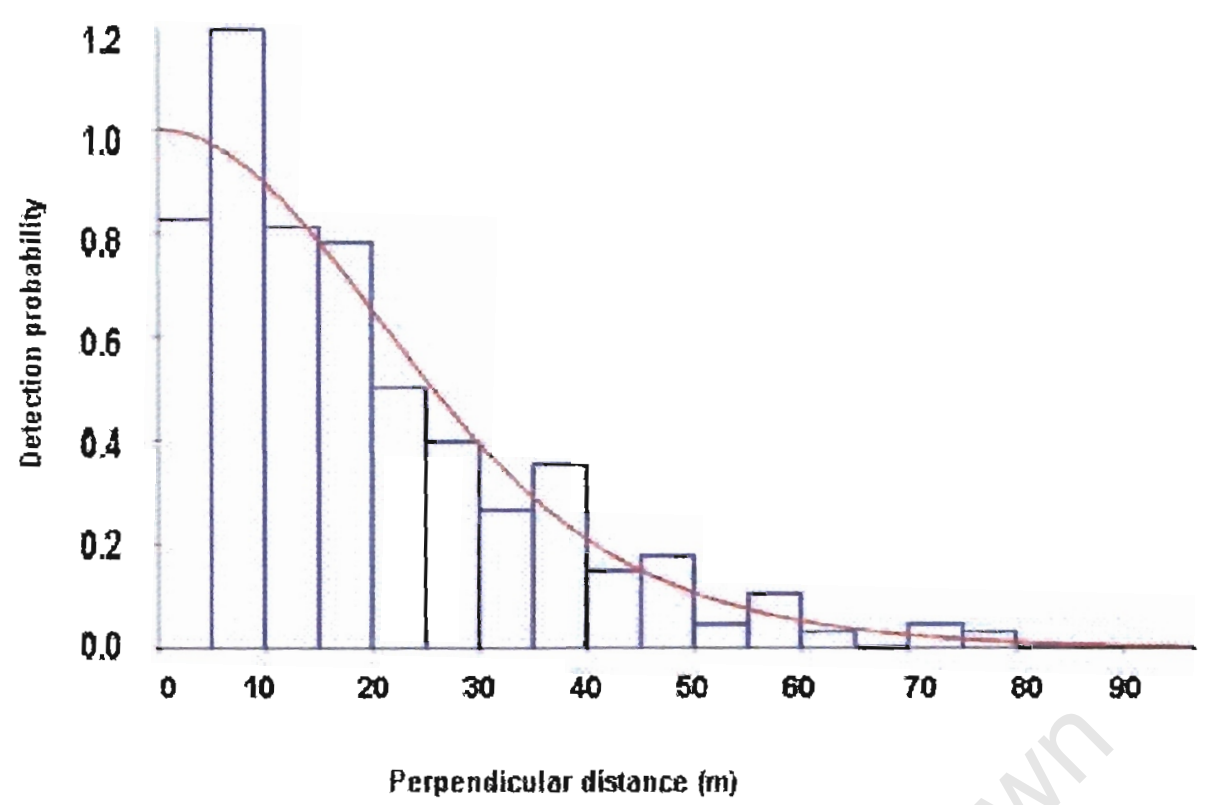

Figure 3.5: Evidence of evasive movement before detection in the African Pipit data. The Hazard rate model was selected to correct for this problem.

The best possible model was fitted to each bird species dataset using Akaike's Information Criterion (AIC) values. Although the techniques for estimating density in the tall and short grass swards differ, both estimate density, and their results are thus statistically comparable.

Bird species diversity for each site was calculated using the Shannon-Wiener diversity index:

$$
H^{\prime}=-\Sigma p_{i} \log _{2} p_{i}
$$

$i=1$

$s=$ total number of species

$\mathrm{p}_{\mathrm{i}}=$ observed proportion of individuals that belong to the ith species

This index is influenced by the number of species present and the evenness of their distribution; increasing values of $H^{\prime}$ reflect higher species diversity. A one way 
ANOVA with grass type as the categorical predictor was used to test for differences in species number, density and diversity between the tall and short grass areas.

True habitat specialists were identified from presence /absence data from all sample sites. These were species that occurred significantly more often in the grassland types than in other habitats as tested by Fisher's exact probability test using the software STATISTICA (StatSoft, Inc. 19842003).

I used Detrended Correspondence Analysis (DCA) to determine if different bird communities occur at either end of the grassland continuum. DCA was used as it is a more reliable method than reciprocal averaging and principle component analysis (Hill 1979) because it avoids the arch effect (Gauch 1982). This multivariate datareduction and ordination technique spatially arranges a matrix of species abundance and composition data or habitat variables by site. The position of each site is plotted using DCA scores for the first and second axes, as these two axes account for the greatest proportion of the variation in the original data set. Each axis may represent some identifiable environmental gradient. Hence, the DCA score represents the position of the site along these environmental gradients. For example, sites that share similar bird communities will be close together and dissimilar sites will be far apart.

Bird species replacement from site to site (turnover) along a gradient of increasing grass height, was firstly illustrated by plotting the number of species lost and/ or gained against sites of varying grass height, and secondly by plotting ß-diversity against a gradient of increasing grass height. Wilson and Schmida's formula (1984) was used to determine $\beta$-diversity:

$\mathbf{B}=[\mathbf{g}(\mathbf{H})+\mathbf{l}(\mathbf{H})] / 2 \mathbf{a}$

B = the beta diversity between sites of different grass height

$g(H)=$ the number of species gained along the gradient $\mathrm{H}$

$l(H)=$ the number of species lost along gradient $H$

a $=$ the mean sample richness of all the samples along the gradient.

A Detrended Canonical Correspondence Analysis (DCCA) was used to relate bird communities identified in DCA, or specialists identified from Fisher's exact test, to 
structural habitat variables and plant species composition. This will indicate whether the incidence and abundance of bird species is a function of plant species composition or vegetation structure. For example, short grass sites may be true grazing lawns consisting of short stoloniferous grass species, or a grazing patch consisting of shortly grazed caespitose bunch grass species. Thus if short grass inhabiting birds are present at both grazing lawns and grazing patches it is likely they are responding to some structural variable rather than the grass species composition. Conversely if they only occur on grazing lawns, they are likely to be sensitive to changes in grass species composition. Because there are so many possible variables to consider, a DCCA is used to help enhance the interpretation of environmental gradients and allow for individual species to be related to all major environmental factors (Kent \& Coker 1997).

The computer program CONOCO for windows (version 4.02) was used for all ordinations.

The associations displayed in the ordinations were examined using a generalised linear model (GLM) in the software JMP (version 5.0.1.2.) using the scores from axis 1 and 2 from the DCCA as the dependant variable with habitat variables as the independent variables. GLMs quantify the relative significance of vegetation characteristics. such as floristics and structure, as predictors of avian communities in the grasslands, by noting changes and associated probability values in the coefficient of determination $\left(\mathrm{R}^{2}\right)$ as variables are sequentially added.

\section{Results}

\section{Vegetation}

Structural habitat variables at each site varied throughout the year, according to season, recent rainfall and grazer activity. Structural vegetation characteristics are displayed in Appendix 3.1. The majority of tall grass site were dominated by Themeda triandra, while short grass sites in Hluhluwe were dominated by Digitaria longiflora and in iM folozi by Digitaria argyrograpta (Table 3.1). Some short grass sites had a 
high proportion of non-stoloniferous species and thus were considered grazing patches rather than grazing lawns. Tree species composition varied from site to site (Table 3.1).

Table 3.1: Area (ha), dominant trees species and dominant grass species of each study site

\begin{tabular}{|c|c|c|c|}
\hline HB1 & 10.0 & Acacia nilotica/Dichrostachys cinerea & Themeda triandra \\
\hline $\mathrm{HB} 2$ & 40.0 & A. nilotica/D. cinerea & T. triandra \\
\hline HB3 & 30.0 & A. nilotica/D. cinerea & T. triandra \\
\hline HB4 & 25.0 & A. nilotica/Gymnosporia senegalensis & Sporobulus pyramidalis/Eragrostis curvula \\
\hline HL1 & 1.4 & A. nilotica/D. cinerea & Eragrostis curvula/Dactyloctetium australe \\
\hline $\mathrm{HL} 2$ & 16.3 & D. cinerea & Digitaria longiflora \\
\hline HL3 & 4.0 & D. cinerea & D. longiffora \\
\hline $\mathrm{HL4}$ & 3.1 & D. cinerea/G senegalensis & Digitaria longiflora/Sporobolus pyramidalis \\
\hline UB1 & 23.0 & Acacia nigrescens & T. triandra \\
\hline UB2 & 20 & Acacia tortilis & T. triandra \\
\hline UB3 & 4.0 & A. tortilis & T. triandra \\
\hline UB4 & 7.0 & A. tortilis & T. triandra \\
\hline UB5 & 12.0 & A. tortilis & T. triandra \\
\hline UB6 & 15.0 & A. tortilis & T. triandra \\
\hline UB7 & 2.5 & A. nigrescens & T. triandra \\
\hline UB8 & 3.1 & A. nigrescens & T. triandra \\
\hline UL.1 & 1.9 & Acacia rabusta & Sponibolus nitens/Sporobolus ioclados \\
\hline UL2 & 8.0 & Acacia tortilis & Digitaria argyrograpta \\
\hline UL3 & 6.5 & D. cinerea & T. triandra \\
\hline UŁ4 & 12.1 & A. tortilis & D. argyrograpta \\
\hline ULS & 9.0 & A. tortilis & D. argyrograpta \\
\hline UL6 & 6.9 & Acacai grandicornuta/A. tortilis & Sporubolus nitens/Sporobolus ioclados \\
\hline UL7 & 2.4 & A. nigrescens & D. argyrograpta \\
\hline UL8 & 25.0 & A. nigrescens & D. argyrograpta \\
\hline Mean & 11.3 & & \\
\hline
\end{tabular}

$\mathrm{H}=$ Hluhluwe, $\mathrm{U}=$ iMfolozi, $\mathrm{B}=$ tall grass, $\mathrm{L}=$ short grass

Note: The sites are grasslands areas; trees are only present at very low densities

\section{Bird abundances in the different grassland states}

The abundances of all birds detected in each of the grassland sites are presented in Appendix 3.2. A total of 87 bird species were encountered within the grasslands, with short grass areas supporting 74 species and tall grasslands 59 .

An ANOVA (Table 3.3) indicated that the differences in the species richness and diversity between the short and tall grass areas were significant, with short grass areas 
having higher species richness and diversity. No significant difference was detected in overall densities of all species combined.

Table 3.2: Mean species richness, density and species diversity (H') for all birds detected at each site.

\begin{tabular}{cccc}
\hline Site & Spp. Richness & Density & Spp. Diversity \\
\hline Tall grass sites & & & \\
ub6 & 25 & 6.1 & 4.0 \\
ub1 & 27 & 11.5 & 3.9 \\
ub4 & 20 & 3.7 & 3.4 \\
hb4 & 20 & 10.0 & 3.2 \\
ub2 & 14 & 7.6 & 3.2 \\
ub3 & 18 & 5.5 & 3.0 \\
ub8 & 10 & 4.4 & 2.9 \\
ub7 & 11 & 5.3 & 2.8 \\
hb2 & 12 & 7.3 & 2.6 \\
hb3 & 9 & 5.3 & 2.5 \\
ub5 & 12 & 14.1 & 2.4 \\
hb1 & 13 & 6.8 & 2.3 \\
mean & $\mathbf{1 5 . 9}$ & $\mathbf{7 . 3}$ & 3.0 \\
std. dev. & $\mathbf{5 . 7}$ & $\mathbf{3 . 0}$ & $\mathbf{0 . 5}$ \\
& & & \\
Short qrass sites & & & \\
ul6 & 36 & 10.3 & 4.6 \\
ul5 & 34 & 6.3 & 4.5 \\
ul8 & 40 & 16.5 & 4.3 \\
ul4 & 31 & 9.2 & 4.2 \\
h11 & 25 & 7.0 & 4.1 \\
ul7 & 26 & 8.8 & 3.9 \\
h14 & 27 & 7.5 & 3.9 \\
ul3 & 33 & 8.3 & 3.8 \\
ul2 & 29 & 12.0 & 3.7 \\
ul1 & 20 & 8.4 & 3.7 \\
h13 & 19 & 6.9 & 3.2 \\
hl2 & 19 & 6.6 & 2.7 \\
mean & $\mathbf{2 8 . 3}$ & $\mathbf{9 . 0}$ & $\mathbf{3 . 9}$ \\
std. dev. & $\mathbf{6 . 6}$ & $\mathbf{2 . 8}$ & $\mathbf{0 . 5}$ \\
& & & \\
\hline & & & \\
\end{tabular}


Table 3.3: Results of analyses of variance comparing the species richness, species diversity $\left(H^{\prime}\right)$ and density of birds in the short and tall grasslands

\begin{tabular}{|c|c|c|c|c|c|}
\hline & Df & Mean squares & F Ratio & Prob $>F$ & \\
\hline Species number & 1 & 912.66 & 22.03 & 0.0001 & $* * *$ \\
\hline Error & 22 & 41.41 & & & \\
\hline Species Diversity & 1 & 4.56 & 15.43 & 0.0007 & $* * *$ \\
\hline Error & 22 & 0.29 & & & \\
\hline Density & 1 & 16.65 & 1.85 & 0.1874 & \\
\hline Error & 22 & 8.99 & & & \\
\hline
\end{tabular}

True habitat specialists were identified by comparing presence /absence data from the point count surveys (Appendix 3.3) with those found in the grasslands and testing for statistical significance of habitat occurrences with Fisher's Exact Test. Only the top 35 numerically dominant species listed in Appendix 3.3 were tested. The analysis revealed that birds present in both the short and tall grass swards were mainly itinerant species, but there were three short grass specialists, seven tall grass specialists and two grassland specialists that made use of both short and tall grass areas (Table 3.4). 
Table 3.4. A list of the most numerically dominant bird species found in the grassland sites indicating of the proportion of sightings of these species in short grass areas, tall grass areas and in other habitats. Grassland specialists are highlighted (Fisher's exact test), the number of sightings ( $\mathrm{n}$ ) is also given.

\begin{tabular}{|c|c|c|c|c|c|c|}
\hline \multirow[t]{2}{*}{ Species } & \multicolumn{3}{|c|}{ Habitats } & \multirow[t]{2}{*}{$\mathbf{n}$} & \multicolumn{2}{|c|}{ Fisher's exact p } \\
\hline & Short Grass & Tall Grass & Other & & & \\
\hline Helmeted Guineafowl & & 40 & 60 & 15 & 0.157 & \\
\hline Small Buttonquail & & 95 & 5 & 20 & 0.002 & $\star \star$ \\
\hline Black-bellied Bustard & & 44 & 56 & 16 & 0.119 & \\
\hline Crowned Lapwing & 83 & & 17 & 28 & 0.007 & $\star \star$ \\
\hline Cape Turtle Dove & 56 & & 44 & 68 & 0.242 & \\
\hline Red-faced Mousebird & & $3 \uparrow$ & 69 & 29 & 0.596 & \\
\hline Flappet Lark & & 46 & 54 & 11 & 0.289 & \\
\hline Rufous-naped Lark & 40 & 47 & 13 & 27 & 0.004 & $\star \star$ \\
\hline Sabota Lark & 89 & & 11 & 33 & 0.001 & $* * * x$ \\
\hline Fork-tailed Drongo & 76 & & 24 & 43 & 0.342 & \\
\hline Dark-capped Bulbul & 63 & & 37 & 48 & 0.325 & \\
\hline African Stonechat & & 97 & 3 & 50 & 0.001 & $\star * * *$ \\
\hline Zitting Cisticola & & 77 & 23 & 24 & 0.013 & * \\
\hline Rattling Cisticola & 1 & 56 & 44 & 56 & 0.109 & $\nabla$ \\
\hline Croaking Cisticola & & 83 & 17 & 14 & 0.049 & * \\
\hline Southern Black Flycatcher & 79 & & 21 & 28 & 0.289 & \\
\hline Pale Flycatcher & 84 & & 16 & 38 & 0.260 & \\
\hline Chin-spot Batis & & 57 & 43 & 32 & 0.346 & \\
\hline African Pipit & 98 & & 2 & 40 & 0.000 & $* * *$ \\
\hline Yellow-throated longclaw & 38 & 43 & 19 & 27 & 0.050 & * \\
\hline Common Fiscal & 77 & & 23 & 36 & 0.255 & \\
\hline Red-backed Shrike & 67 & & 33 & 37 & 0.256 & \\
\hline Cape Glossy Starling & 76 & & 24 & 73 & 0.237 & \\
\hline Violet-backed Starling & 36 & & 74 & 23 & 0.184 & \\
\hline Southern Grey-headed Sparrow & 76 & & 24 & 30 & 0.119 & \\
\hline Yellow-throated Petronia & 35 & & 65 & 49 & 0.705 & \\
\hline Red-billed Quelea & 63 & & 37 & 22 & 0.315 & \\
\hline Fan-tailed Widowbird & & 84 & 16 & 13 & 0.050 & * \\
\hline White-winged Widowbird & & 88 & 12 & 11 & 0.050 & * \\
\hline Red-collared Widowbird & & 83 & 17 & 17 & 0.050 & * \\
\hline Pin-tailed Whydah & & 60 & 40 & 15 & 0.410 & \\
\hline Blue Waxbill & 64 & & 36 & 42 & 0.345 & \\
\hline Yellow-fronted Canary & 30 & & 70 & 44 & 0.299 & \\
\hline Golden-breasted Bunting & 28 & & 72 & 35 & 0.063 & \\
\hline
\end{tabular}




\section{Ordination of bird data}

Bird abundance data of all individuals observed at each of the study sites, commonly referred to as the 'grassland birds' in this study, were ordinated on a site-by-site basis to detect similarities and/or differences between bird communities. A gradient of decreasing grass height is evident from left to right in the DCA ordination diagram (Figure 3.6), with tall grass areas clustering on the left hand side and short grass areas on the right, indicating that the two extremes of the grassland continuum support distinctly different bird communities. The high eigenvalues (Axis $1=0.677$, Axis $2=$ 0.214 ) indicate that these patterns are well supported. There is also a high turnover of bird species along the gradient of increasing grass height, i.e. high B-diversity. This is highlighted in Figures 37 and Figure 3.8, which show how a suite of bird species is present when the grass is short (1-4 DPM units), and are then replaced by another suite of species when the grass height reaches 6 DPM units. .

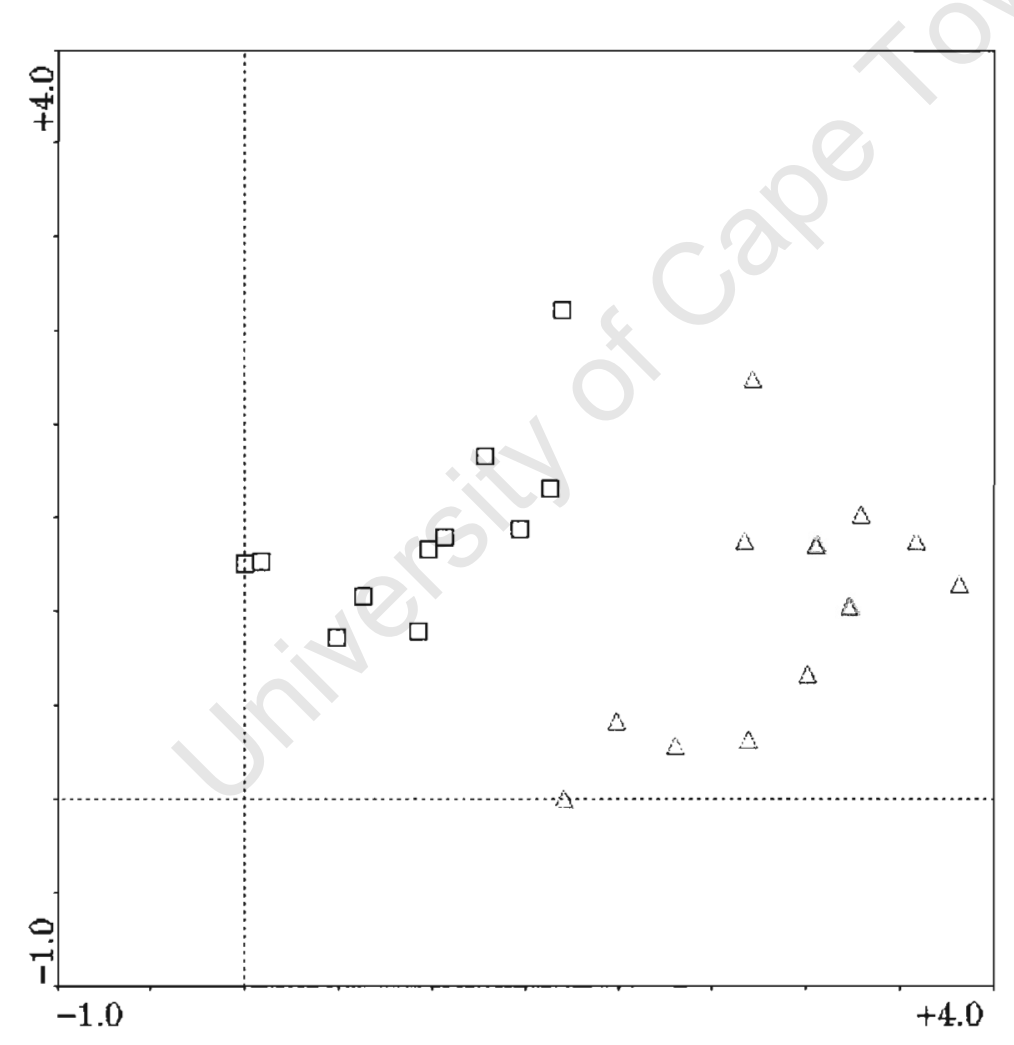

Figure 3.6: Detrended correspondence analysis (DCA) ordination of the first two axes of grassland bird species and density data. The triangles represent sites with short grass swards and squares sites with tall grass swards. 


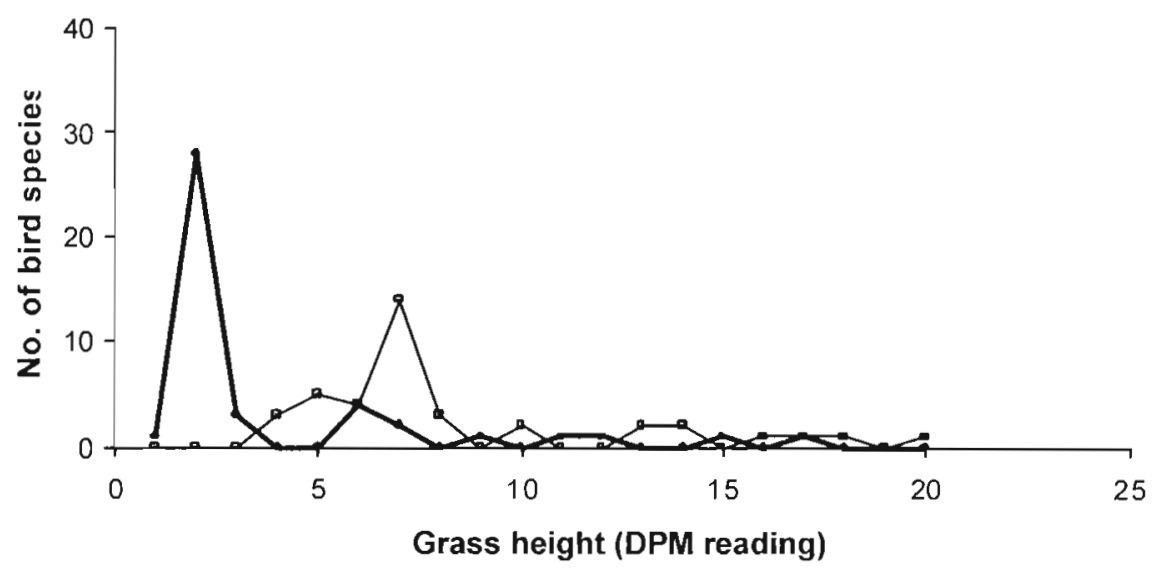

$\rightarrow$ lost $\longrightarrow$ gained

Figure 3.7: The number of bird species lost and gained along a gradient of increasing grass height (DPM readings)

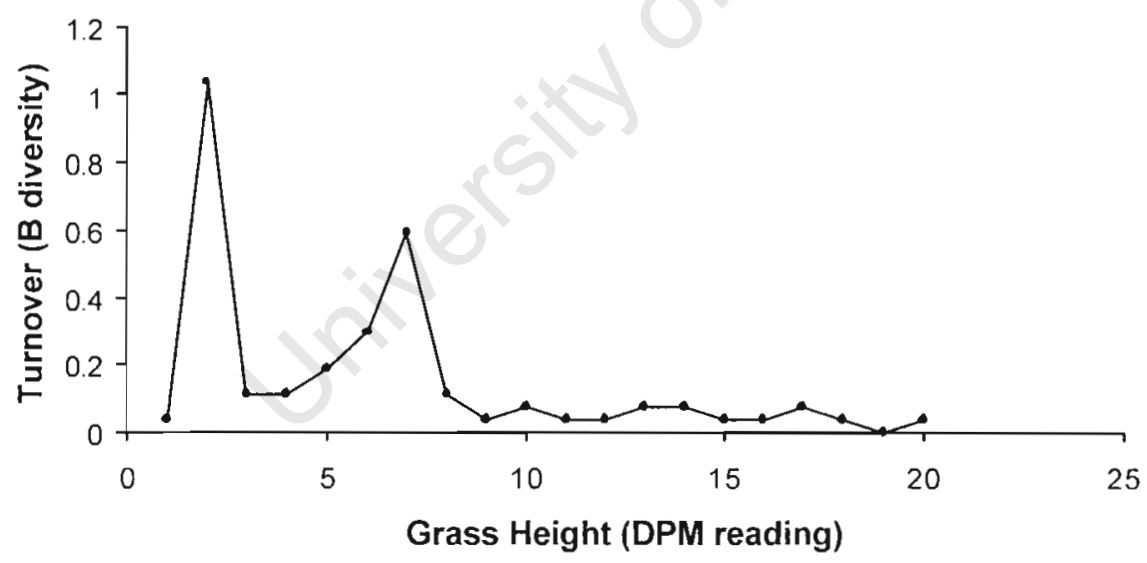

Figure 3.8: Turnover in bird species along a gradient of increasing grass height (DPM readings). 


\section{Ordination of bird data and habitat variables}

The environmental variables, including two plant species variables and 12 structural variables (Appendix 3.1), were used in the DCCA to relate bird incidence and abundance to vegetation characteristics (Figure 3.7). The eigenvectors derived from axis 1 and axis 2 of a DCA of plant species composition data (ordination not shown) were used as the plant species variables. All habitat variables displayed in Appendix 3.1 were used as the structural variables. The DCCA ordination scattered tall grass bird specialists on the left while short grass specialists are distributed on the right hand side of the diagram. Grassland specialists that make use of both short and tall grass areas clustered in the middle, along with other generalist species.

Environmental variables are represented as arrows on the ordination diagram. The relative length and direction of the arrows are important as they indicate relative strengths and the direction of the gradients. Several of the environmental variables in this ordination indicated similar gradients. Thus, to simplify the diagram, only the variable with the greatest correlation in a particular direction was displayed (Figure 3.9). Grass height had the highest correlation, with the location of bird assemblages along the ordination axes whereas grass species composition produced the lowest correlation (Table 3.5). This suggests that habitat structure i.e. grass height, is having the greatest influence on bird species composition. The DCCA produced eigenvalues of 0.638 and 0.028 for the first and second axes, and explained 73.6 percentage of the variance in the relationship between bird species and the environment variables.

Chapter 3. Effect of vegetation structure on grassland bird community composition within Hluhluwe-iMfolozi Park 


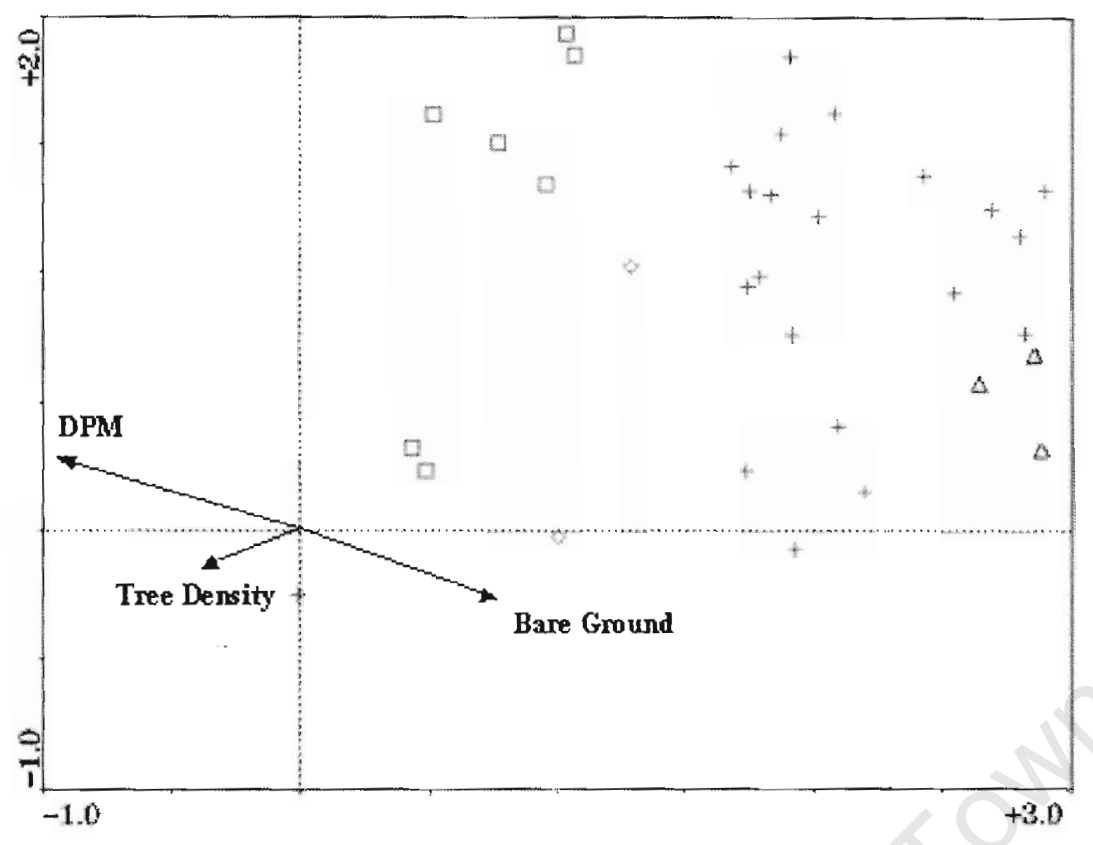

Figure 3.9: Detrended Canonical Correspondence Analysis (DCCA) ordination of the first two axis of the incidence and abundance of bird and environmental variables. The triangles represent short grass hird specialists, squares tall grass specialists, diamonds grassland specialists that make use of both tall and short grass swards and the plus signs represent generalist species. The arrows indicate the gradient of the grass height (DPM), tree density and percentage bare ground. 
Table 3.5: Scores for environmental variables on the first 2 axes of a DCCA

\begin{tabular}{|c|c|c|}
\hline Environmental variables & Axis 1 & Axis 2 \\
\hline \multicolumn{3}{|l|}{ Grass height gradient } \\
\hline DPM & $-0.892+$ & -2.522 \\
\hline $0 \mathrm{FHP}$ & -0.770 & -1.547 \\
\hline $0.5 \mathrm{FHP}$ & 0.759 & 3.768 \\
\hline $0.25 \mathrm{FHP}$ & -0.608 & -0.708 \\
\hline $0.75 \mathrm{FHP}$ & 0.471 & -0.300 \\
\hline $1 \mathrm{FHP}$ & 0.217 & -0.060 \\
\hline $1.5 \mathrm{FHP}$ & -0.237 & 0.151 \\
\hline Plant species Axis 1 & -0.125 & -1.435 \\
\hline Plant species Axis 2 & 0.000 & 0.000 \\
\hline GC3 & 0.000 & 0.000 \\
\hline \multicolumn{3}{|l|}{ Bare ground qradient } \\
\hline Bare Ground & $0.265+$ & -0.510 \\
\hline GC2 & 0.166 & -0.277 \\
\hline GC1 & -0.145 & -1.445 \\
\hline \multicolumn{3}{|l|}{ Tree gradient } \\
\hline Tree Density & $0.194+$ & 0.349 \\
\hline
\end{tabular}

A generalised linear model was used to test the relative importance of grass structure, grass species composition and tree densities on bird incidence and abundance. The natural logarithms of DPM readings were used as an index of grass structure. The total number of lawn grass (stoloniferous) species present versus the total number of bunch grass (caespitose) species present at each site, was used to categorise each site as either a lawn or bunch grass class, to provide nominal data on grass species composition, along with data on tree densities. The scores of axis 1 and 2 from DCA of average bird densities at each site were utilised as the response variable. The model explained 90 percent of the variation of the three independent variables. Results from the 1st axis revealed that bird abundances were not related to grass species or to the trees, but were related to the physical structure of grasslands, as it showed a highly significant $(\mathrm{P}<0.0001)$ relationship with the natural logarithm of grass height (Table 3.6). The second axis showed no significant relationships (Table 3.6). 
Table 3.6: Results of a generalised linear model using bird assemblage as the response variable (DCA axis 1 and axis 2) and grass composition (Grass Class). grass biomass (Log DPM) and tree density as the independent variables.

\begin{tabular}{cccc} 
Factors & Sum of Squares & F Ratio & Prob>F \\
\hline \multicolumn{4}{l}{ Response: DCA Axis 1 scores } \\
Grass Class & 0.1003 & 0.6016 & 0.4470 \\
Log DPM & 7.7414 & 46.4077 & $<.0001$ \\
Tree density & 0.3173 & 1.9026 & 0.1830 \\
& & & \\
Response: DCA Axis 2 scores & & \\
Grass Class & 0.1952 & 0.5301 & 0.4750 \\
Log DPM & 0.0001 & 0.0003 & 0.9868 \\
Tree density & 0.4985 & 1.3535 & 0.2584 \\
& & & \\
\hline
\end{tabular}

\section{Discussion}

There was considerable bird species turnover along the gradient from short grass areas to tall grass areas, with each extreme of the continuum supporting a distinct avifaunal community. A total of 88 birds species were identified within the grasslands, with short grass areas supporting 74 and tall grasslands 59 (Appendix 3.2). Short grass areas had a significantly higher species richness and diversity than tall grass areas. Of the grassland specialists identified, seven inhabited tall grass areas, three inhabited short grass areas, with two utilised both tall and short grass areas. Many itinerant species made use of the grasslands. This was particularly evident in the short grass areas, suggesting that these short grass areas provide valuable food resources for a large suite of species.

There was a significant link between grassland bird distribution and vegetation structure, with grass height having the greatest influence, but little association with floral composition. Structure is therefore the main driving force of grassland bird distribution in HiP. 
Although short grass birds were found on both grazing patches and grazing lawns, grazing lawns may be of more value, because they represent a more stable form of short grass, persisting for longer periods and being less likely to revert to tall bunch grassland. In the chapters that follows I will to test if post-burn bunch grasslands (inside $\mathrm{HiP}$ ), which are short in the early post-burn recovery stage and therefore structurally resemble lawns, or the heavily grazed communally farmed areas outside the park support similar birds to those found on the short grass areas inside the park. If this is the case, then fire, or areas outside the park, would provide an alternate habitat to grazing lawns within the park. If they do not support the short grass specialists, then the grazing lawn habitat in HiP would be important for the conservation of these birds on a regional scale.

The findings of this chapter suggest that grassland bird communities would be particularly sensitive to changes in vegetation structure, and therefore vegetation management could have a direct effect on bird assemblages. For example Archibald et al. (2005) has shown how frequent burning, of fire intervals of less than four years inhibits the development of grazing lawns in HiP. After a fire event, herbivores are attracted to the post-burn flush of new growth and consequently drawn off heavily grazed patches. Very small fires may concentrate grazers which might initiate a grazing patch but the normal large fires will pull grazers off grazing patches and cause the herbivores to spread out on the large burnt areas and thus have a less concentrating effect. In the long term, frequent large fires will indirectly reduce the density and diversity of large mammals species on grazing patches, and reduce lawn grass formation because grazers would not persist in a grazing patch long enough to cause a compositional shift from tall grass to lawn grass species. Consequently birds that require grazing lawns would be lost and those requiring tall bunch grasslands would benefit. However the use of post burn habitats still needs to be investigated (see next chapter), as it may well provide a vital habitat for short grass birds, in which case frequent fire may be beneficial.

Reductions in large herbivore numbers, in particular white thino that are key in maintaining grazing lawns (Zululand Grass Project, unpublished, MS Waldram, pers. comm.) could also result in the reduction of grazing lawns. This will once again benefit species requiring tall grass and adversely affect those requiring short grass. 
In summary, direct and indirect effects of the management of fire and large herbivores can have a direct and/or indirect effect on habitat for other species. The results of this chapter show that changes in the grassland sward, readily infuenced by such management, are likely to influence bird assemblages in the park. Both tall and short grassland types are utilised by habitat specialists, and these species would be directly affected by changes in the extent of the different grassland types. 
Appendix 3.1: Means of habitat variahles at each grassland site

\begin{tabular}{|c|c|c|c|c|c|c|c|c|c|c|c|c|}
\hline Sites & DPN & BG & GC1 & GC2 & GC3 & Tree Den & OFHP & $0.25 \mathrm{FHP}$ & $0.5 \mathrm{FHP}$ & $0.75 \mathrm{FHP}$ & 1FHP & 1.5FHP \\
\hline hb1 & $10.3 \pm 5.8$ & $3 \pm 1.2$ & $0.4 \pm 0.2$ & $20.4 \pm 4.7$ & $76.1 \pm 5.2$ & 15.2 & 1.7 & 0.7 & 0.3 & 0.1 & 0.1 & 0.0 \\
\hline hb2 & $11.9 \pm 5.1$ & $0.1 \pm 0.1$ & $0.1 \pm 0.1$ & $8.0 \pm 2.7$ & $91.7 \pm 2.8$ & 18.0 & 1.9 & 1.0 & 0.5 & 0.1 & 0.0 & 0.0 \\
\hline hb3 & $13.7 \pm 9.5$ & $0.5 \pm 0.6$ & $0.0 \pm 0.0$ & $14.1 \pm 3.2$ & $85.3 \pm 3.2$ & 19.0 & 2.0 & 0.9 & 0.5 & 0.2 & 0.0 & 0.0 \\
\hline hb4 & $9.8 \pm 4.9$ & $3.2 \pm 0.7$ & $1.5 \pm 0.5$ & $26.5 \pm 1.7$ & $68.6 \pm 2.0$ & 30.2 & 1.8 & 0.4 & 0.1 & 0.1 & 0.0 & 0.0 \\
\hline hl1 & $4.0 \pm 2.6$ & $18 \pm 4.0$ & $53.5 \pm 4.7$ & $18.1 \pm 4.6$ & $10.4 \pm 1.8$ & 23.7 & 0.3 & 0.1 & 0.1 & 0.0 & 0.0 & 0.0 \\
\hline hl2 & $3.9 \pm 2.3$ & $10.1 \pm 2.9$ & $63.2 \pm 6.6$ & $20.3 \pm 6.5$ & $6.3 \pm 1.3$ & 17.6 & 0.3 & 0.2 & 0.1 & 0.0 & 0.0 & 0.0 \\
\hline$h \mid 3$ & $6.4 \pm 4.1$ & $9.6 \pm 3.6$ & $48.3 \pm 9.5$ & $33.2 \pm 9.1$ & $8.7 \pm 4.8$ & 16.9 & 0.2 & 0.1 & 0.1 & 0.0 & 0.0 & 0.0 \\
\hline$h / 4$ & $3.1 \pm 2.4$ & $14.5 \pm 3.0$ & $68.4 \pm 2.8$ & $13.5 \pm 1.6$ & $3.4 \pm 1.0$ & 17.4 & 0.2 & 0.2 & 0.1 & 0.1 & 0.0 & 0.0 \\
\hline ub1 & $9.3 \pm 6.5$ & $9.2 \pm 4.9$ & $9.2 \pm 9.2$ & $24.0 \pm 9.4$ & $57.5 \pm 17.7$ & 11.6 & 3.8 & 2.8 & 2.1 & 0.7 & 0.2 & 0.0 \\
\hline ub2 & $9.1 \pm 5.5$ & $1.8 \pm 0.5$ & $9.5 \pm 0.4$ & $18.5 \pm 3.3$ & $70 \pm 5.5$ & 57.3 & 2.8 & 1.2 & 0.6 & 0.3 & 0.2 & 0.0 \\
\hline ub3 & $12.4 \pm 9.2$ & $1.7 \pm 0.9$ & $1.1 \pm 0.7$ & $25.7 \pm 9.5$ & $71.3 \pm 10.4$ & 45.2 & 2.0 & 0.8 & 0.4 & 0.2 & 0.1 & 0.0 \\
\hline ub4 & $7.0 \pm 3.5$ & $7.3 \pm 4.0$ & $10.1 \pm 8.9$ & $33.8 \pm 9.9$ & $48.6 \pm 18.2$ & 18.3 & 1.6 & 0.8 & 0.4 & 0.3 & 0.2 & 0.1 \\
\hline ub5 & $9.0 \pm 4.6$ & $0.6 \pm 0.5$ & $1.0 \pm 0.8$ & $13.6 \pm 5.3$ & $84.6 \pm 6.0$ & 21.3 & 3.1 & 1.5 & 0.8 & 0.4 & 0.1 & 0.0 \\
\hline ub6 & $5.8 \pm 2.5$ & $12.8 \pm 7.2$ & $23.0 \pm 9.7$ & $30.5 \pm 9.0$ & $33.5 \pm 12.3$ & 18.4 & 1.9 & 0.6 & 0.3 & 0.2 & 0.1 & 0.0 \\
\hline ub7 & $10.2 \pm 5.1$ & $0.7 \pm 0.4$ & $2.1 \pm 1.3$ & $23.1 \pm 6.7$ & $74.0 \pm 7.6$ & 8.8 & 1.0 & 0.5 & 0.2 & 0.1 & 0.1 & 0.0 \\
\hline ub8 & $8.7 \pm 4.7$ & $1.0 \pm 0.6$ & $2.0 \pm 0.9$ & $27.5 \pm 9.9$ & $69.4 \pm 11.3$ & 24.2 & 1.7 & 0.5 & 0.3 & 0.2 & 0.1 & 0.0 \\
\hline ul1 & $2.4 \pm 1.3$ & $24.4 \pm 5.6$ & $58.5 \pm 5.8$ & $10.9 \pm 5.0$ & $6.0 \pm 5.3$ & 20.9 & 0.1 & 0.1 & 0.1 & 0.0 & 0.0 & 0.0 \\
\hline ul2 & $3.4 \pm 1.6$ & $12.4 \pm 3.6$ & $59.4 \pm 8.7$ & $28.1 \pm 9.1$ & $0.0 \pm 0.0$ & 19.5 & 0.1 & 0.1 & 0.1 & 0.0 & 0.0 & 0.0 \\
\hline ul3 & $3.6 \pm 3.4$ & $13.2 \pm 4.6$ & $71.1 \pm 6.7$ & $15.0 \pm 8.0$ & $0.6 \pm 0.7$ & 15.8 & 0.1 & 0.1 & 0.1 & 0.0 & 0.0 & 0.0 \\
\hline ul4 & $2.7 \pm 2.4$ & $30.8 \pm 6.3$ & $57.8 \pm 2.9$ & $11.1 \pm 4.8$ & $0.1 \pm 0.1$ & 17.6 & 0.1 & 0.1 & 0.1 & 0.1 & 0.0 & 0.0 \\
\hline ul5 & $3.2 \pm 1.7$ & $7.3 \pm 10.3$ & $62.0 \pm 3.6$ & $30.6 \pm 9.3$ & $0.0 \pm 0.4$ & 22.8 & 0.1 & 0.1 & 0.0 & 0.0 & 0.0 & 0.0 \\
\hline$u l 6$ & $2.5 \pm 1.4$ & $42.5 \pm 8.4$ & $47.8 \pm 4.5$ & $9.4 \pm 5.2$ & $0.1 \pm 0.1$ & 25.8 & 0.1 & 0.1 & 0.0 & 0.0 & 0.0 & 0.0 \\
\hline$u l 7$ & $3.8 \pm 2.0$ & $11.8 \pm 4.4$ & $52.8 \pm 10.2$ & $35.1 \pm 14.2$ & $0.1 \pm 0.1$ & 29.8 & 0.1 & 0.1 & 0.1 & 0.0 & 0.0 & 0.0 \\
\hline uls & $3.4 \pm 1.3$ & $26.6 \pm 8.7$ & $52.1 \pm 4.2$ & $19.4 \pm 9.2$ & $1.7 \pm 1.3$ & 18.4 & 0.1 & 0.1 & 0.0 & 0.0 & 0.0 & 0.0 \\
\hline
\end{tabular}

$\mathrm{DPM}=$ index of grass biomass; $\mathrm{BG}=$ percentage bare ground: $\mathrm{GCl}=$ amount of short grass: $\mathrm{GC} 2=$ amount of tall grass; $\mathrm{GC} 3=$ amount of tall grass; Tree den $=$ relative tree density. FH P0 = Foliage height profile value at $0 \mathrm{~m}$. FHP $0.25=$ Foliage height profile value at $0.25 \mathrm{~m}$. FHPO. $5=$ Foliage height profile value at $0.5 \mathrm{~m}$, FHP $0.75=1$ :ohage height profile value at $0.75 \mathrm{~m}$. FHP $1=$ Foliage height profile value at $1 \mathrm{~m}$ : FHP $1.5=$ Foliage height profile value at $1.5 \mathrm{~m}$ and $\pm=$ standard error 
Appendix 3.2 Mean bird densities per $\mathrm{km}^{2}$ at grassland sites

\begin{tabular}{|c|c|c|c|c|c|c|c|c|c|c|c|c|c|c|c|c|c|c|c|c|c|c|c|c|}
\hline Common name & hb1 & hb2 & hb3 & hb4 & hl1 & $\mathrm{h} 12$ & $\mathrm{~h} / 3$ & $\mathrm{~h} / 4$ & ub1 & ub2 & ub3 & ub4 & ub5 & ub6 & ub7 & ub8 & ul1 & $\mathrm{u} 12$ & ul3 & $\mathrm{u} / 4$ & ul5 & $\mathrm{u} 16$ & ul7 & $\mathrm{ul8}$ \\
\hline Acacia Pied Barbet & & & & & & & & & & & 0 & & & 5 & & 12 & & & 4 & & 4 & & 15 & 7 \\
\hline African Hoopoe & & & & 4 & 4 & 6 & 4 & 14 & & & & & 7 & & & & & & 2 & 3 & 16 & 19 & 5 & 31 \\
\hline African Pipit & & & & 12 & & 243 & 150 & 58 & & & & & & & & & & 211 & 230 & 150 & 28 & & & 28 \\
\hline African Stonechat & & 66 & 45 & 31 & & & & & & & & & & & & & & & & & & & & \\
\hline Bald Ibis & & & & & & & & & & & & & & & & & & & 16 & & & & & \\
\hline Black Cuckooshrike & 8 & & & & & & & & & & & & & & & & 5 & & & & & & & 2 \\
\hline Black-backed Puffback & & & & & & & & & & & & & & & & & & & & & & 1 & & \\
\hline Black-bellied Bustard & & 5 & & 4 & & & & 1 & & 47 & & & & 5 & & & & & 1 & & & & & \\
\hline Black-collared Barbet & & & & & & & & 1 & & & & & & & & & & & & & & & & \\
\hline $\begin{array}{l}\text { Black-crowned Tchagra } \\
\text { Black-headed Oriole }\end{array}$ & & & & & 16 & & & 6 & & 9 & & & & 5 & & 12 & 4 & 6 & & & & & 10 & \\
\hline Blue Waxbill & & & & & & & & 91 & & & 8 & & & & 40 & & & 244 & 42 & 93 & & 41 & 218 & 133 \\
\hline Brubru & & & & & & & & & & 2 & & 2 & & & & 12 & 4 & & & 6 & 2 & 7 & & 6 \\
\hline Burchell's Coucal & & & & 4 & 3 & & & & & & & & & & & & & & & & & & & \\
\hline Cape Glossy Starling & & & & 16 & 62 & 53 & 13 & 20 & 17 & & & 5 & & & & 36 & 11 & 15 & 17 & 35 & 33 & 68 & 45 & 83 \\
\hline Cape Turtle Dove & & & & 8 & 9 & 15 & 16 & 40 & & & 10 & 15 & & 21 & & & 124 & 74 & 60 & 40 & 20 & 53 & 27 & 110 \\
\hline Cardinal Woodpecker & & & & & & & & & & & & & & & & & & & & & 2 & & & \\
\hline Chin-spot Batis & & & & & & & & 8 & & 9 & & & 14 & & 26 & & 15 & 15 & 3 & 11 & 3 & 8 & & 8 \\
\hline Common Fiscal & & & & 16 & & 16 & 18 & & & & & 35 & 14 & 15 & & & 62 & 6 & 3 & 2 & & & 11 & 3 \\
\hline $\begin{array}{l}\text { Common Scimitarbill } \\
\text { Common Waxbill }\end{array}$ & & & & & & & & & & & & & 7 & & & & & & & & 2 & 5 & & 8 \\
\hline Corn Crake & 8 & & & & & & & & & & & & & & & & & & & & & & & \\
\hline Crested Barbet & & & & & & 1 & & & & & & & & & & & 6 & & & & & 2 & & 8 \\
\hline Croaking Cisticola & 142 & 280 & 203 & 86 & & & 6 & 3 & 127 & 122 & 85 & 5 & 229 & 5 & 172 & 60 & & & & & & & & \\
\hline Crowned Lapwing & & & & & & 106 & 120 & & & & & & & 10 & & & & 21 & 51 & & & & & 10 \\
\hline Dark-capped Bulbul & 8 & 22 & & 19 & 31 & 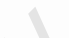 & 25 & 58 & 12 & 19 & 5 & 5 & & 10 & 13 & & 62 & 11 & & 10 & & 15 & 44 & \\
\hline Emerald-spotted Dove & & & & & 18 & 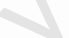 & 5 & 7 & 6 & & & & & & & & 7 & & & & 13 & 4 & 6 & 8 \\
\hline European Roller & & & & & & 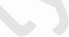 & & & & & 15 & & & & & & & & & 1 & & & & \\
\hline Fan-tailed Widowbird & 16 & 82 & 45 & 19 & 6 & 2 & 9 & & & & 45 & & 201 & 15 & & & & & 5 & & & & & \\
\hline Fiscal Flycatcher & & & & & 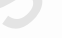 & & & & & & & & & & & & & 13 & & & & 37 & 5 & \\
\hline Flappet Lark & & & 15 & & & & & & 35 & & & & & & & & & & & & & & & \\
\hline Fork-tailed Drongo & & 5 & & & 39 & & 10 & 22 & 6 & & & 25 & & 5 & & & 6 & 20 & 2 & 22 & 17 & 25 & & 16 \\
\hline $\begin{array}{l}\text { Golden-breasted Bunting } \\
\text { Golden-tailed Woodpecker }\end{array}$ & & & & & 25 & 2 & 3 & 20 & 35 & & & 20 & 7 & & & & 16 & 4 & 3 & 12 & 21 & 13 & 38 & $\begin{array}{r}11 \\
1\end{array}$ \\
\hline Greater Honeyguide & & & & & & & & & 6 & & & & & & & & & & & & & & & \\
\hline Green Wood-hoopoe & & & & & & & & & & & & & & & & & & & & & 3 & 4 & & 15 \\
\hline Grey Penduline Tit & & & & & & & & & & & & & & & & & & & & & & & & 7 \\
\hline Hadeda Ibis & & & & & 7 & 3 & & 8 & & & & 5 & & 3 & & & 28 & 3 & & 14 & 11 & 15 & & 6 \\
\hline Helmeted Guineafowl & & & & & & & & & & & & & & 57 & & & & & 8 & & & & & \\
\hline Jacobin Cuckoo & & & & & & & & & & & & 5 & & & & & & & & & & & & \\
\hline Kurrichane Thrush & & & & & & & & & & & & & & & & & & & & & 11 & 11 & 24 & 25 \\
\hline Lazy Cisticola & & & & & & & & & 6 & & & & & & & & & & & & & & & \\
\hline Lilacbreasted Roller & & & & & & & & & & & & & & & & & & & & & 1 & & & 2 \\
\hline
\end{tabular}


Appendix 3.2 cont.: Mean bird densities per $\mathrm{km}^{2}$ at grassland sites

\begin{tabular}{|c|c|c|c|c|c|c|c|c|c|c|c|c|c|c|c|c|c|c|c|c|c|c|c|c|}
\hline Common name & hb1 & hb2 & hb3 & hb4 & $\mathrm{h} 11$ & $\mathrm{~h} / 2$ & $\mathrm{~h} / 3$ & $h / 4$ & ub1 & ub2 & ub3 & ub4 & ub5 & ub6 & ub7 & ub8 & ul1 & $u / 2$ & $\mathrm{ul3}$ & $\mathrm{u} / 4$ & ul5 & ul6 & ul7 & 418 \\
\hline Longbilled Crombec & & & & & & & & & 6 & & 5 & & & & & & & & & 8 & 19 & 9 & & \\
\hline Long-tailed Paradise Whydah & & & & & & & & & & & & & & & & & & & 4 & & & & & 8 \\
\hline Marico Sunbird & & & & & & & & & 35 & & & & & & & & & & & & & & 6 & \\
\hline Melba Finch & & & & & & & & & & & & & & & & & & & & & & & 25 & 11 \\
\hline Orange-Breasted Bush shrike & & & & & & & & & & & 5 & 1 & & & & & & & & & & & & \\
\hline Pale Flycatcher & & & & & 10 & & & 19 & 6 & & 10 & & & 5 & & & & & 6 & 26 & 35 & 72 & 12 & 73 \\
\hline Paradise Flycatcher & & & & & & & & & & & & & & & & & & 1 & & & & & & \\
\hline Red-backed Shrike & & & & & 5 & 2 & & 29 & 40 & & & 5 & & 36 & 13 & 36 & 51 & 33 & 30 & 36 & 39 & 73 & 64 & 36 \\
\hline Red-billed Quelea & & & & & & & & & 69 & & & & & & & & 72 & 36 & & 72 & 55 & 80 & & 282 \\
\hline Red-collared Widowbird & & 60 & 38 & 32 & & & & & 173 & & & & & 15 & & & & & 34 & & & & & \\
\hline Red-faced Mousebird & & & & & & & & 23 & 6 & & 20 & 5 & & & & & 94 & 36 & & 47 & 18 & 65 & 56 & 42 \\
\hline Red-throated Wryneck & & & & & & 2 & & & & & & & & & & & & & & 6 & & & & 12 \\
\hline Rufous-naped Lark & 8 & 11 & & 66 & 11 & 39 & 27 & & & 56 & 5 & & 97 & 62 & & & & 7 & 21 & 9 & & & & \\
\hline Sabota Lark & & & & & & & & & & & & & & 31 & & & & 70 & 10 & 46 & 53 & 61 & 7 & 144 \\
\hline Southern Grey-headed Sparrow & & & & & 34 & & 20 & 5 & & & & & & & & & & 5 & 40 & & 37 & 6 & & 53 \\
\hline Southern Ground-hornbill & & & & & & & & & & & & & & & & & & & 2 & & & & & \\
\hline Southern Yellow-billed hornbill & & & & & & & & & & & & & & & & & & & & & 4 & & & 16 \\
\hline Speckled Mousebird & 8 & & & & & & & & & & & 5 & & & & & & & & & & & & \\
\hline Striped Kingfisher & & & & & 22 & & & & 0 & & & & & & & & & & & 17 & 13 & 19 & & 12 \\
\hline Tawny-flanked Prinia & & 16 & & & & & & & & & & & & & & & & & & & & & & \\
\hline Three-banded Plover & & & & & & & & & & & & & & & & & & & & & & & & \\
\hline Three-streaked Tchagra & & & & & & & & & & & & & 7 & 5 & & & & & & & & & & \\
\hline Village Weaver & & & & & 6 & 5 & & 5 & & & & & & & & & & 5 & 7 & 5 & & 10 & 18 & 10 \\
\hline Violet-backed Starling & & & & & 60 & & & 4 & 6 & 19 & & & & & & & 8 & & 6 & & 12 & 4 & & 28 \\
\hline White-bellied Sunbird & & & & & & & 2 & 2 & & & & & & & & & & & & & & & & \\
\hline White-browed Scrub-robin & & & & & & & & & & & & & & & & & & & & & & 24 & & \\
\hline White-fronted Bee-eater & & & & & & & & & & & & & & & & & & & & 3 & 20 & 7 & 10 & 18 \\
\hline White-winged Widowbird & & & & & & & & & 169 & & 5 & & & 10 & & & & 13 & & & & & & \\
\hline Woolly-necked Stork & & & & & & & & & & & & & & & & & & & 7 & & & & & \\
\hline
\end{tabular}

Zitting Cisticola

$\mathrm{h}=$ Hluhluwe, $\mathrm{u}=\mathrm{iMfolozi}, \mathrm{b}=$ tall grass, $\mathrm{I}=$ short grass 
Appedix 3.3: Presence absence data of birds in thickets $(T)$, low density woodland $(L)$, medium density woodland and $(M)$ and high density $(H)$.

\begin{tabular}{|c|c|c|c|c|c|c|c|c|c|c|c|c|c|c|c|c|c|c|c|c|}
\hline Common name & T1 & T2 & $\overline{\mathrm{T} 3}$ & T4 & T5 & T6 & $T 7$ & T8 & T9 & $\mathrm{T} 10$ & L1 & $\mathrm{L} 2$ & L3 & L4 & L5 & L6 & $\mathrm{L} 7$ & L8 & L9 & $\mathrm{L} 10$ \\
\hline Acaica Pied Barbet & & & & & & & & & & & & & & 1 & & & & & & \\
\hline African Hoopoe & & & & & & & & & & & 1 & & & & 1 & & & & & 1 \\
\hline African Paradise Flycatcher & & & & & & & & & & & & & & & & & & & & \\
\hline Black-backed Puffback & & & & & & & & & & & & 1 & & & & & & 1 & & \\
\hline Black-bellied Bustard & & 1 & & & 1 & & 1 & & & 1 & & & & & & & & & & \\
\hline Black-collared Barbet & & & & & & & & & & & & 1 & & 1 & & 1 & 1 & & & \\
\hline Blue Waxbill & 1 & & 1 & & 1 & & 1 & & & & & & & & & 1 & & 1 & 1 & 1 \\
\hline Brown-crowned Tchagra & & & & & & & & & & & & & & & 1 & & & & & \\
\hline Brown-hooded Kingfisher & & & & & & & & & & & & 1 & & & & 1 & & 1 & & \\
\hline Brubru & & & & & & & & & & & & 1 & & 1 & & & & & 1 & \\
\hline Buhveld Pipit & & & & & & & & & & & & & & & & & & & & \\
\hline Burcell's Coucal & & & 1 & & & & & & 1 & & 1 & & 1 & & & & & & & \\
\hline Cape Glossy Starling & 1 & & 1 & 1 & & 1 & & 1 & $\uparrow$ & & & 1 & & & & & & 1 & & 1 \\
\hline Cape Turtle Dove & & 1 & & & 1 & & & & & 1 & & 1 & & 1 & & & & & & 1 \\
\hline Cape White-eye & & & 1 & & 1 & & & & & & & & & & & & & & & \\
\hline Chinspot Batis & & & & & & & & & & & 1 & & & & 1 & & 1 & & & \\
\hline Commmon Fiscal & & & & & & & & & & & & & & & & 1 & & 1 & 1 & \\
\hline Common Scimitarbill & & & & & & & & & & & & 1 & & & & & & & 1 & \\
\hline Common Waxbill & & & & & & & & & & & & & & & & & & & & \\
\hline Crested Barbet & & & & 1 & & 1 & & & & 1 & & & & 1 & & & & & & 1 \\
\hline Crested Francolin & & & 1 & & 1 & & 1 & & & & & & & & & & & & & \\
\hline Dark-capped Bulbul & & 1 & & 1 & 1 & 1 & & & & & & 1 & & & & 1 & & & 1 & \\
\hline Eastem Nicator & & 1 & & & & & & & & & & & & & & & & & & \\
\hline Emerald-spotted Dove & & & & & & 1 & & & & & & & & & & & & & & \\
\hline European Roller & & & & & & & & & & & & & & & & 1 & & & 1 & \\
\hline Fork-tailed Drongo & & & 1 & & 1 & & 1 & & & & & & & & & 1 & & & & \\
\hline Golden-breatsed Bunting & & & & & & & & & & & & & & & & & & & & 1 \\
\hline Golden-tailed Woodpecker & & & & & & & & & & & & & 1 & & & & 1 & & & \\
\hline Greater Honeyguide & & & & & & & & & & & & & & & & & & & & \\
\hline Green Wood-Hoopoe & & & & & & & & & & & & & & & & & & & & \\
\hline Green-back Camaroptera & & & & & 1 & & & & & & & & & & & & & & & \\
\hline Grey-headed Bush Shrike & & 1 & & & & & & & & & & & & & & & & & & \\
\hline Hadeda Ibis & & & 1 & & & & & & & & & & & & & & & & & \\
\hline Helmeted Guineafow & & & 1 & & & 1 & & 1 & & & & & & & & 1 & & & & \\
\hline Klaas's Cuckoo & & & & & & & & & & & & & & & & & 1 & & & \\
\hline Lilac-breasted Roller & & & & & & & & & & & & & & & & & & & & 1 \\
\hline Little Bee-eater & 1 & 1 & & & & 1 & & & & & & & & & & & & & & \\
\hline Long-billed Crombec & & & & & & & & & & & 1 & & & & & & 1 & & 1 & \\
\hline Magpie Shrike & & & & & & & & & & & & & & & & & 1 & & & \\
\hline Natal Francolin & & & & & 1 & & & & & & & & 1 & & & & & & 1 & \\
\hline Purple-crested Turacc & & & & $\cdot$ & & & & & & & & & & & & & & & & \\
\hline Rattling Cisticola & & 1 & 1 & & 1 & 1 & 1 & & & 1 & & 1 & & & 1 & & 1 & & 1 & \\
\hline $\begin{array}{l}\text { Red-backed Shrike } \\
\text { Red-billed Firefinch }\end{array}$ & & & & 1 & & & 1 & & 1 & & 1 & & 1 & & & 1 & & 1 & & \\
\hline Red-billed Quelea & & & & & & & & & & & & 1 & & & & & & 1 & & \\
\hline Red-faced Mousebird & & & & & & & & & & & & & & & 1 & & & & & \\
\hline Red-fronted Tinkerbird & & & & & & & & & 1 & & & & & & & & & & & \\
\hline Red-thorated Wryneck & & & & & & & & & & & & & & & 1 & & & 1 & & \\
\hline $\begin{array}{l}\text { Rudd's Apalis } \\
\text { Scarlet-chested Sunbird }\end{array}$ & & & & & & & & & & & & & & & & 1 & & & & \\
\hline Sombre Greenbul & & & & 1 & & 1 & & & & & & & & & & & & & & \\
\hline Southern Bald Ibis & & & & & & & & & & & 1 & & & & & & & & & \\
\hline Southern Black Tit & & & & & & & & 1 & & 1 & & & & 1 & & 1 & & & & \\
\hline Southern Boubou & & & & 1 & 1 & & & & & & & & & & & & & & & \\
\hline Southern Yellow-billed Hornbill & & & & & & & & & & & & & & 1 & & & & & & \\
\hline Speckled Mousebird & & & & & 1 & & & & & & & & & & & & & & & \\
\hline Striped Kingfisher & & & & & & & & & & & & 1 & & & & & & & & \\
\hline Tawny-flanked Prinia & & & & & & & & & & & & & & & & & & & & \\
\hline Village Weaver & & 1 & & & & 1 & 1 & & & 1 & & & & 1 & & & & 1 & & \\
\hline Village Widowfinch & & & & & & & & & & & & & & & & & & & & \\
\hline White-browed Robin-Chat & & & & 1 & & & & & & & & & & & & & & & & \\
\hline White-browed Scrub-Robin & & & & & & & & & & & & & & & & & & & & \\
\hline White-fronted Bee-eater & & & & & 1 & & & & & 1 & & & & & 1 & & & & & \\
\hline Woolly-necked Stock & 1 & & & & & & & & & & & & 1 & & & & & & & 1 \\
\hline Yellow-breasted Apalis & & & & & & & & & & & & & & & & & & & & \\
\hline Yellow-fronted Canary & & 1 & & & 1 & & & & 1 & & & 1 & & 1 & & 1 & & & & \\
\hline Yellow-throated Petronia & & & 1 & & 1 & & 1 & & & & 1 & & 1 & & 1 & & 1 & & 1 & \\
\hline
\end{tabular}


Appedix 3.3 cont.: Presence absence data of birds in thickets ( $T$ ), low density woodland (L), medium density woodland and $(M)$ and high density $(H)$.

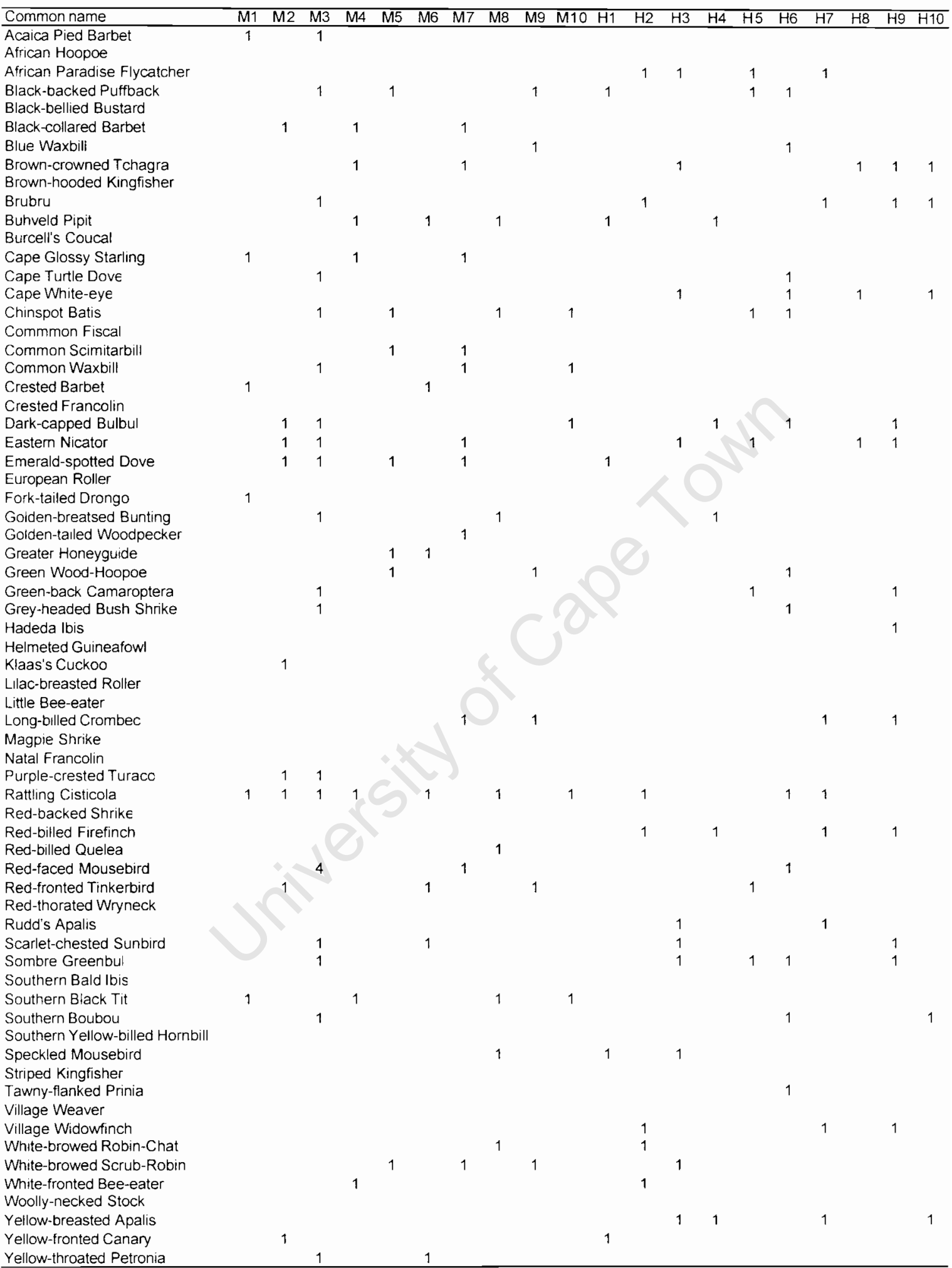




\section{Chapter 4: Post-fire vegetation change and bird responses in}

\section{Hluhluwe-iMfolozi Park}

\section{Introduction}

Fire is a natural form of disturbance of savanna ecosystems and has influenced the evolution of many organisms (Bond \& Van Wilgen 1996). Its role and implementation have, however, remained contentious issues, and topics of much debate. Although a great deal of literature is available on fire in African savannas, few studies have addressed the ecological effects that fire has on bird communities. In Australia, fire is now recognised as a significant threat to many rare, vulnerable and endangered bird species (Woinarski 1999), with most of the fire-threatened species requiring fire intervals longer than those that have been imposed since European settlement (Woinarski 1999).

In HiP. two distinct grassland types occur, short stoloniferous grazing lawns and tall tussock-like bunch grasslands. Bunch grasslands burn readily due to high biomass of combustible, tall standing material. In contrast, the grazing lawns hardly support fire and are preferred by grazing animals that depend on these grasslands for high quality forage. These lawn and bunch grasslands support distinctly different avifaunal assemblages, including several short and tall grass specialists (Chapter 3). Reports suggest that grasslands as a whole have diminished in HiP (Brooks \& Macdonald 1983: Macdonald 1979; Watson \& Macdonald 1983a) and evidence exists that suggest that grazing lawns in particular have decreased in extent since the 1960 s (Bond et al. 2001). This is particularly evident in Hluhluwe, were long-term monitoring has shown dramatic changes from short grass in the late 1960s to tall grass swards in the 1980s. This decrease in grazing lawns coincided with the disappearance of many grassland-frequenting bird species in the 1970s (Macdonald 1984), several of which frequented short-grass habitats. The majority of these species are known to be nomadic, migratory or on the edge of their range. However, their disappearance nonetheless strongly suggests that some change has taken place. It is possible that this change has occurred beyond the park boundaries, but it may equally well be a 
response to habitat changes within the park. If the latter is the case, an understanding of the processes responsible would provide insight that may help prevent further biodiversity loss.

Studies have shown that different experimentally manipulated fire regimes may drive measurable and consistent differences in habitat structure and composition over both the short and long term (Enslin et al. 2000; Trollope et al. 1987). It has been suggested that frequent fire of intervals of less than four years, inhibits the development of grazing lawns in HiP (Archibald et al. 2005). After a fire event, herbivores are attracted to the post-burn flush of new growth and consequently drawn off heavily grazed patches. Very small fires may concentrate grazers which might initiate a grazing patch but the normal large fires will pull grazers off grazing patches and cause the herbivores to spread out on the large burnt areas and thus have a less concentrating effect. In the long term, frequent large fires will indirectly reduce the density and diversity of large mammal species on grazing patches, and reduce lawn grass formation because grazers would not persist in a grazing patch long enough to cause a compositional shift from tall grass to lawn grass species. Thus a highfrequency fire regime will negatively impact on the grazing lawn bird community. However, a significant link exists between grassland bird distribution and vegetation structure (Chapter 3). After a fire has burnt tall grasslands, the initial recovery is structural short grassland. The short post-burn areas may be sufficiently structurally similar to grazing lawns to support grazing lawn bird assemblage for a period of time. Should this be the case, a frequent fire regime would be beneficial for the grazing lawn bird community, as it would ncrease the amount of habitat available to them. These two ideas contradict one another and thus I investigated the role of post-burn habitats in HiP, to acquire a better understanding of the short-term bird responses to fire. This will help determine the importance of post burn habitats for grazing lawn bird communities and provide insight to whether or not high or low frequency fire regimes are more beneficial.

This chapter sets out to:

Chapter + Post-fire vegetation change and bird responses in Hluhluwe-iMfolozi Park 
1. Determine which bird species occur in bunch grassland before a fire event.

2. Determine how birds respond to a fire event.

3. Determine if a succession from short grass bird community to tall grass bird assemblage does exist, and over what time scale it is likely to occur.

\section{Methods}

Fifteen potential sites were identified in tall bunch grassland. Each of these sites fell within the proposed burning program for the year, and thus potentially would be burnt at the end of the dry season. During July and August 2003, nine of the proposed sites burnt, five in mesic areas (Hluhluwe) and four within semi-arid savanna (iMfolozi). At each of these sites, bird and vegetation surveys were conducted 10 to 20 days before the fire event. During a fire event, observations were made of birds at the fire front; thereafter, bird and vegeta tion surveys were made at 3, 5, 7, 15, 30, 45, 60, 75, $90,120,180,240$ and 300 days post fire.

At each study site, two metal pegs were used to demarcate the start and end points of a $200 \mathrm{~m}$ transect. This was to ensure the same route was traversed during each sampling period. Due to the large changes in vegetation height pre and post fire, two different bird survey techniques were needed for short and tall grass swards. When the mean DPM reading (grass height) was greater than $5 \mathrm{~cm}$, the rope drag technique was applied, when the DPM reading was less than $5 \mathrm{~cm}$ a standard line transect was used (see Chapter 3 for details of bird survey techniques).

At the same localities where bird data were collected, grass height was also measured An index of grass height was obtained using a Disc Pasture Meter (Bransby \& Tainton 1977). A total of 50 points were sampled per transect at two metre intervals along the first $100 \mathrm{~m}$ of the marked (with metal pegs) transect. This was done after each bird survey. 
The probability of occurrence of each of the grassland bird specialists at different grass heights was determined using incidence functions. For example, if African Pipit was only found at eight of the nine sites when the DPM reading grass height was 2 $\mathrm{cm}$, the probability of occurrence was $0.89(8 / 9)$. Incidence curves also were constructed to examine bird presence after fire of the three short-grass specialists and the three numerically dominant tall-grass specialists. This was done at mesic (Hluhluwe) and arid (iMfolozi) sites.

\section{Results}

Ten different bird species made use of the fire fronts as a hunting ground, hawking and pouncing on invertebrates and vertebrates flushed by the fire (Table 4.1).

Table 4.1: Birds present and moving with the fire front, hawking or pouncing on prey items, or feeding on aerial prey above fires in Hluhluwe and iMfolozi.

\begin{tabular}{lcc}
\hline Species & Hluhluwe & iMfolozi \\
\hline Yellow-billed Kite & 1 & 1 \\
Jackal Buzzard & 1 & 1 \\
White-fronted Bee-eater & 1 & 1 \\
Little Bee-eater & 1 & 1 \\
Lilacbreasted Roller & & 1 \\
Southern Yellow-billed Hornbill & 1 & 1 \\
Crowned Hornbill & 1 & 1 \\
Fork-tailed Drongo & 1 & 1 \\
Common Fiscal & 1 & 1 \\
Cape glossy Starling & &
\end{tabular}

Senegal Lapwing and Plain-backed Pipits moved into burnt areas within 2 hours of the fire event and were present for approximately 2 weeks. There was a turnover from short grass specialists to tall grass specialists in the post-burn areas. Short grass specialists were present for 50-100 days post burn, being replaced by tall grass specialists soon thereafter (Figure 4.1). In iMfolozi, where grass growth is less than Hluhluwe due to a lower rainfall, the short-grass specialists were present for longer periods (Figure 4.1).

Each of the grassland specialists showed distinct preference for a particular range of grass height (Figure 4.2/3/4). Short-grass specialists were not present before the fire; however, after the fire they were present until the grass exceeded a certain height. I 
was unable to establish the grass height preference for African Stonechat due to lack of replication. Zitting Cisticola, Redcollared Widowbird and Small Buttonquail showed similar patterns to short-grass specialists in that they had a distinct grass height range preference (Zitting Cisticola 410 DPM units, Red-collared Widowbird 4.5-10 DPM units, Small Buttonquail 4.5-20 DPM units). When a minimum grass height was reached the brds started utilising the burnt areas. Once the grass height had exceeded a maximum threshold they moved off. The rest of the tall grass specialists appeared once the grass swards reached a minimum height, but thereafter did not show a decrease with an increase in grass height. Rufous-naped Lark and Yellow-throated Longclaw are generalists, and tolerated a broad range of grass heights. 


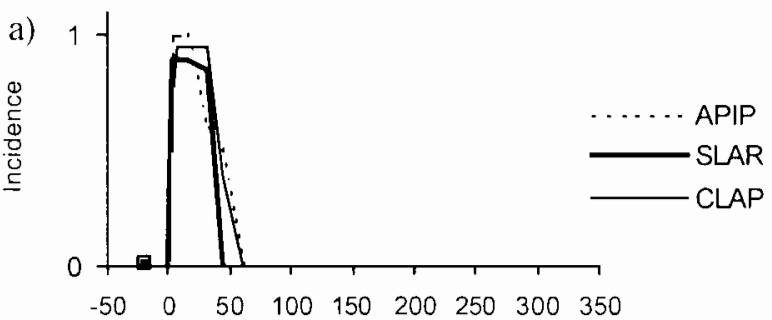

Time (days)

d)

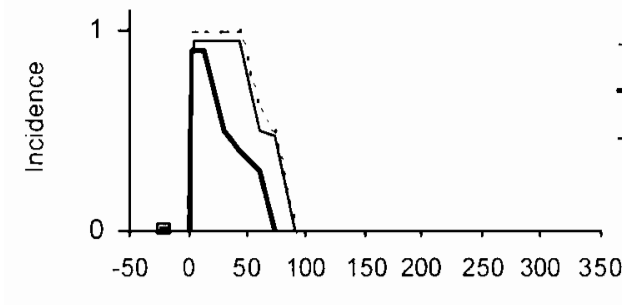

Time (days)

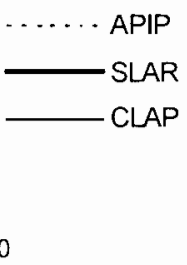

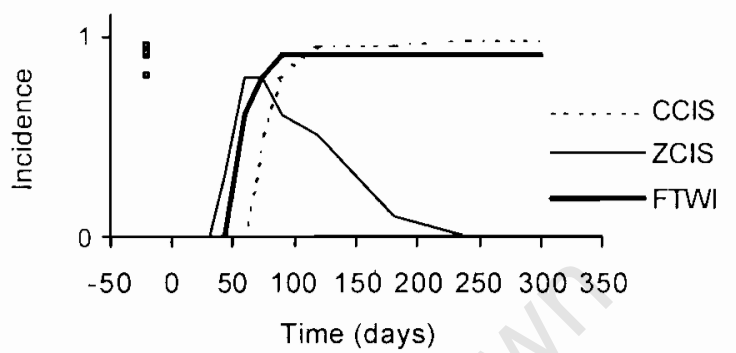

e)

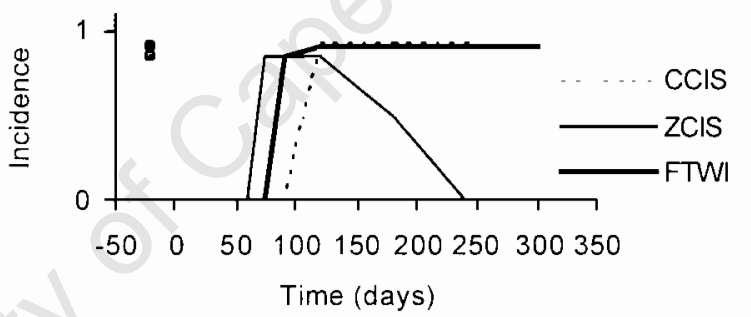

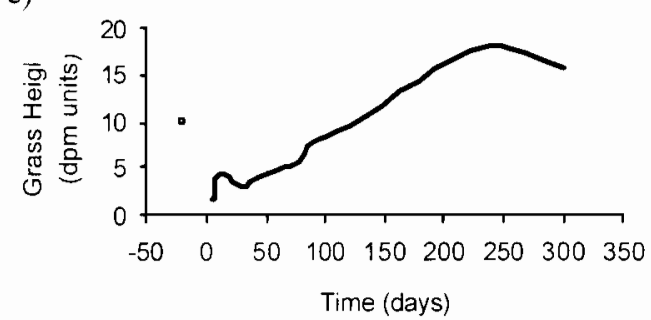

f)

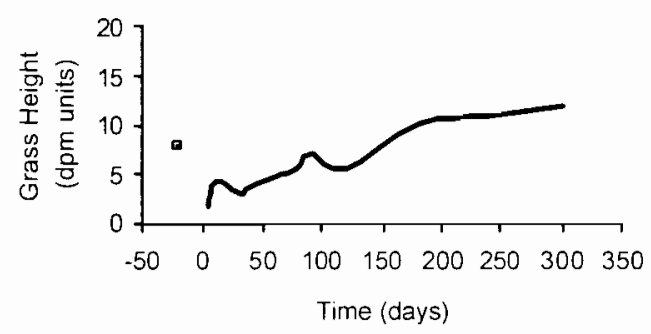

Figure 4.1: Incidence curves of three short grass specialists, the three most dominant bunch grass specialists and the corresponding grass height after a fire event of four Hluhluwe sites $(a, b, c)$. Incidence curves of three short grass specialists, the three most dominant bunch grass specialists and the corresponding grass height after a fire event of five iMfolozi sites (d.e.f). Squares represent bird incidence and grass height before fire (APIP African Pipit. SLAR Sabota Lark. CLAP Crowned lapwing. CCIS Croaking Cisticola. ZCIS Zitting Cisticola. FTWI Fan-taile Widowbird) 
African Pipit

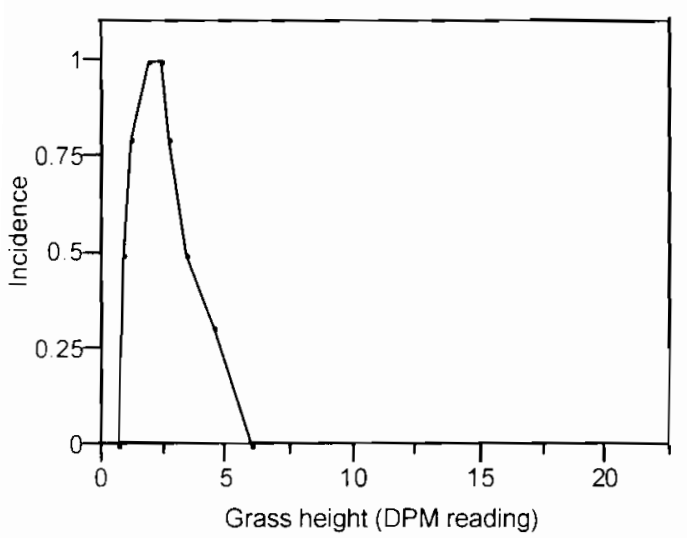

Sabota Lark

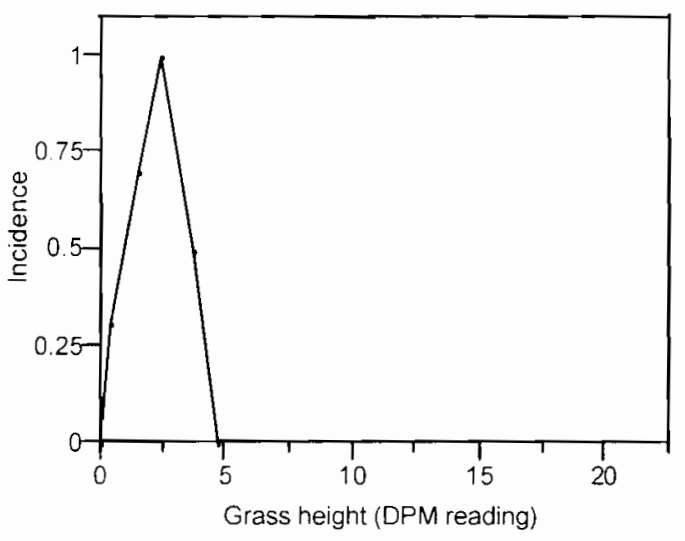

Crowned Lapwing

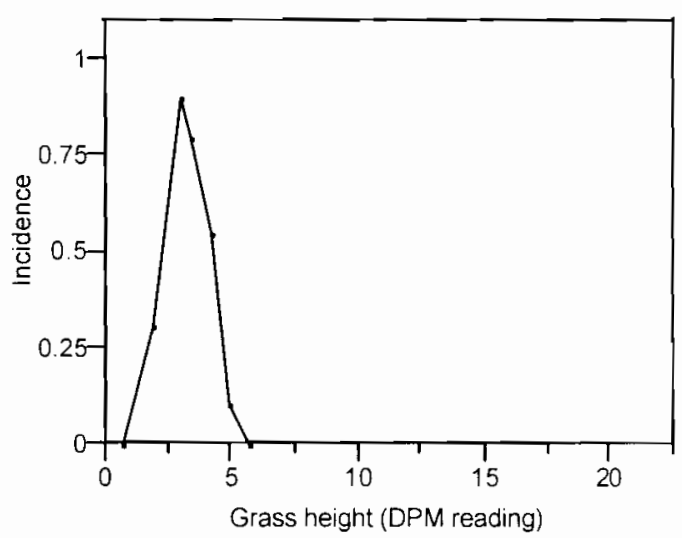

Figure 4.2: Incidence curves of short grass specialists in relation to grass height. Note: The points represent the proportions of sites in which birds were present at a particular grass height. 

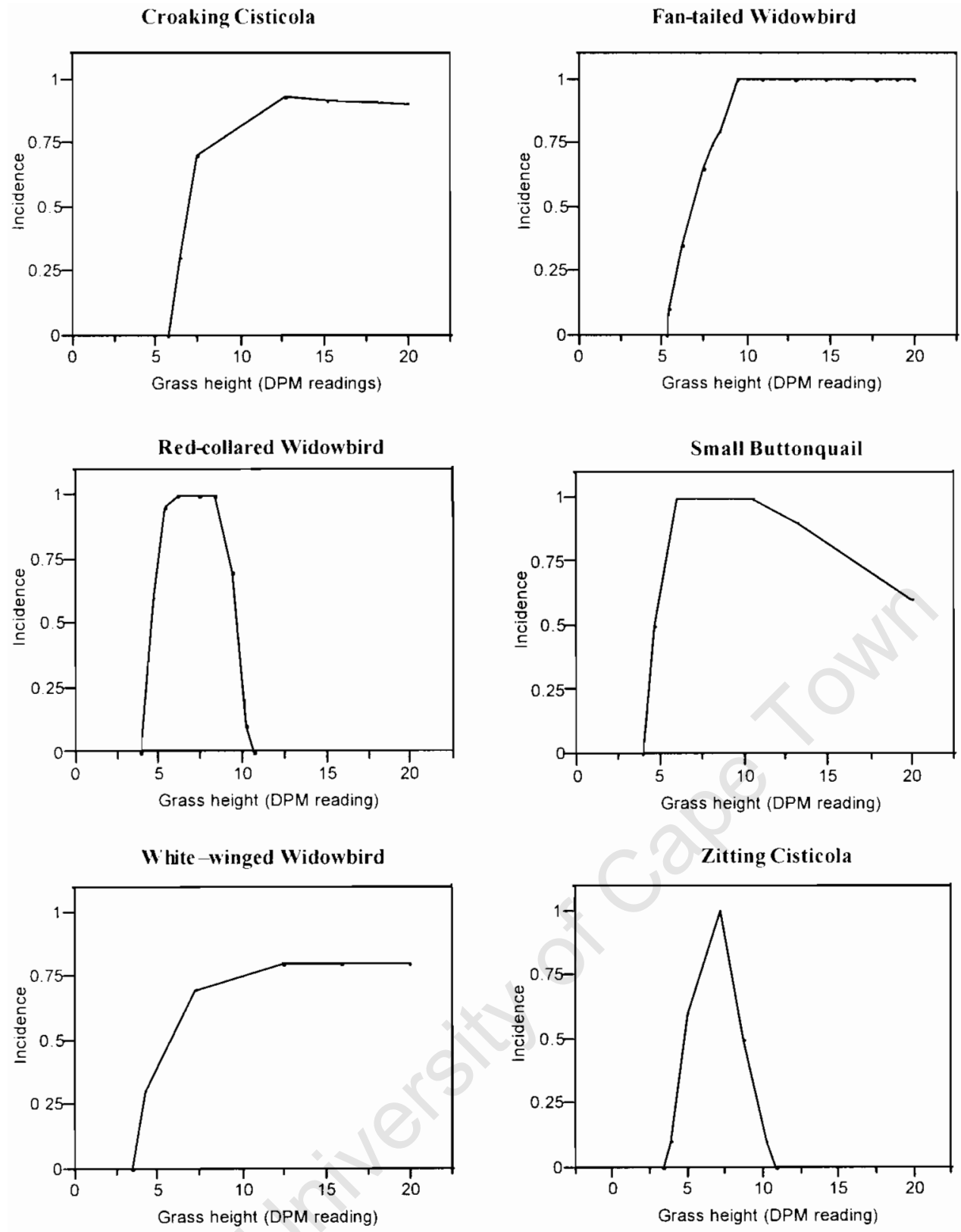

Figure 4.3: Incidence aurves of tall grass specialist species in relation to grass height. Note: The points represent the proportions of sites in which birds were present at a particular grass height. 

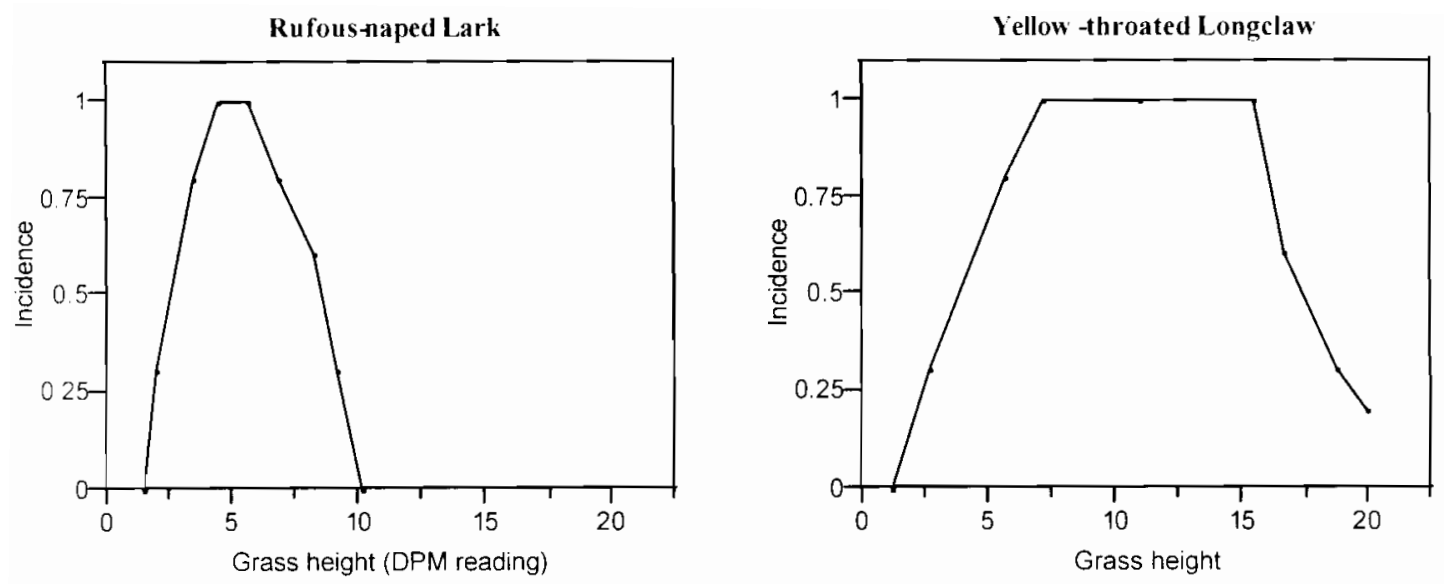

Figu re 4.4: Incidence curves of short and tall grass specialists in relation to grass height. Note: The points represent the proportions of sites in which birds were present at a particular grass height. 
Table 4.2: Birds observed 10 to 20 days before the fire events, and birds seen 0-90, 91180, 181-270 and 271-350 days post fire. Specialists are highlighted

\begin{tabular}{|c|c|c|c|c|c|}
\hline Species & preburn & $0-90$ & $91-180$ & $181-270$ & $271-350$ \\
\hline Woolly-necked Stork & & 1 & & & \\
\hline Southern Bald Ibis & & 1 & & & \\
\hline Hadeda lbis & & 1 & 1 & 1 & \\
\hline Secretarybird & & 1 & & & \\
\hline Helmeted Guineafowl & & 1 & 1 & & \\
\hline Small Buttonquail & 1 & & 1 & 1 & 1 \\
\hline Corn Crake & & & 1 & & \\
\hline Black-bellied Bustard & 1 & & 1 & 1 & 1 \\
\hline Crowned Lapwing & & 1 & & & \\
\hline Senegal Lapwing & & 1 & & & \\
\hline Cape Turtle Dove & 1 & 1 & 1 & 1 & 1 \\
\hline Emerald-spotted Dove & 1 & 1 & 1 & 1 & 1 \\
\hline Jacobin Cuckoo & & & & 1 & \\
\hline Burchell's Coucal & 1 & 1 & 1 & & 1 \\
\hline Speckled Mousebird & 1 & & 1 & 1 & 1 \\
\hline Striped Kingfisher & 1 & 1 & 1 & 1 & 1 \\
\hline White-fronted Bee-eater & & 1 & 1 & & \\
\hline Little Bee-eater & 1 & 1 & 1 & 1 & 1 \\
\hline European Roller & & & 1 & 1 & \\
\hline Lilacbreasted Roller & & 1 & & & \\
\hline African Hoopoe & 1 & 1 & 1 & 1 & 1 \\
\hline Green Wood-hoopoe & 1 & 1 & & & \\
\hline Common Scimitarbill & & 1 & & & 1 \\
\hline Southern Yellow-billed Hor & & 1 & & & \\
\hline Southern Ground-hornbill & & 1 & & & \\
\hline Black-collared Barbet & & 1 & & & 1 \\
\hline Acacia Pied Barbet & 1 & 1 & 1 & 1 & 1 \\
\hline Crested Barbet & & & & & 1 \\
\hline Greater Honevquide & & & 1 & & 1 \\
\hline Golden-tailed Woodpecker & & 1 & & 1 & \\
\hline Cardinal Woodpacker & & 1 & & & \\
\hline Red-faced Mousebird & 1 & 1 & 1 & 1 & 1 \\
\hline Rufous-naped Lark & 1 & 1 & 1 & 1 & 1 \\
\hline Flappet Lark & 1 & & 1 & 1 & 1 \\
\hline Sabota Lark & & 1 & & & \\
\hline Black Cuckooshrike & 1 & 1 & 1 & 1 & 1 \\
\hline Fork-tailed Drongo & 1 & 1 & 1 & 1 & 1 \\
\hline Black-headed Oriole & & 1 & & & 1 \\
\hline
\end{tabular}

Chapter 4: Post-fire vegetation change and bird responses in Hluhluwe-iMfolozi Park 
Table 4.2 cont.: Birds observed 10 to 20 days before the fire events, and birds seen 0-90, 91-180, 181-270 and 271-350 days post fire. Specialists are highlighted

\begin{tabular}{|c|c|c|c|c|c|}
\hline Species & preburn & $0-90$ & $91-180$ & $181-270$ & $271-350$ \\
\hline Southern Black tit & 1 & 1 & 1 & 1 & 1 \\
\hline Green-winged Pytilia & & 1 & & & \\
\hline Dark-capped Bulbul & 1 & 1 & 1 & 1 & 1 \\
\hline Kurrichane Thrush & & 1 & 1 & & \\
\hline African Stonechat & & & & & 1 \\
\hline White-browed Scrub-Robin & & 1 & & 1 & \\
\hline Longbilled Crombec & 1 & & & 1 & 1 \\
\hline Zitting Cisticola & 1 & & 1 & 1 & \\
\hline Rattling Cisticola & 1 & 1 & 1 & 1 & 1 \\
\hline Croaking Cisticola & 1 & & 1 & 1 & 1 \\
\hline Southern Black Flycatcher & & 1 & 1 & & \\
\hline Pale Flycatcher & & 1 & & & \\
\hline Fiscal Flycatcher & & 1 & & & \\
\hline Chinspot Batis & 1 & 1 & 1 & 1 & \\
\hline African Pipit & & 1 & & & \\
\hline Plain-backed Pipit & & 1 & & & \\
\hline Yellow-throated Longclaw & 1 & 1 & 1 & 1 & 1 \\
\hline Common Fiscal & 1 & 1 & 1 & 1 & 1 \\
\hline \multicolumn{6}{|l|}{ Red-backed Shrike } \\
\hline Black-backed Puffback & & 1 & & 1 & \\
\hline Brubru & 1 & 1 & 1 & 1 & 1 \\
\hline Black-crowned Tchagra & 1 & 1 & 1 & & 1 \\
\hline Brown-crowned Tchagra & & & & 1 & \\
\hline Oranqe-breasted Bush Shrike & & & & & 1 \\
\hline Violet-backed Starling & 1 & 1 & 1 & 1 & 1 \\
\hline Cape glossy Starling & 1 & 1 & 1 & 1 & 1 \\
\hline Marico Sunbird & & & 1 & 1 & \\
\hline White-bellied Sunbird & & & & 1 & \\
\hline Scarlet-chested Sunbird & & & 1 & 1 & \\
\hline Southern Grey-headed Sparrov & & 1 & & & \\
\hline Yellow-throated Petronia & & 1 & 1 & 1 & \\
\hline Village Weaver & & 1 & & & \\
\hline Red-billed Quelea & & 1 & & & \\
\hline Fan-tailed Widowbird & 1 & & 1 & 1 & 1 \\
\hline White-winged Widowbird & 1 & & 1 & 1 & 1 \\
\hline Red-collared Widowbird & & & 1 & & 1 \\
\hline Blue Waxbill & 1 & 1 & 1 & 1 & 1 \\
\hline Common Waxbill & & & 1 & & \\
\hline Pin-tailed Whydah & & 1 & 1 & & \\
\hline Long-tailed Paradise-Whydah & & & 1 & & \\
\hline Yellow-fronted Canary & & 1 & 1 & 1 & \\
\hline Golden-breasted Bunting & 1 & 1 & 1 & 1 & 1 \\
\hline
\end{tabular}




\section{Discussion}

A number of African bird species are known have clear associations with fire. Fire fronts are used opportunistically to feed on fleeing insects (Dean 1987; Frost 1984), while post burn habitats are used for breeding and feeding (Dean 1987; Frost 1984; Tarboton 2001) . Certain species are known to be almost entirely restricted to early post burn areas, either for feeding or breeding (Frost 1984). This habitat may provide important and unique conditions for these species and be vital for maintaining populations (Hutto 1995). In HiP, small raptors and insectivorous birds followed the fire front with Fork-tailed Drongo and Yellow -billed Kite being the most numerous.

Senegal Lapwing and Plain-backed Pipits appeared shortly after the fire event. Both these species are known to feed and nest on recently burnt grasslands (Tarboton 2001). It is unlikely that they were breeding because both species were only present for approximately two weeks after the fire. Thus they were probably feeding on invertebrates and small vertebrates that were killed and exposed by the fire.

All tall grass specialists (with the exception of Red-collared Widowbird) were present before the fire event. After the fire event the regrowth vegetation was short and was colonised by short-grass inhabiting species. All short-grass specialists were present, but only for a relatively short time. Areas in iMfolozi (arid) were available for longer than in Hluhluwe (mesic) due to slower growth rates of grasses. A shift from short grass species to species more reliant on tall grass swards took place; within three months short grass specialists had been replaced by tall grass specialists.

Post-fire habitats recovered quickly and only created ephemeral habitats for short-grass specialists. A high-frequency fire regime may benefit insectivorous species feeding at the fire front and species that rely on fire for breeding and feeding. However species that feed at the fire front do so opportunistically and do not depend on fire fronts as their only food source. Species breeding and feeding in post burn areas tend to be highly mobile, enabling them to locate suitable breeding habitat irrespective of the fire management strategy employed, other than complete suppression (Mills 2003). Thus, it seems unlikely that these species will be affected by changes in fire frequency regimes. It would thus be more beneficial for the park to implement a fire management policy with low-frequency

Chapter 4: Post-fire vegetation change and bird responses in Hhuhluwe-iMfolozi Park 
fires, because a high-frequency regime would reduce the formation of grazing lawns (Archibald et al 2005), which is currently the only long-term sustainable habitat known to be available for short-grass specialists in the park.

More work relating to the ecological effect of fire on African avifauna is needed, to ensure that African avifauna does not fall into the same trap as the Australian avifauna, with some species already extinct and many others negatively affected by high-frequency fire regimes (Woinarski 1999). It would be particularly interesting to explore spatial variability in the fire regime and whether fire refugia are important for some bird species. 


\section{Chapter 5: Comparing grassland avifauna within HiP with surrounding communal lands}

\section{Introduction}

Although Hluhluwe-iMfolozi Park (HiP) consists mostly of savanna woodlands (Whateley \& Porter 1983), a mosaic of short and tall grasslands do occur. These two alternate grassland types not only provide a valuable food source for indigenous savanna herbivores but also provide an important habitat for birds. They support many generalist species and several short and tall grass specialists (Chapter 3). Outside the park, in the adjacent communal areas, domestic livestock has replaced savanna herbivores and much of the land has been altered by agriculture. Many of the savanna woodlands have been transformed into grasslands due to the high demand of trees for firewood and building material (Gjlbertson, pers comm.), resulting in a landscape with large expanses of short and tall grasslands, agricultural lands and rural settlements.

Because of the different land use practises outside the park, the grasslands inside and outside the park may be floristically and structurally different. In this chapter, I compare the grasslands outside the park with those inside the park with a particular emphasis on the short grass areas, as they may provide an alternative habitat for the short grass bird community dependent on the decreasing grazing lawns. If grasslands outside the park do support similar bird species, then they would be important for the overall conservation of grassland bird species. If 'overgrazed' communally farmed areas do not support these grassland bird species, then HiP would be important for the conservation of grassland birds on a regional scale. It would also highlight the need to conserve the remaining grasslands inside $\mathrm{HiP}$, in particular grazing lawns.

This chapter sets out to determine:

1. If short and tall grass areas outside the park are floristically similar to those inside HiP.

2. If short and tall grass areas outside the park are structurally similar to those inside HiP. 
3. If short and tall grass areas outside the park support a similar avifaunal assemblage to those inside HiP.

\section{Methods}

Study sites inside and outside HiP were used to compare grassland avifauna found inside HiP to that of the communal lands surrounding the park. Matched sites close to one another would have been ideal, however the distribution of grasslands within HiP did not allow for such a comparison. I therefore used the 24 sites already identified within the park (Chapter 3). Half of these sites were predominantly short-grass swards and the other half tall grass swards. Thirty sites were selected in the surrounding communal land, with half of the sites being short grass areas and the other half tall grass areas. The grassland patches ranged from 1 to 79 hectares in size and were marked with a fixed transect that traverses the longest axis. The location of these sites is shown in Figure 5.1. 


\section{Hluhluwe-iMfolozi Park}

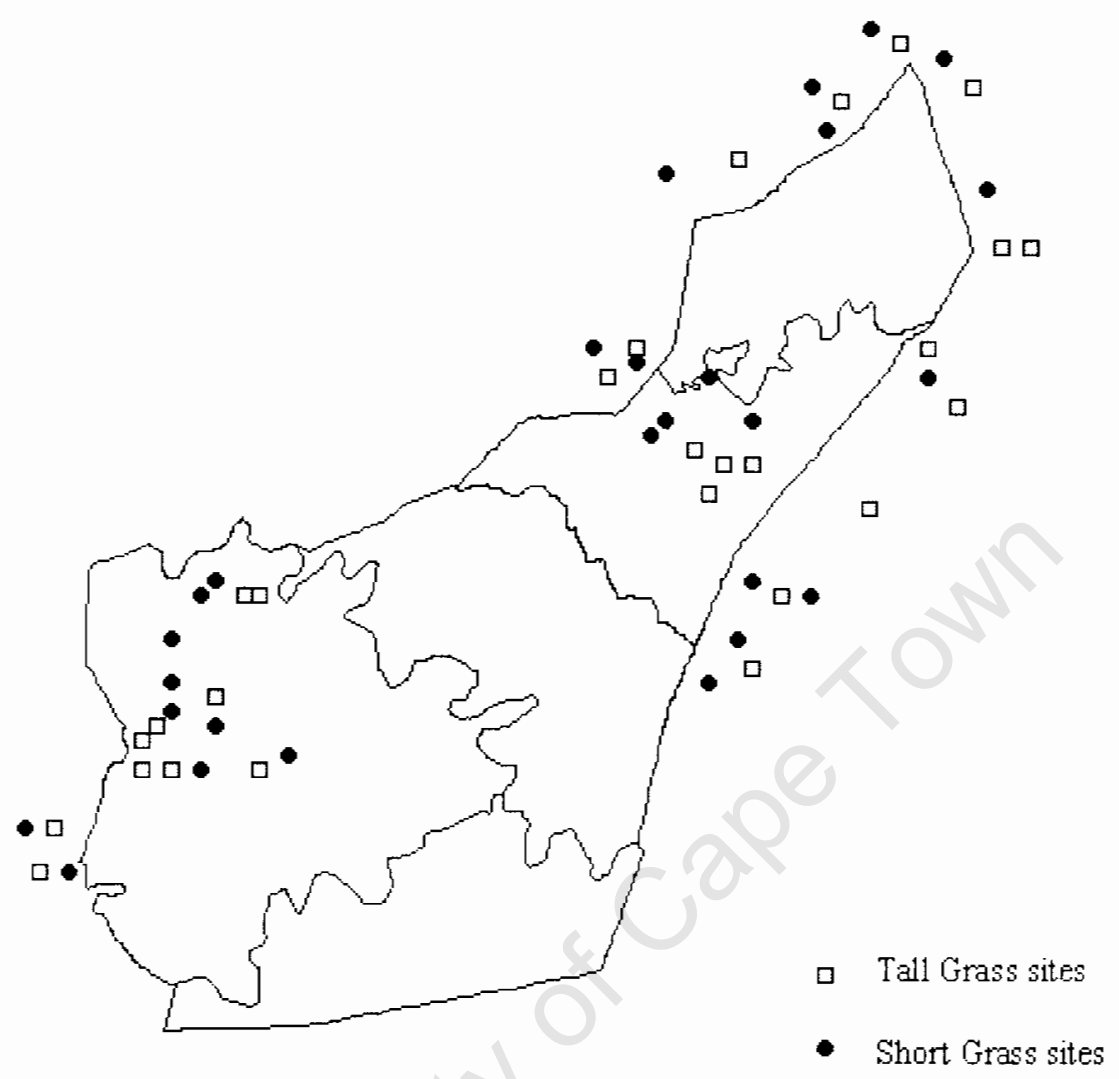

Figure 5.1: Map of Hluhluwe-iMfolozi Park illustrating the study sites 


\section{Quantifying bird populations}

The same bird survey techniques described in Chapter 3 were used to quantify bird population in the short and tall grasslands, inside and outside the park. However each site was only surveyed four times on two consecutive days in January 2004. Sampling took place during the first two hours after sunrise and the last two hours before sunset. When rain or wind appeared to affect bird activity or detectability, sampling was terminated. Data from these temporal replicates were pooled and treated as a single sample for each site.

\section{Characterising vegetation}

At the same localities where avifaunal data was collected, a survey of the structure and species composition of the vegetation was conducted. The following data were collected at each site:

1. Grass species composition.

2. Foliage biomass.

3. Horizontal foliage diversity and bare ground.

The dominant grass species were identified at one-metre intervals along the first $100 \mathrm{~m}$ of the fixed transect. An index of foliage biomass was obtained using a Disc Pasture Meter (Bransby \& Tainton 1977). A total of 50 data points were collected per transect at two metre intervals along the first $100 \mathrm{~m}$ of the fixed transect at each site. Horizontal foliage diversity of vegetation height, density and amount of bare ground were determined using the Intercept Method which gives a spatial index of bare ground, short grass swards, medium grass swards and tall grass swards (Chapter 3). Data from the Intercept Method, Foliage Biomass Index and grass species composition were collected once at each site during the study.

\section{Analytical methods}

In tall grass sward areas, where the rope-drag techniques were used, I assumed that all birds within the strip were flushed out. Hence calculations of density were simply a matter of dividing the total number of birds seen within the strip by the strip area. Within short grass swards, the computer program DISTANCE (Laake et al. 1994) was used to 
calculate densities. Although the techniques for estimating density in the tall and short grass swards differ, both estimate density, and thus their results are statistically comparable (see Chapter 3 for more details).

PRIMER (version 5.2.2.) was used to obtain a measure of diversity for each site, using the Shannon-Wiener diversity index:

$$
\mathrm{H}^{\prime}=-\sum_{i=1} \mathrm{p}_{i} \log 2 \mathrm{p}_{i}
$$

$\mathrm{s}==$ total number of species

$\mathrm{p}_{i}=$ observed proportion of individuals that belong to the $i$ th species

This index is influenced by the number of species present and the evenness of their distribution. Hence, increasing values of $H^{\prime}$ reflect higher species diversity. I used a Wilcoxon Test to test for differences in species number, density and diversity between the short and tall grass areas inside and outside the park.

\section{Results}

\section{Grass species composition}

There were differences between the grass species composition in $\mathrm{HiP}$ and on the adjacent communal lands (Table 5.1). Within the tall-grass areas, the sites inside the park were dominated by Themeda triandra. Outside the park, the majority of tall-grass sites, were dominated by Sporobolus pyramidalis. Short-grass sites within the park and outside the park were very similar. They were dominated by Digitaria argyrograpta in the south and Digitaria longiflora in the north. The only notable difference in the short-grass areas was that Aristida congesta was more prevalent in sites outside the park.

Chapter 5 . Companng grassland avifauna within HiP with surrounding communal lands 
Table 5.1: The relative percentage basal cover of the five most dominant grass species found inside and outside the park in tall and short grasslands

\begin{tabular}{|c|c|c|c|}
\hline Inside & & Outside & \\
\hline \multicolumn{4}{|l|}{ Tall grasslands } \\
\hline Themeda triandra & 80 & Sporobolus pyramidalis & 37 \\
\hline Sporobolus pyramidalis & 5 & Themeda triandra & 21 \\
\hline Bothrocloa insculpta & 3 & Hyparrhenia tamba & 20 \\
\hline Eragrostis curvula & 2 & Eragrostis curvula & 13 \\
\hline Hyparrhenia filiformes & 2 & Hyparrhenia filiformes & 7 \\
\hline \multicolumn{4}{|l|}{ Short grasslands } \\
\hline Digitaria argyrograpta & 24 & Digitaria longiflora & 28 \\
\hline Digitaria longiflora & 20 & Digitaria argyrograpta & 11 \\
\hline Sporobolus nitens & 15 & Aristida congesta & 10 \\
\hline Sporobolus ioclades & 13 & Sporobolus nitens & 7 \\
\hline Themeda triandra & 6 & Themeda triandra & 6 \\
\hline
\end{tabular}

\section{$\underline{\text { Vegetation structure }}$}

A Wilcoxon test revealed that the short grasslands outside the park were structurally very similar to the grazing lawns inside the park. The only significant difference was that the short grasslands outside the park had significantly more bare ground than the grazing lawns inside the park $(\mathrm{P}<0.05)$. Within the tall bunch grasslands, no significant difference was revealed between grasslands outside and inside the park. The results are shown in Table 5.2 
Table 5.2: A comparison of structural characteristics of short grazing lawns inside the park versus short grassland outside the park and tall grasslands inside versus tall grasslands outside the park. A Wilcoxon Test was used. The disk pasture meter reading is the settling height of the disk in $\mathrm{cm}$.

\begin{tabular}{lrrrr}
\hline & $\boldsymbol{n}$ & \multicolumn{1}{c}{ Inside } & Outside & Z \\
\hline & & & & \\
Short grass & & & & \\
Disc pasture metre reading & 27 & $2.8 \pm 0.1$ & $2.75 \pm 0.1$ & 0.04 \\
\% bare ground & 27 & $16.3 \pm 1.5$ & $20.7 \pm 1.5$ & $-1.95^{*}$ \\
$\%$ short grass & 27 & $72.5 \pm 1.6$ & $71.2 \pm 1.2$ & 0.09 \\
\% medium grass & 27 & $7.9 \pm 1.5$ & $6.0 \pm 0.9$ & 0.92 \\
$\%$ tall grass & 27 & $3.1 \pm 0.9$ & $1.9 \pm 0.7$ & 0.96 \\
& & & & \\
Tall grass & & & & \\
Disc pasture metre reading & 27 & $6.1 \pm 0.4$ & $7.68 \pm 0.7$ & -1.34 \\
\% bare ground & 27 & $5.8 \pm 1.9$ & $4.9 \pm 0.9$ & -0.09 \\
$\%$ short grass & 27 & $5.6 \pm 2.8$ & $2.3 \pm 0.8$ & 0.67 \\
$\%$ medium grass & 27 & $30.7 \pm 4.8$ & $27.0 \pm 4.7$ & 0.68 \\
\% tall grass & 27 & $57.7 \pm 5.0$ & $66.3 \pm 5.2$ & -1.51 \\
& & & & \\
\hline
\end{tabular}

${ }^{*} P<0.05 \pm$ standard error

\section{Bird species composition}

A total of 42 bird species were identified on the short-grass areas within HiP compared with only 21 species on the short-grass areas outside the park. The tall-grass areas inside the park supported 29 bird species and tall grasslands outside the park only 18 species. The number of birds species seen inside the park was lower than the number reported in Chapter 3, as the number reported in Chapter 3 stems from a full year of surveys while these results only reflect birds seen during January 2004.

For tall grass swards, a Wilcoxon test showed that species richness, density and species diversity on sites inside the park were significantly higher than at equivalent sites outside the park (Table 5.3). Similarly, species richness, density and species diversity on short grass swards were significantly higher inside HiP (Table 5.3). 
Table 5.3: Comparison between grassland birds on sites inside HiP with sites in the surrounding communal lands outside the park.

\begin{tabular}{|c|c|c|c|c|c|}
\hline & $n$ & Inside & Outside & $\mathrm{z}$ & \\
\hline \multicolumn{6}{|l|}{ Short grass } \\
\hline Species richness & 27 & $9.7 \pm 1.1$ & $3.7 \pm 0.33$ & 4.06 & 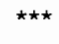 \\
\hline Density & 27 & $6.5 \pm 0.7$ & $1.7 \pm 0.2$ & 4.02 & $\star \star \star *$ \\
\hline Species diversity & 27 & $2.8 \pm 0.1$ & $1.6 \pm 0.1$ & 4.06 & $* \star \star$ \\
\hline \multicolumn{6}{|l|}{ Tall grass } \\
\hline Species richness & 27 & $6.8 \pm 0.8$ & $3.7 \pm 0.2$ & 2.97 & $* *$ \\
\hline Density & 27 & $10.6 \pm 1.3$ & $2.4 \pm 0.2$ & 4.27 & *** \\
\hline Species diversity & 27 & $2.3 \pm 0.2$ & $1.7 \pm 0.1$ & 2.44 & * \\
\hline
\end{tabular}

${ }^{\star} \mathrm{P}<0.05{ }^{\star \star} \mathrm{P}<0.01{ }^{* \star *} \mathrm{P}<0.001 \pm$ standard error

Inside the park, specialists were the numerically dominant species, outside the park the more ubiquitous species dominated (Figure 5.4 \& Figure 5.5). Although there were fewer species outside the park, all grassland bird specialists were present, except for Whitewinged Widowbird. 


\section{Short Grass areas}

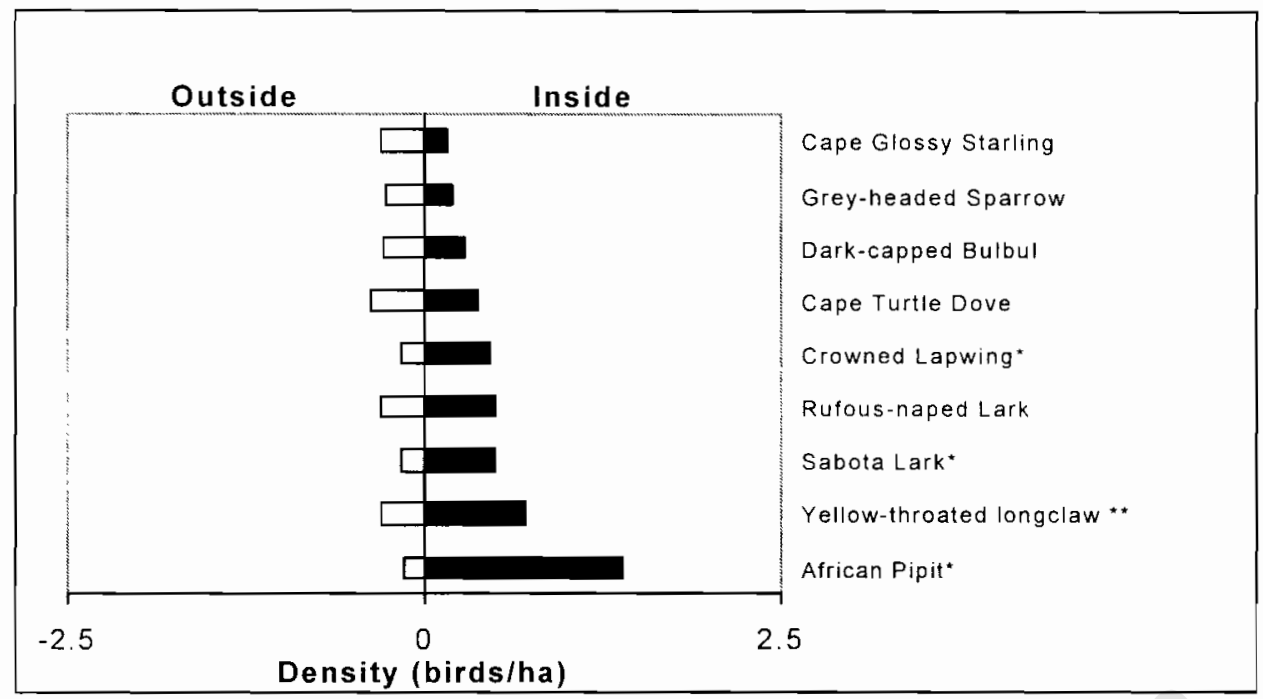

Figure 5.4: Comparison of individual densities of dominant bird species in short grass areas inside and outside HiP. One star represents short grass specialists and, two stars represent grassland generalists that make use of both tall and short grass areas

\section{Tall Grass areas}

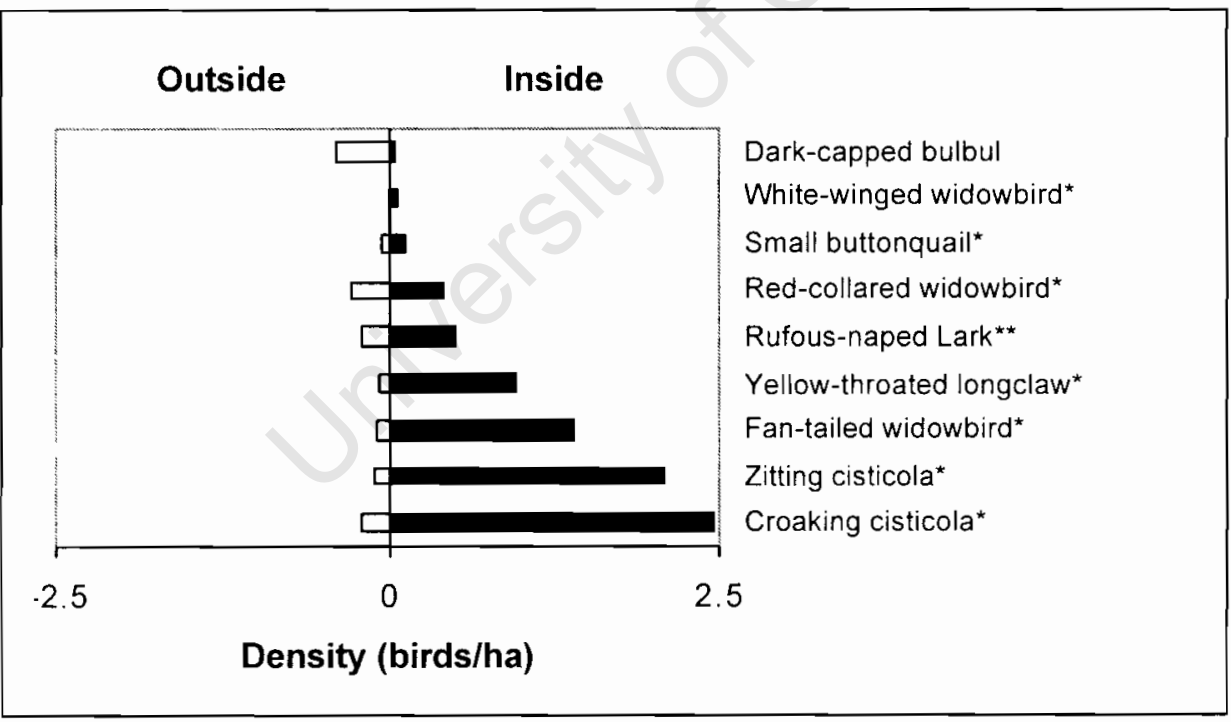

Figure 5.5: Comparison of individual densities of dominant bird species in tall grass areas found inside and outside HiP. One star represents tall grass specialists; two stars represent grassland generalists that make use of both tall and short grass areas 


\section{Discussion}

The results from this study suggest that grazing lawns inside the park and short grass areas outside the park share a similar grass species composition, with the exception of the grass species Aristida congesta which was more prevalent outside the park. Structurally the short grasslands are very similar, the only significant difference being that sites outside the park had a higher proportion of bare ground. Thus, with sites inside and outside the park being not only being structurally similar but also floristically similar, it was expected that sites outside the park would support similar bird communities to those found on the grazing lawns. Sites outside the park did support similar bird species, but densities outside the park were far lower than inside. Inside the park, specialists were the numerically dominant species, outside the park the more ubiquitous species dominated.

In tall grass areas, the floral compositions between bunch grassland inside and outside the park were quite different. Grasslands inside the park were dominated by Themeda triandra. Outside the park the dominant species was always Sporobolus pyramidalis However, there was no significant structural difference. As noted in chapter 3, bird distribution is related to structure and not floral composition; thus, these grasslands should support similar species. Similar bird species were present in bunch grasslands inside and outside the park but, as in the case of the short-grass areas, the densities outside the park were very low and the bird assemblage was numerically dominated by ubiquitous species rather than by tall-grass specialists.

These results suggest that some factor is affecting the grasslands birds outside the park. The exact cause is unknown, however it has been suggested that the low densities may be related to heavy predation by people living within these areas. This is investigated in the next chapter. 


\section{Chapter 6: Human predation on bird populations outside Hluhluwe- iMfolozi Park}

\section{Introduction}

Hluhluwe-iMfolozi Park is situated in the heart of Zululand, KwaZulu-Natal. Once the royal hunting grounds of King Shaka, this game reserve is now enclosed by an electric fence that separates it from the surrounding human population. The park supports a high diversity of animal and bird species, with over 400 indigenous bird species recorded. Bush encroachment, changes in fire regimes and herbivore numbers have resulted in the decrease of both tall and short grassland inside the park (Bond et al. 2001; Watson \& Macdonald 1983b). These decreases may be linked to the local extinction of several short grass frequenting species in the 1970s (Macdonald 1984). 88 bird species still make use of the grasslands within the park. These include three short-grass specialists, seven tallgrass specialists and two grassland specialists that use both short and tall grass areas(Chapter 3).

Ironically, in the unconserved communal rangelands that surround the park, vast expanses of grassland still exist. This is probably an artefact of the continual use of trees for firewood and building material by the local inhabitants. Consequently the grasslands outside the park have not suffered from bush encroachment to the same extent as has happened inside the park. Grasslands outside the park are structurally similar (Chapter 5) and hence are predicted to support similar species. This is the case, but they occur at unexpectedly low densities. Inside the park the grassland bird specialists are numerically dominant, while outside the park, generalists dominate. The cause of these differences is unknown and may be as a result of several factors.

One possibility is human predation since discussion with people living in the surrounding communal lands revealed that birds provided a valuable source of bushmeat. Bushmeat is an important source of protein in many rural and urban households throughout Africa (Nitamoa-Baidu 1997). In areas where wildlife still exists, people collect, hunt or purchase and eat bushmeat for a variety of reasons. Some people depend on bushmeat for their animal protein supply because they have no alternate source or cannot afford alternative sources; others eat bushmeat as a matter of preference or as a delicacy to be 
eaten on special occasions. For such people, wild animals constitute a valuable food resource that cannot be easily withdrawn or replaced without causing wide -ranging socio economic imbalances (Ntiamoa-Baidu 1997). This is particularly true in sub-Saharan Africa, where bushmeat is often the primary source of dietary protein (Anadu et al. 1988; Asibey 1977; Geist 1988; Juste et al. 1995; Martin 1983)

In this chapter 1 investigate the extent of bird hunting and egg harvesting in the communal lands surrounding $\mathrm{HiP}$, as it may provide valuable insight and help explain the low bird densities outside the park.

\section{Methods}

The extent to which grassland birds are being depredated by local villagers adjacent to $\mathrm{HiP}$ was assessed using a questionnaire survey. I trained seven local people to conduct the questionnaire survey on my behalf. This was done to encourage honest answers, as I was concerned that if I personally conducted them, the interviewee may associate me with a wildlife department and be less inclined to answer truthfully. This also allowed for the interview to be conducted in Zulu, the home language of the interviewees.

Members of local communities in the Dakaneni, Ezibayeni, Gunjaneni, Mansibomvu Mansiya, Mpanzakazi, Mpembeni, Phidsweni, Seme, Smolo and Sososo areas were visited in February 2004. A total of 136 people, 37 females and 99 males, all living within ten kilometres of the park boundary, were questioned in a single interview. The questionnaire was designed to evaluate three factors: namely to what extent are indigenous bird species and their eggs being consumed by local people, which birds species are preferred, and which techniques are used to catch the birds (Table 6.1). Additional information was also gathered regarding which cohort may be having the greatest impact.

Chapter 6 Human predationon bird populations outside Hluhluwve-iMfolozi Park 
Table 6.1: Questions asked to local people living adjacent to Hluhluwe-iMfolozi Park to examine the extent of bird predation by humans.

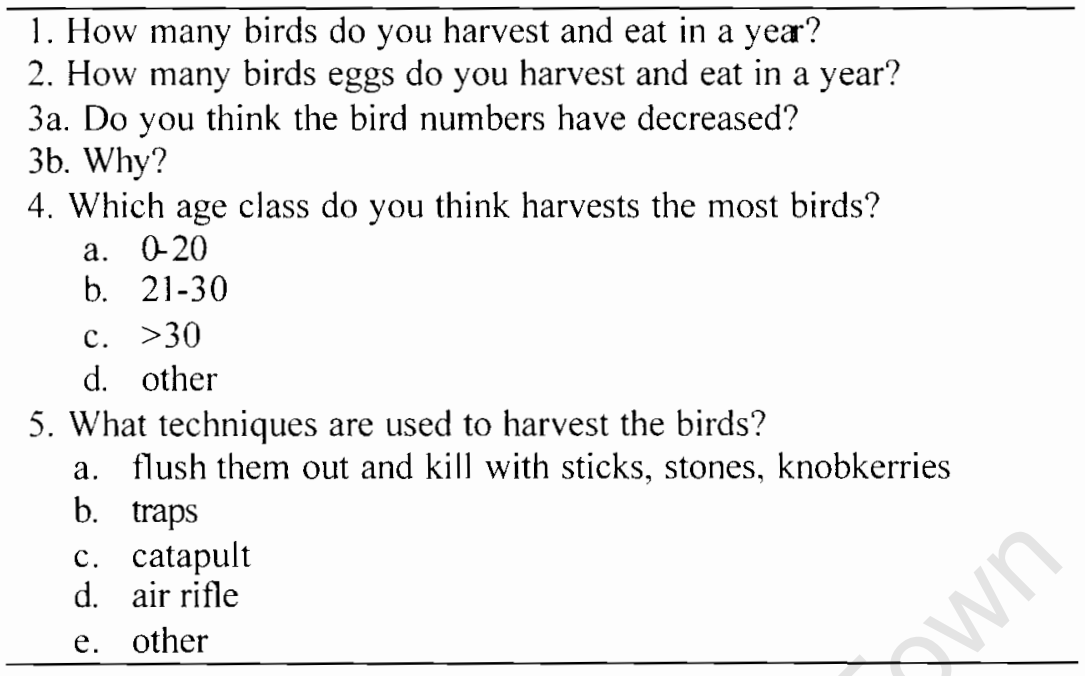

To avoid over - or underestimates when the interviewer requested each respondent to recall how many birds he or she had harvested/eaten over the preceding 12 month period, a series of questions regarding shorter periods were constructed. With this data in hand a calculation of the year's harvest was made, and the respondent asked if he or she felt the figure was reasonable.

A t-test was used to determine if a difference existed between the amount of birds and bird's eggs eaten by men and women. A one-way Anova was used to compare the consumption of the different age classes. For multiple response questions (Table 1, questions 4 and 5) I reported the results as a percentage based on the total number of people surveyed. In some cases more than one response was given, hence the results do not add up to 100. The answers to open ended questions were summarised.

Estimates of the total population living around the park were taken from a 1999 census undertaken by the African Centre (Gjlbertson 1999). These census results were used to estimate how many birds were being consumed by the total population living around the park. 


\section{Results}

A total of 136 people were questioned, 37 females and 99 males. The age varied from 7 to 72 years. At least 68 bird species were hunted for food in the study area, 9 of which were grassland specialists identified in Chapter 3 and two red data species: Grey Crowned Crane and Southern Bald Ibis (Table 6.2). Both these species are considered Vulnerable in South Africa (Barnes 2000).

Eggs of 20 species were collected, including 2 grassland specialists (Table 6.2). The occasional hunting of chicks and adults from the nest was also reported by the local people.

A total of 6787 birds were estimated to have been consumed in the year 2003 by the 136 people surveyed. Average consumption was 50 (10 lower quartile, 100 upper quartile) birds per person per year and 3 (0 lower quartile, 5 upper quartile) eggs per year. A comparison of consumption by men and women suggested that men ate significantly more birds per year $($ men $=66$ women $=7 \mathrm{P}<0.001)$ with no significant difference in egg consumption (Table 6.3). This was supported by comments made by several interviewees, in which it was mentioned that men actively go out and hunt birds and women only eat them when they are given a bird as a gift from a male family member. More than 25 percent of all people surveyed consumed more than 100 birds per year, with the highest harvest estimated at 250 birds per year.

People aged 21-30 consumed significantly more birds than those of other ages. This was supported by comments from the local people in which 73 percent of the people reported that the age class 21-30 harvested the most birds (Table 6.4). 
Table 6.2. List of all birds and bird's eggs reported to have been consumed from a questionnaire survey done in the communal areas surrounding Hluhluwe-iMfolozi Park. Grassland specialists are highlighted.

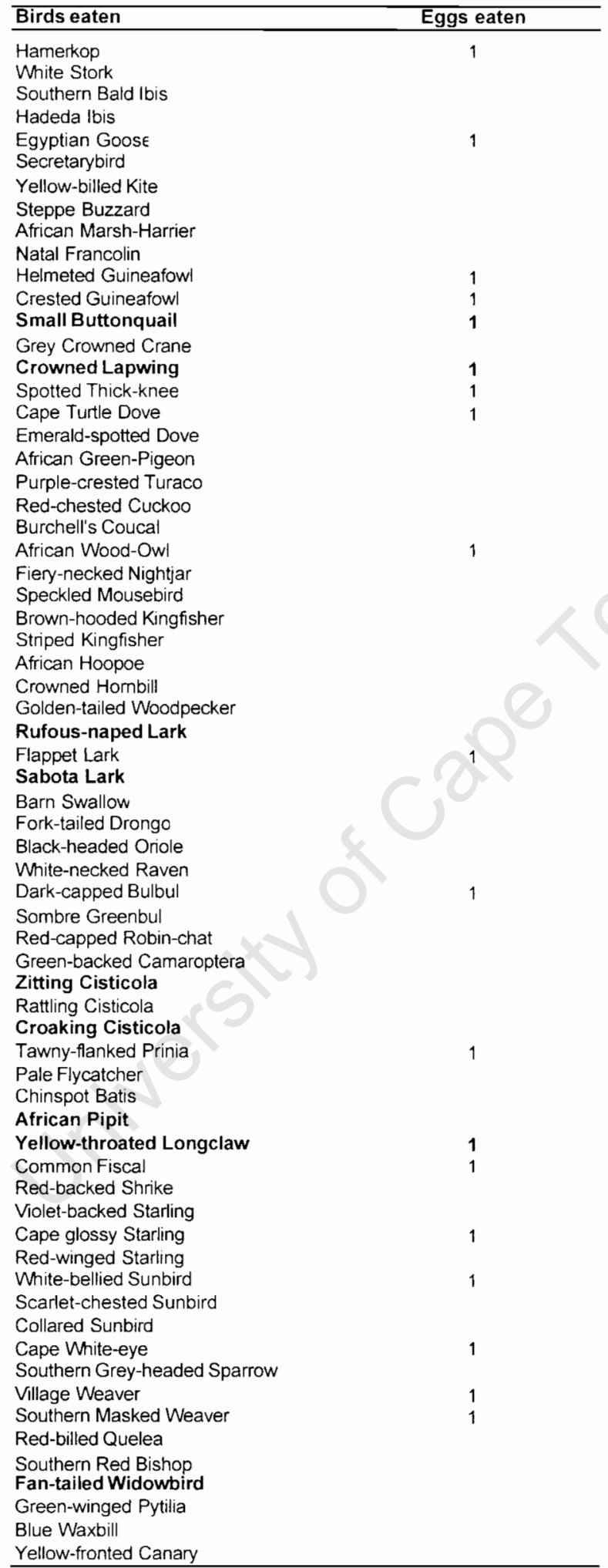


Table 6.3: The mean number of birds and eggs eaten over a 12 month period, by men and women of different age classes from in the communal area surrounding HluhluweiMfolozi Park.

\begin{tabular}{lcccc}
\hline Age Class & \multicolumn{2}{c}{ Birds eaten } & \multicolumn{2}{c}{ Eggs eaten } \\
& Women & Men & Women & Men \\
\hline $\mathbf{0 - 2 0}$ & $7.6 \pm 1.4$ & $56.4 \pm 1.0$ & $2.8 \pm 1.0$ & $2.7 \pm 0.5$ \\
$\mathbf{2 1 - 3 0}$ & $7.5 \pm 1.5$ & $138.6 \pm 7.8$ & $1.2 \pm 0.6$ & $6.4 \pm 2.3$ \\
& & & & \\
$\mathbf{3 0}$ & $6.5 \pm 1.4$ & $45.0 \pm 8.9$ & $1.4 \pm 0.5$ & $3.2 \pm 0.8$ \\
\hline
\end{tabular}

Table 6.4: Response to questions regarding age group responsible for the majority of hunting and hunting techniques used.

\begin{tabular}{rrr}
\hline Question & Response & Frequency \\
\hline \multirow{4}{*}{4} & $0-20$ & 22 \\
& $21-30$ & 73 \\
& $>30$ & 5 \\
& other & 0 \\
& & 67 \\
5 & flush & 53 \\
& traps & 21 \\
& catapult & 9 \\
& air rifle & 0 \\
\hline
\end{tabular}

The most common hunting techniques used were to flush the birds and then kill them with sticks, stones and knobkerries (67\%). This was done with the aid of hunting dogs or by several people walking $10 \mathrm{~m}$ abreast and driving the birds out. During such hunting sessions, hunters would often return with 20 or more birds. This technique was favoured during the summer month, while traps were used mainly during the winter months. The majority of traps described were set on the ground, thus targeting ground-dwelling species; however, traps were occasionally set in trees (Figure 6.1). The sap from mistletoes (Locanthaceae) was used as an adhesive to trap perching birds. Trees in fruit provided easy hunting ground, as many frugivores were easily shot with air rifles and catapults when they fed in such trees. 

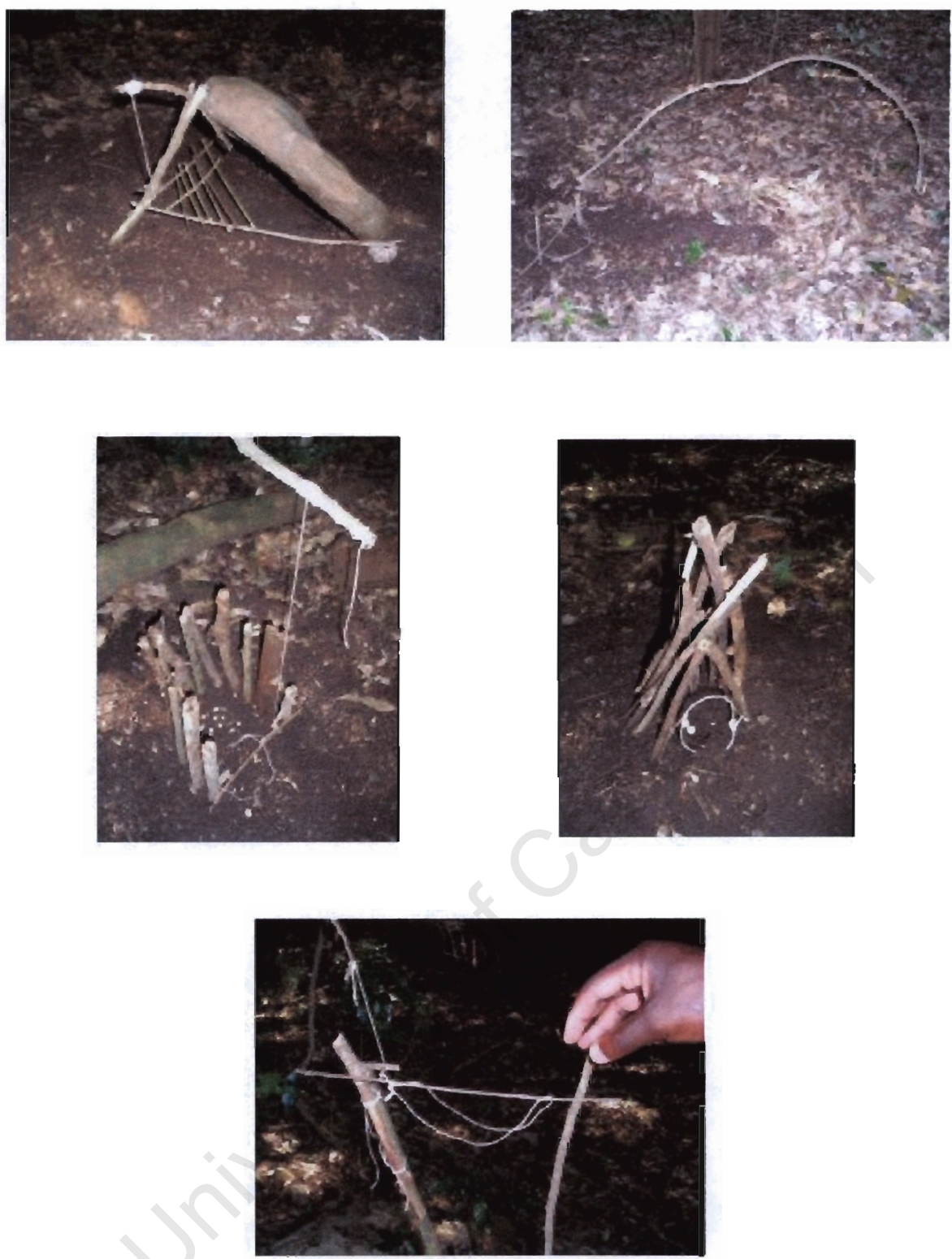

Figure 6.1: A selection of traps used to catch birds in the communal lands surrounding Hluhluwe-iMfolozi Park. 


\section{Discussion}

Human activities or 'anthropogenic factors' have had a dramatic impact on birds in South Africa, from deliberate and accidental poisoning to active hunting by farmers. There are several large raptor species that now have their only viable populations inside large protected areas (Kruger National Park, Kalagadi Transfontier Park, Ndumo, St Lucia, Hluhluwe-iMfolozi Park and Mkuzi), and have become virtually extinct outside them (Barnes et al. 2001). Many ground-nesting species also show distinct distribution 'gaps' over Lesotho and the former Transkei, both areas with dense human populations of rural people. These gaps are clearly due to anthropogenic factors though it is not clear whether the absence of the birds is caused by direct exploitation or incidental disturbance by people and livestock, or both (Barnes et al. 2001). The findings of this study suggest that bird populations in the communal areas surrounding HiP are also experiencing similar anthropogenic pressure. The human depredation of birds is rife in these communal areas, with egg harvesting also taking place but on a much smaller scale.

Sixty-eight bird species were reported to have been consumed. The survey did not reveal which species were the most heavily exploited, but the hunting techniques used targeted certain guilds more than others. The primary hunting technique of flushing birds with dogs or people was conducted in open landscapes such as grasslands with few trees. I would thus expect that birds that make use of the grasslands are at greatest risk. Similarly the second most common form of hunting was that of setting traps. Traps were usually placed on the ground, targeting ground-feeding species, which would once again include several grassland-frequenting species. The persistence of such hunting activities would have a greater effect on the grassland specialists than on generalists, as the specialists are limited to the grasslands for feeding, breeding and roosting, unlike the generalists that make use of a wide range of habitats to fulfil these roles. Thus I would expect generalist species to be more resilient towards such activities, which may explain why generalists were numerically dominant over specialists outside the park.

As from 2001, South Africans no longer required a license to own an air rifle. Rifles, together with catapults, are used to kill frugivores feeding on trees in fruit. Consequently frugivores are another guild at risk. The susceptibility to human predation may also be 
related to body size. A larger bird would be chosen over a smaller bird as it provides greater benefit (more food). Being of a large size makes it an easier target to hit and may also result in it being a clumsier flyer when flushed. As a result, large birds may be disproportionately at risk.

Men between the age of 20 and 30 harvested and consumed more birds than those of other age classes, with women rarely consuming birds. The average person was estimated to consume 50 birds per year, with men consuming more birds than women. The population around the park is $c a 118$ persons $/ \mathrm{km}^{2}$ (Gjlbertson 1999). Thus, if the findings of the questionnaire are a true reflection of bird predation, approximately $5900 \mathrm{birds} / \mathrm{km}^{2}$ are consumed annually. By extrapolating densities displayed in Table 5.2, it is estimated that within HiP the average bird density is $650 \mathrm{birds} / \mathrm{km}^{2}$, and outside the park it is approximately $170 \mathrm{bird} / \mathrm{km}^{2}$. This suggests that the estimate of $5900 \mathrm{birds} / \mathrm{km}^{2}$ may be grossly exaggerated and unreliable. This ten-fold discrepancy may lie in underestimates of bird densities, overestimates of birds eaten, or it may represent the annual harvestable surplus produced by the bird populations. The later is highly unlikely, as this would still indicate a production of almost ten times the standing stock. Bird density estimates seem reasonable; one bird in a circular patch with a radius of $c a .22 \mathrm{~m}$ inside the park compared to a patch of $43 \mathrm{~m}$ radius in the predated areas outside the park. The estimates of birds eaten rely entirely on the questionnaires, and clearly direct estimates of off-take are needed to help validate these estimates. It should, in principle, be possible to estimate potential annual harvest from estimates of bird population growth rates scaled, say, for different body mass of the species. An analysis of this kind might reveal that the park is an important source of birds, whereas communal areas act as a sink because of heavy predation pressure. There is very little information on demographic parameters of birds within the study areas and was therefore not possible to estimate harvestable off-take.

Given the apparent importance of birds as a supplementary food for people living in this area, it would be useful to explore the importance of the park as a potential source of birds in future research. This would help indicate whether the apparently high hunting pressure would be sustainable in the absence of a supply of birds from the adjacent protected area.

It is widely accepted that parks such as HiP are essentially for the conservation of large mammals. However as land degradation in South Africa increases, their role in 
conserving other biota increases. The findings of this chapter illustrate how communal areas, though less transformed than, say, a sugar cane field, are unable to conserve avifaunal species, in particular the grassland specialists. It has highlighted the importance of $\mathrm{HiP}$ as a protection area within the region, as it provides a safe refuge, in which the populations can grow and then re-colonise into unprotected areas. Over the longer term, the high human pressure on natural resources such as birds may dwindle as South Africa becomes more urbanised. 


\section{Chapter 7: The importance of large grazing lawns for grassland avifauna in Hluhluwe-iMfolozi Park}

\section{Introduction}

In South Africa (and elsewhere) rangeland scientists have perceived grazing lawns as products of overgrazing and mismanagement and considered tall Themeda triandra bunch grasslands as 'ideal veld'. The presence of 'overgrazed' patches prompted managers to reduce grazing pressure in an effort to convert short-grass areas to tall bunch grasslands. This was achieved by large-scale culling and game-capture operations. Recent studies (Zululand Grass Project, unpublished) have shown that grazing lawns are highly productive under intense grazing pressure. They are floristically different from tall bunch grasslands and support a high density and diversity of grazing herbivores. This, together with results from recent studies showing that grazing lawns support unique bird (Chapter 3) and grasshopper (Currie 2003) assemblages, suggests that they have a long evolutionary association with grazing herbivores and are thus a 'normal 'component of the African savanna.

Evidence exists to suggest that drought, fire and mammal removal may have influenced the extent of grazing lawns in HiP since the 1960s (Archibald et al. 2005; Bond et al. 2001). This is particularly evident in Hluhluwe, where long-term monitoring has shown dramatic clanges from short grass in the late 1960s to tall grass swards in the 1980s. White Rhinoceroses Ceratotherium simum are primarily responsible for maintaining grazing lawns in the northern higher rainfall areas of HiP (MS Waldram pers. com.). Thus, even though the rhinoceros population of the park is increasing (HiP park records) removal of many animals in the late 1970s and early 1980s resulted in low densities. Removal of rhinoceroses and other grazers may have been responsible for the decrease and disappearance of grazing lawns in the northern part of the park. Archibald et al. (2005) have shown how fire intervals of less than four years may reduce grazing lawn formation in HiP. After a fire event, herbivores are attracted to the postburn flush of new growth and consequently drawn off heavily grazed patches. Very small fires may concentrate grazers which might initiate a grazing patch but the normal large fires will pull grazers off grazing patches and cause the herbivores to spread out on the large burnt 
areas and thus have a less concentrating effect. In the long term, frequent large fires will indirectly reduce the density and diversity of large mammals species on grazing patches, and reduce lawn grass formation because grazers would not persist in a grazing patch long enough to cause a compositional shift from tall grass to lawn grass species. Thus the historical high fire frequencies of large fires in the park may have contributed to the decrease in grazing lawns.

This decrease in grazing lawn has coincided with the local extinction of many grassland birds, several of which are dependent on short grass areas (Macdonald 1984). The reason for their disappearance is unknown, but may be linked to the decrease in grazing lawns. This effect of habitat loss and fragmentation is not new and has been documented worldwide. The majority of avian examples stem from studies in forests, showing that species richness and relative abundance of area-sensitive species decreases significantly as patch size decreases (Opdam et al. 1985; Robbins et al. 1989). Grassland studies have also shown that grassland birds are experiencing extensive population decreases because of loss of large grassland patches (Helzer \& Jelinski 1999; Herkert 1994; Vickery et al. 1994). In a review of literature of bird and mammal responses to habitat fragmentation, Andren (1994) found that when the proportion of original habitat remaining was less than $30 \%$, habitat fragmentation increased isolation of patches and resulted in a decrease in species richness of birds and mammals.

Very little is known on the history of grazing lawns, and the reason behind the local bird extinctions are largely speculative. However, with the realisation that gazing lawns are not overgrazed areas and artefacts of mismanagement but rather highly productive grasslands hosting unique species, the need arises to conserve grazing lawns and the biota they support. To do so, we need to know how much grazing lawn is needed, and in what configurations should they exist within the landscape to ensure persistence of the biota they support. One way to answer this would be to determine the minimum viable populations of the relevant habitat specialists and the area required to support the minimum viable population. As a first general estimate of the minimum viable population for vertebrates, Franklin (1980) and Soule (1980) suggested 500 individuals, though much larger populations (or possible smaller ones) may be required depending on species biology (Meffe \& Carroll 1997).

Chapter 7: The impontance of large grazing lawns for grassland avifauna in Hlulyuwe-iMfolozi Park 
In this chapter I attempt to determine the area of grazing lawns habitat, and its configuration, needed to sustain viable populations of birds specialising on this habitat. Because no detailed information is available on populations sizes needed $\mathbf{b}$ maintain viable populations, I used the Frankin-Soule estimates and ask what area of lawns is needed to conserve them sustainably in HiP.

This chapter sets out:

1. to determine which of the birds species utilising grazing lawns are sensitive to changes in patch size;

2. to determine the minimum patch size for area-sensitive species;

3. to determine the population size of area-sensitive birds in HiP

4. to determine minimum area requirements to support 500 individuals; and

5. to use this information to recommend conse rvation strategies for grassland birds within HiP

\section{Methods}

\section{Field methods}

The 12 short grass areas identified in chapter 3 along with all bird data collected at these sites were used in this study. The mean number of individuals of each species occurring at each site was used to test whether a species-area relationship existed. This was done by creating a scatter plot of mean bird density versus area. A range of linear and non linear equations were fitted. The best fitting curve was determined by eye and by comparing correlation coefficients. This was done using the software JMP (version 5.0.1.2.).

Helzer \& Jelinski (1999), Herkert (1994) and Vickery et al. (1994) make use of the Robbins et al (1989) criteria for estimating minimum area requirements for area-sensitive grassland bird species. Due to lack of replication in my dataset, I was unable to make us of these criteria and thus devised alternative criteria. I calculated the minimum area, as the area of the smallest patch in which a particular species was seen and at which all patches larger than it also supported that particular bird species. For example, a particular species may have been observed on a patch that was 3 hectares in size, however this

Chapter 7 The importance of large grazing lawns for grassland avifauna in Hluhluwe-iMfolozi Park 
species was not seen in patches that were 4 and 5 hectares in size, but was seen on a 6 hectares patch and all patches larger than 6 hectares. Therefore although the smallest patch in which this species occurred was 3 hectares, my criteria for minimum area would conclude that the 6 hectares was the minimum area. However as the sample size of patches was limited to 12, I expressed minimum area as a range of 1 hectare above and below the value calculated above. Thus I would express the minimum patch area in this example as $5-7$ hectares.

The number of individual birds that the different size patches would support was calculated from the best-fit curve equation. These results together with information on the distribution of grazing lawn in the HiP (Archibald 2003) were used to estimate current population size of area-sensitive species and to determine how many grazing lawns of the minimum size patch would be required to support 500 individuals.

\section{Results}

A total of 74 bird species were identified as utilising the grazing lawns. This included many ubiquitous species and five grassland specialists. A non-linear reciprocal equation best described the density versus area relationship. Six species showed a significant increase in density with increasing patch area (Table 7.1). Dark-capped Bulbul $\left(\mathrm{R}^{2}=0.49\right.$, $\mathrm{P}<0.01)$, Golder breasted Bunting $\left(\mathrm{R}^{2}=0.52, \mathrm{P}<0.01\right)$, and Rattling Cisticola $\left(\mathrm{R}^{2}=0.35\right.$, $\mathrm{P}<0.05$ ) showed a significant negative relationship with a reciprocal best-fit curve. African Pipit $\left(R^{2}=0.72, P<0.001\right)$, Crowned Lapwing $\left(R^{2}=0.77, P<0.001\right)$ and Sabota Lark $\left(R^{2}=0.56, P<0.01\right)$ showed a significant positive relationship with a reciprocal best fit curve (Figure 7.1)

African Pipit required a minimum patch size of 3-5 ha, supporting 1-7 individuals. Crowned Plover required a minimum patch size of 46 ha, supporting $1-3$ individuals. Sabota Lark required the largest minimum patch size of 6-8 ha, supporting 2-4 individuals. Thus a minimum area of $c a 8$ ha is required to support all three short grass specialists (Figure 7.1).

According to the best fit equation a patch of 8 ha would support, 3.5 Crowned Lapwing and Sabota Lark and 13.6 African Pipit. Thus in order to support 500 individual Crowned 
Lapwing and Sabota Lark, 143 grazing lawn patches of 8 ha in size would be equired. Similarly 37 patches of 8 ha in size would be required to support 500 African Pipit. The cumulative total of grazing lawn required would then be 1144 ha for the former species and 296 ha for the latter.

Examination of the grazing lawns in the park from a Landsat image (Archibald 2003) revealed that in 1999 , about 6897 ha $(7 \%)$ of HiP consisted of grazing lawns. These consisted of 8231 patches ranging from 0.1 to 223 ha in size (Figure 7.2). A large percentage $(98.3 \%)$ were smaller than 8 ha in size, and thus unable to support all three area-sensitive species. The best-fit curve equation and the minimum patch size was used to calculate the number of Crowned Lapwing, Sabota Lark and African Pipits that could occur on each patch shown on the 1999 Landsat image. It was estimated that these grazing lawns could support 2343 Crowned Lapwing, 2247 Sabota Lark and 9219 African Pipit, with the greatest proportion of the population occurring on patches greater than 25 ha (Figure 7.3 ). 
Table 7.1: The probability of bird density versus area fitting a reciprocal best-fit curve of the most abundant birds found in grazing lawns

\begin{tabular}{|c|c|c|}
\hline Common name & F Ratio & Prob $>F$ \\
\hline \multicolumn{3}{|l|}{ Positive curve } \\
\hline Sabota lark & 16.420 & $0.002 * *$ \\
\hline African pipit & 13.580 & $0.006^{* *}$ \\
\hline Crowned lapwing & 7.080 & 0.032 * \\
\hline Red-billed quelea & 1.700 & 0.220 \\
\hline Rufous-naped lark & 1.270 & 0.302 \\
\hline Common fiscal & 0.809 & 0.389 \\
\hline Blue waxbill & 0.705 & 0.420 \\
\hline Pale flycatcher & 0.566 & 0.469 \\
\hline Fork-tailed drongo & 0.460 & 0.512 \\
\hline Yellow-throated longclaw & 0.450 & 0.517 \\
\hline Southern black flycatcher & 0.201 & 0.663 \\
\hline Red-backed shrike & 0.092 & 0.768 \\
\hline Southern grey-headed sparrow & 0.088 & 0.771 \\
\hline Cape glossy starling & 0.038 & 0.850 \\
\hline Cape turtle dove & 0.010 & 0.921 \\
\hline Red-faced mousebird & 0.009 & 0.956 \\
\hline \multicolumn{3}{|l|}{ Negative curve } \\
\hline Golden-breasted bunting & 10.910 & $0.008^{\star \star}$ \\
\hline Dark-capped bulbul & 9.928 & $0.010^{* *}$ \\
\hline Rattling cisticola & 5.400 & $0.042^{*}$ \\
\hline Violet-backed starling & 1.090 & 0.321 \\
\hline Yellow-throated petronia & 0.689 & 0.425 \\
\hline Yellow-fronted canary & 0.470 & 0.508 \\
\hline
\end{tabular}

${ }^{*} P<0.05^{* \star} P<0.01^{* \star *} P<0.001$ 
a)

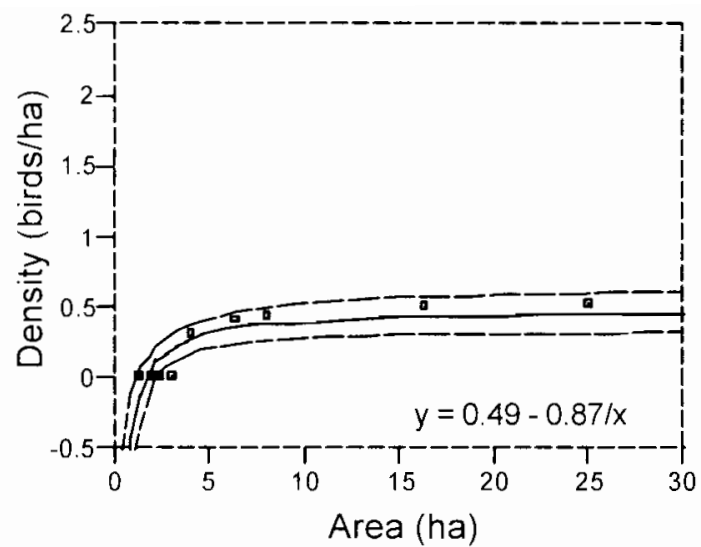

b)

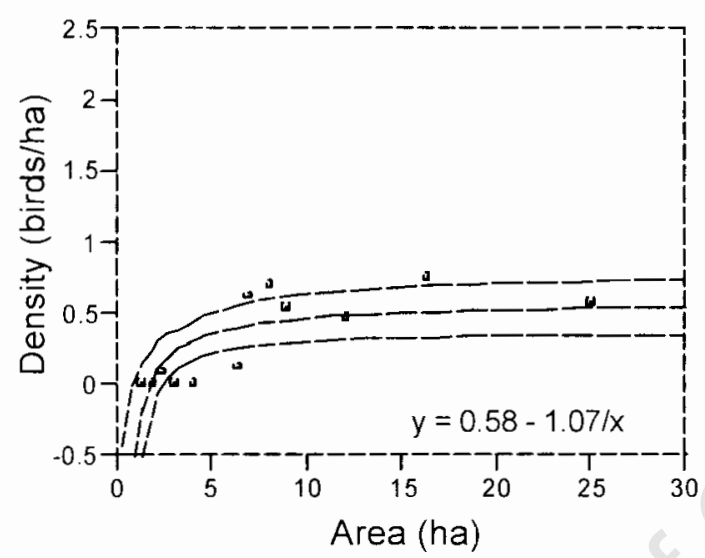

c)

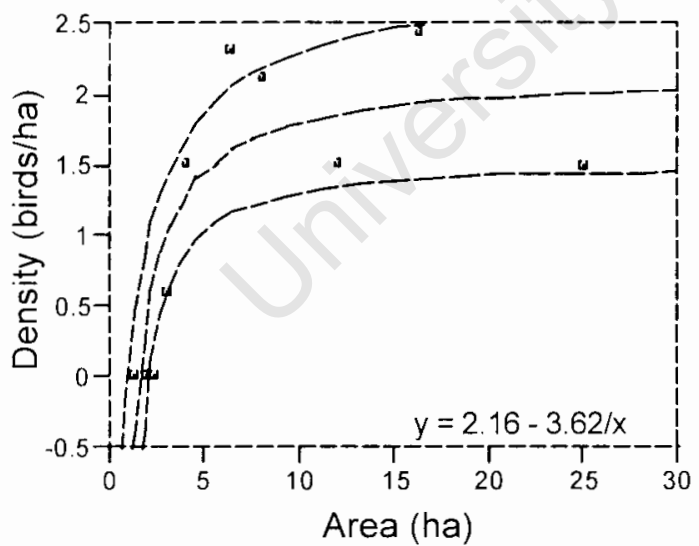

Figure 7.1: Scatter plot of density of a) Crowned Lapwing, b) Sabota Lark and c) African Pipit versus area. Solid line represents a best-fit reciprocal curve. Dashed lines represent $95 \%$ confidence limits. 


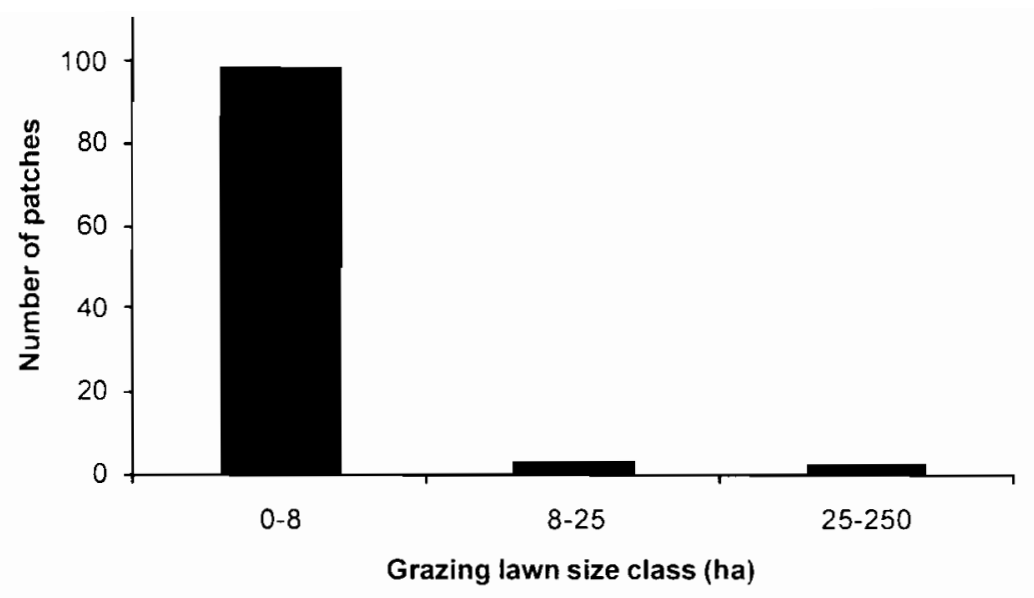

Figure 7.2: Frequency distribution of different sized grazing lawn patches in HiP from a 1999 Landsat image.

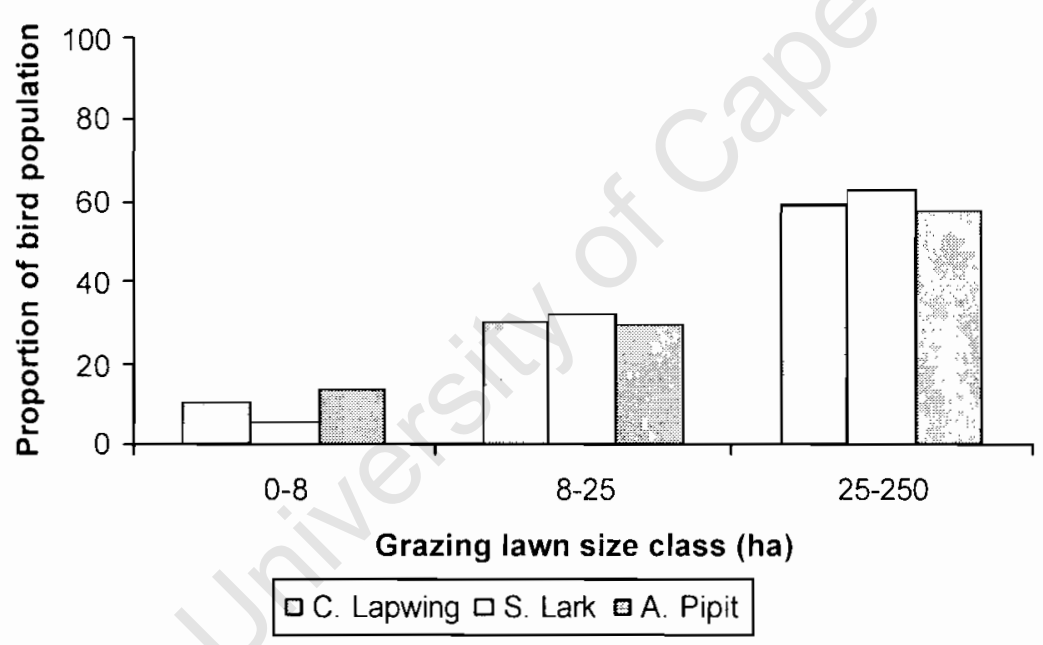

Figure 7.3: The estimated proportion of total Crowned Lapwing. Sabota Lark and African Pipit populations on different size grazing lawns 


\section{Discussion}

Grassland studies around the world have shown that grassland birds are experiencing extensive population decreases because of loss of large grassland patches (Helzer \& Jelinski 1999; Herkert 1994; Vickery et al. 1994). In the previous chapters I have shown that even though the distribution of the short grass bird specialists in HiP is largely related to vegetation structure and not floral composition, post burn bunch grasslands and heavily grazed communally farmed areas outside the park that are structurally similar, do not provide a suitable long term habitat. The post burn grassland only provided an ephemeral habitat as grass regowth is fast. Outside the park, dense human populations have resulted in the exploitation of indigenous species as a form of protein resulting in low bird densities. Thus in terms of the short grass bird community, HiP is effectively a biological island surrounded by a biological near-desert, and it appears that it is only the grazing lawns inside the park that can provide a sustainable habitat for the short grass specialists. Consequently the loss or decrease in these grazing lawns may result in the loss of these species from this region.

This study revealed that 74 bird species make use of grazing lawns within HiP. This includes many ubiquitous species, three short grassland specialist and two grassland specialists that make use of both short and tall grass habitats. Six species showed sensitivity to changes in area. Dark-capped Bulbul, Rattling Cisticola and Golden breasted Bunting significantly decreased in density as the size of grassland patches increased. These species are known to have an affinity with trees and shrubs, thus their decrease in number is probably related to decrease in edge effect as patch size increases. Crowned Lapwing, Sabota Lark and African Pipit all significantly increased in density with an increase in patch size, until a minimum patch size was reached and the densities leveled off. These species are all short grass specialists (Chapter 3). The two grassland specialists that inhabit both short and tall grass areas showed no sensitivity to changes in grassland patch size. Thus I would expect Crowned Lapwing, Sabota Lark and African Pipit to be the species to be most adversely affected by habitat loss or fragmentation, should grazing lawn patch size fall below their minimum patch size requirement. .

Using the Frankin-Soule 'rule of thumb' of 500 individuals as the minimum number for a viable population, I estimated that grazing lawns greater than 8 ha in size, that 
cumulatively total 1144 ha would be sufficient to support 500 Crowned Lapwing and Sabota Larks, and 296 ha for African Pipits. An examination of the grazing lawns in the park from a Landsat image (Archibald 2003), revealed that in 1999 about 6897 ha (7\%) of HiP consisted of grazing lawns. However, only a small percentage of these grazing lawns are large enough to support the specialist birds, with patches $>8$ ha accounting for only $1.74 \%$ of the number of grazing lawns. Taking into account minimum patch size, and the make-up of grazing lawns in 1999, it was estimated that grazing lawns in HiP could support 2343 Crowned Lapwing, 2247 Sabota Lark and 9219 African Pipit. These figures are well above the 500 'rule of thumb'. It is interesting to note that the grazing lawns in the mesic Hluhluwe end of the park are inadequate for supporting viable populations of short grass specialists, while those in the semi-arid iMfolozi end seem more than adequate (Figure 7.4). According to this study, f, say, iMfolozi were de-proclaimed, these species would be lost from this region.

Grazing lawns seem to have been much more extensive in the mesic savannas of Hluhluwe several decades ago. It is interesting to speculate whether the short grass specialists that have gone locally extinct in this reserve were as a result of the decline of lawn areas. In order to support viable populations of the current set of three short grass specialists in Hluhluwe, managers would need to extend the lawn grass area to at least 1144 ha. It is difficult to determine the exact size and configuration of the individual patches, however the results from this study suggest that at least 143 patches of 8 ha or one or several very large patches would be necessary.

This is a first approximation of the extent of grazing lawns needed to maintain specialist bird species. It does not include aspects of the biology of birds that might be affected by the spatial configuration of lawns, or that may require multiple patches for feeding or breeding. Nonetheless it does give a first indication of the extent of grassland area required. Of course, the current extent may already be too small for some species that no longer occur in the park.

Chapter 7 The umportance of large grazing lawns for grassland avifauna in Hlunluwe-ıMfolozi Park 


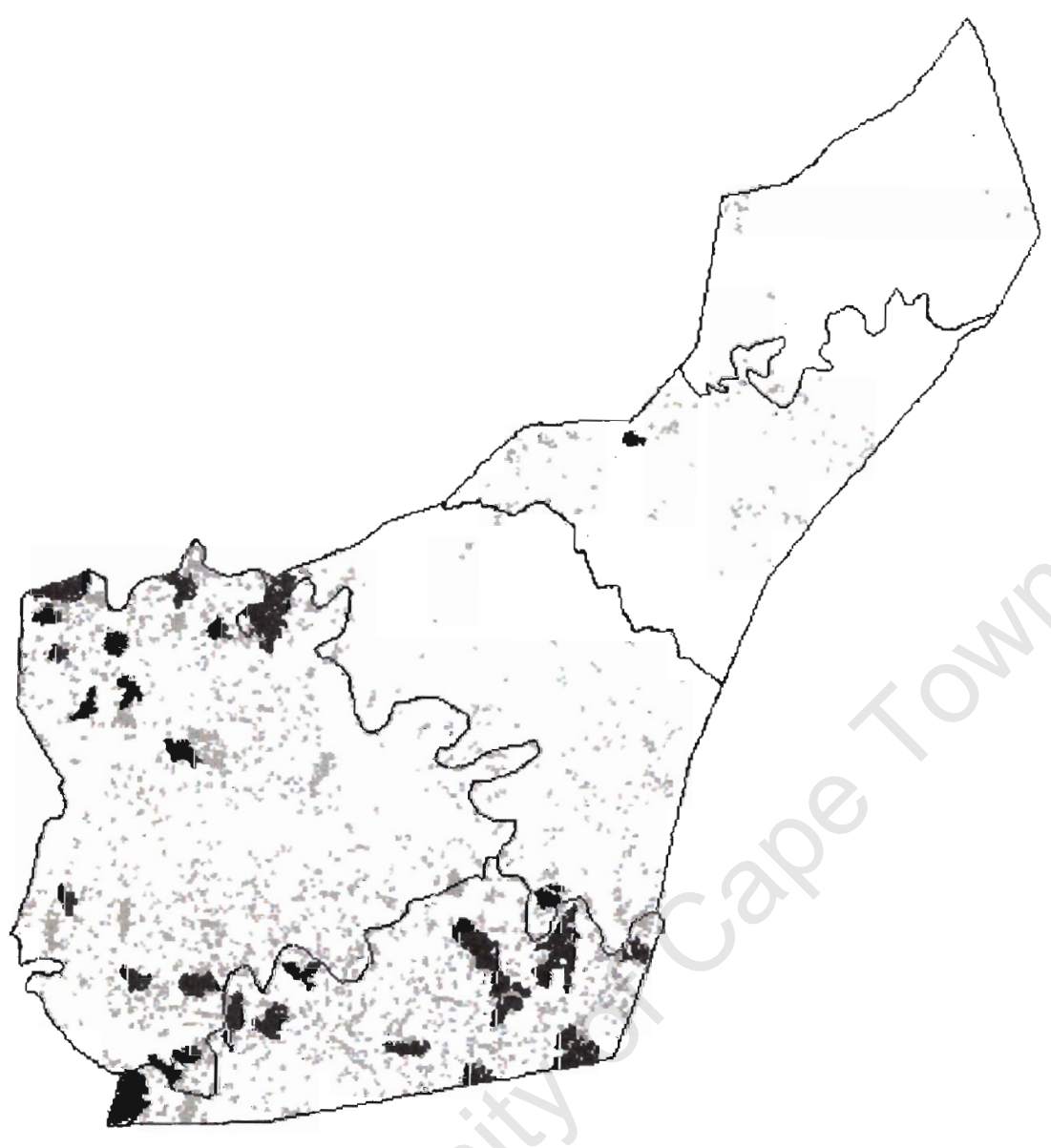

Figure 7.4: Map illustrating important grazing lawns in Hluhluwe-iMfolozi Park. Dark shaded areas represent grazing lawns that are larger than 25 hectares and are important in terms of grassland bird conservation. Lightly shaded areas represent grazing lawns that are smaller than 25 hectares and are of lesser importance. (Adapted from Archibald 2003) 


\section{Chapter 8: Conclusion}

Grassland ecologists recognise that grazing is a keystone process in maintaining the diversity of grasslands in the North American Great Plains (Collins 1992; Knapp et al. 1999). Shortgrass prairies evolved under intense grazing by prairie dogs Cynomys ludovicianus and bison Bison bison (Samson \& Knopf 1994). Consequently the shortgrass prairie avifauna evolved to select a variety of different site characteristics, created within a landscapes receiving grazing pressure ranging from light to severe (Vickery et al. 2000). Unfortunately, current rangeland practises in the shortgrass prairies strive to graze rangelands uniformly. These practices have removed or inhibited heterogeneous grazing impacts across the landscapes, which do not favour the specific habitat requirements of many bird species. For example, Mountain Plovers Charadruis montanus require heavily grazed sites for breeding, but Lark Buntings Calamospiza melanocorys prefer denser vegetation (Vickery et al. 2000). Therefore modern rangeland grazing techniques, along with the elimination of native herbivores and widespread fire suppression are thought to be responsible for the decline in several grassland bird populations (Fuhlendorf \& Engle 2001).

In Australia, where much of the megafauna no longer exists, fire plays an important role in shaping the landscape and its biota (Gill \& Cathing 2001). Detrimental fire regimes may have contributed to the extinction of two of the three bird species, and three of the four subspecies that have disappeared from Australia since European colonisation. Inappropriate fire management is now a factor in the threatened status of at least 51 nationally recognised threatened bird taxa in Australia (Woinarski 1999).

In Africa, where indigenous mammalian herbivores are still an important part of natural ecosystems, grazing lawn grass communities have a bng evolutionary history with grazing mammals and are a 'normal' component of many African savannas. This has been reflected in this study on grassland avifauna in Hluhluwe-iMfolozi Park (HiP). It has shown that grazing lawns, at one end of the grassland continuum support several uniquely adapted bird species and that bunch grassland at the other end of the continuum support different uniquely adapted bird species. These species have selected a particular suite of habitat features. Crowned Lapwing, Sabota Lark and 
African Pipit, for example, require the short sparse vegetation such as the grazing lawns where Small Buttonquail, African Stonechat, Zitting Cisticola, Croaking Cisticola, Fan-tailed widowbird, White-winged Widowbird and Red-collared Widowbird require taller, more dense vegetation. Some species have shown a preference to a broader range of grass types, such as Rufous - naped Lark and the Yellow-throated Longclaw that occur in both grassland types.

I found a significant link between grassland bird distribution and vegetation structure. Thus, habitats that were structurally similar to the grazing lawns, such as post-burn bunch grasslands and short grass areas created by domestic livestock outside HiP were expected to support short grass specialists. Post-burn bunch grasslands did support short grass specialist, but only for a relatively short time, as the grasslands recovered from the burn. In addition, the majority of management burns occur in July or August (HiP park records), which limits the temporal availability of such short post-burn grasslands to short grass specialists. Consequently, it is unlikely that a shifting mosaic of post fire habitats will be able to support short grass specialists year round. In the surrounding communal lands, specialists were present but bird densities were very low.

This means that in terms of short grass specialists, HiP is effectively a biological island surrounded by a biologically impoverished area with little possibility of outside areas acting as significant s ources of immigrants into the park. Because fire within the park creates only ephemeral habitats, it appears that it is only the grazing lawns that provide a sustainable habitat for short grass specialists.

l attempted to predict minimum area requirements for the specialist species and related this to existing grazing lawn areas. This analysis showed that short grass specialist require grazing patches $>8$ ha. However, only a small percentage of the grazing lawns in HiP are large enough to support the grazing lawn specialists, with patches $>8$ ha accounting for only $1.4 \%$ of the number of grazing lawns. My analysis also showed that the grazing lawns in the mesic Hluhluwe end of the park were inadequate to support viable populations of the birds. However the extent of short grass habitats is more than adequate in the semiarid iMfolozi end. Thus, although these specialists occur within a protected park that has been established for over 100 
years, the habitat in which they occur is still at risk of habitat loss or fragmentation. The two alternate grassland types, short stoloniferous grazing lawns and tall tussock like bunch grasslands are highly dynamic. The mosaic in which they occur is determined by grazing pressure and fire regimes, both of which can and have been used as tools to manipulate the landscape (Anderson 2003; Whateley \& Porter 1983). Consequently the success of these grassland specialists with different habitat preferences is highly dependent on management decisions.

For example, White Rhinoceroses Ceratotherium simum are primarily responsible for maintaining grazing lawns in the northern higher rainfall areas of HiP (MS Waldram pers. comm.). Thus, even though the rhinoceros population of the park is increasing (HiP park records), removal of many animals in the late 1970's and early 1980's resulted in low densities. Consequently the removal of rhinos and other grazers during this period may have been responsible for the decrease and disappearance of grazing lawns in the northern part of the park. Similarly, fire return intervals of less than fours years reduces grazing lawn formation, by indirectly reducing the density and diversity of large mammal species on grazing lawns (Archibald et al. 2005). As a result, the current high-frequency fire regime may have contributed to the decrease in grazing lawns.

To ensure conservation of the full complement of species in these savannas, management of these grassland areas should promote extension of grazing lawn habitat in Hluhluwe, and try to ensure that a mosaic of grassland habitat types exists throughout the park. This would ensure the availability of suitable habitat types at either end of the grassland spectrum, and would also provide habitat for birds whose preferences lie between these extremes. Further research efforts are also needed to identify critical area thresholds for other biota dependant on these grazing lawns 


\section{$\underline{\text { References }}$}

A.L., S., and B. W.J. 2003. Bird community composition in an actively managed savanna reserve, importance of vegetation structure and vegetation composition. Biodiversity and Conservation 1 2:2279- 2294.

Acocks, J. P. H. 1988. Veld types of South Africa. Botanical Research Institute, Pretoria.

Anadu, P. A., P. O. Elmah, and J. F. Oates. 1988. The bushmeat trade in southwestern Nigeria: a case study. Human Ecology 16:199-208.

Anderson. A. N. 2003. Burning Issues in Savanna Ecology and Management in R. J. Williams, editor. Fire in Tropical Savannas: The Kapalga Experiment. Springer-verlag, New York.

Andren, H. 1994. Effects of habitat fragmentation on birds and mammals in landscapes with different proportions of suitable habitat: a review. Oikos 71:355-366.

Archibald, S. 2003. Effects of frequent burning on grass-grazer interactions in a mesic savanna. Botany. University of Cape Town, Cape Town.

Archibald, S., W. J. Bond, W. D. Stock, and D. H. K. Fairbanks. 2005. Shaping the landscape: Fire-grazer interactions in an African savanna. Ecological Applications 15:96-109.

Asibey, E. O. A. 1977. Expected effects of land-use patterns on future supplies of bushmeat in Africa south of the Sahara. Environmental Conservation 4:43-49.

Balfour, D., and O. E. Howison. 2001. Spatial and temporal variation in a mesic savanna fire regime: responses to variation in annual rainfall. African Journal of range \& Forage Science 19:43-51.

Barnes, K. N. 2000. The Eskom Red Data Book of Birds of South Africa, Lesotho and Swaziland. BirdLife South Africa, Johannesburg.

Barnes, K. N., M. D. Johnson, and P. B. Taylor. 2001. South Africa in M. I. Evans, editor. Important Bird areas in African and associated islands: Priority sites for conservation. Pisces Publication and BirdLife International (BirdLife Conservation Series No.11), Newbury and Cambridge, UK.

Bibby, C. J., N. D. Burgess, D. A. Hill, and S. Mustoe. 2000. Point counts and point transects. Pages 91-112. Bird Census Techniques. Academic Press, London. 
Bond. W. J., K. A. Smythe, and D. A. Balfour. 2001. Acacia species turnover in space and time in an African savanna. Journal of Biogeography 28:117-128.

Bond, W. J., and B. W. Van Wilgen 1996. Plants and Fire. Chapman and Hall, London. UK.

Bransby, D. I.. and N. M. Tainton. 1977. The Disc Pasture meter: possible applications in grazing management. Proceedings Grassland Society South Africa 12:115-118.

Brooks, P. M., and I. A. W. Macdonald. 1983. The Hluhluwe-Umfolozi Reserve: An ecological case history. Pages 51-77. Management of large mammals in African conservation areas. Haum Educational Publishers, Pretoria.

Buckland, S. T., D. R. Anderson, K. P. Burnham, J. L. Laake, D. L. Borchers, and L. Thomas 2001. Introduction to Distance Sampling. Estimating abundance of biological populations. Oxford University Press, Oxford.

Catana. A. J. 1953. The wandering quarter method of estimating population density. Ecology 44:349-360.

Collins, S. L. 1992. Fire frequency and community heterogeneity in tallgrass prairie: A field experiment. Ecology 73:2001-2006.

Currie, G. 2003. The impact of megaherbivore grazers on grasshopper communites via grassland conversion in a savanna ecosystem. BSc Honours in Botany. University of Cape Town, Cape Town.

Dean, W. R. J. 1987. Birds associating with fire at Nylsvley Nature Reserve, Transvaal. Ostrich 58:103-106.

Deane, N. N. 1996. Ecological changes and their effect on a population of reedbuck (Redunca arundinum Boddaert). Lammergeyer 6:2-8.

Downing, B. H. 1980. Changes in the vegetation of Hluhluwe Game Reserve, Zululand, as regulated by edaphic and biotic factors over 36 years. J.S.Afr.Bot. 46(3):225-231.

Enslin, B. W., A. L. F. Potgieter, H. C. Biggs, and R. Biggs. 2000. Long term effects of fire frequency and season on woody vegetation dynamics of Sclerocarya birrea/Acacia nigrenscens savanna of the Kruger National Park. Koedoe 43:27-37.

Folse, L. J. J. 1982. An analysis pf the avifauna-resource relationship on the Serengeti plains. Ecological Monographs 52:111-127. 
Franklin, 1. R. 1980. Evolutionary changes in small populations. Pages 135-149 in B. A. Wilcox, editor. Conservation biology: an evolutionary-ecological perspective. Sinauer Associates, Sunderland, Massachusetts, USA.

Frost, P. G. H. 1984. The responses and survival of organisms in fire prone environments. Pages 274-309 in N. M. Tainton, editor. Ecological effects of fire in South African ecosystems. Springer-Verlag, Berlin.

Fuhlendorf, S. D., and D. M. Engle. 2001. Restoring heterogeneity on rangelands: Ecosystem management based on evolutionary grazing patterns. Bioscience 51:625-633.

Gauch, H. G. 1982. Multivariate methods in community ecology. Cambridge University Press, New York.

Geist, V. 1988. How markets for wildlife meat and parts, and the sale of hunting privileges wildlife conservation. Conservation Biology 2:15-26.

Gill, A. M., and P. Cathing. 2001. Fire regimes and biodiversit y of forested landscapes of southern Australia in A. M. Gill, editor. Flammable Australia; The Fire Regimes and Biodiversity of a Continent. Cambridge University Press, Cambridge.

Gjlbertson, B. 1999. Population estimates (1999) surrounding Hluhluwe-iMfolozi Park. Africa Centre for health and population studies, Mtubatuba.

Greyling, T., and B. J. Huntley. 1984. Directory of southern African conservation areas. South African National Scientific Programmes Report No. 98, A foundation for Research Development Publication, Pretoria.

Helzer. C. J., and D. E. Jelinski. 1999. The relative importance of patch area and perimeter-area ratio to grassland breeding birds. Ecological Applications 9:1448-1458.

Herkert, J. R. 1994. The effects of habitat fragmentation on mid-western grassland bird communities. Ecological Applications 4.

Hilden, O. 1965. Habitat selection in Birds. Annales Zoologici Fennici 2:53-75.

Hill, M. O. 1979. A FORTRAN program for detrended correspondence analysis and reciprocal averaging. Ecology and systematics, Cornell University, New York.

Hutto. R. L. 1995. The composition of bird communities following stand-replacement fires in northern Rocky Mountain (U.S.A.) conifer forests. Conservation Biology 9:1041-1058. 
Jansen, R. 2001. Population biology, behavioural ecology and management of the Redwing Francolin Francolinus levaillantii and Swainson's Spurfowl Pternistis swainsonii. Zoology. University of Cape Town. Cape Town.

Juste. J., J. E. Fa, J. Rerez del Val, and J. Castroviejo. 1995. Market dynamics of bushmeat species in Equatorial Guinea. Journal of Applied Ecology 32 :454467.

Kent, M., and P. Coker 1997. Vegetation Description and Analysis. A Practical Approach. John Wiley \& Sons L.td., West Sussex.

King, L. 1970. The geology of Hluhluwe Game Reserve. Petros: 16-19.

Knapp, A. K., J. M. Briggs, S. L. Collins, D. C. Hartnett, L. C. Johnson, and E. G. Towne. 1999. The keystone role of bison in North Americam tallgrass prairie. BioScience 49:39-50.

Knopf, F. L., J. A. Sedgewick, and R. W. Cannon. 1988. Guild structure of a riparian avifauna relative to seasonal cattle grazing. Journal of Wildlife Management $52: 280-290$.

Laake, J. L., S. T. Buckland, D. R. Anderson, and K. P. Burnham 1994. DISTANCE: user's guide, Fort Collins, CO: Colorado Cooperative Fish and Wildifie Research Unit, Colorado.

Low. A. B., and T. G. Rebelo 1996. Vegetation of South Africa, Lesotho and Swaziland. Dept. of Environmental Affairs and Tourism, Pretoria, Pretoria, South Africa.

MacArthur, R. H., and J. W. MacArthur. 1961. On bird species diversity. Ecology 42:594-598.

MacArthur, R. H., J. W. MacArthur, and J. Preer. 1962. On Bird Species Diversity. The American Naturalist XCVI:167-174.

Macdonald, I. A. W. 1979. A summary of recent changes in the vegetation of the complex. Veg. Dynamics workshop of the Central Complex.

Macdonald, I. A. W. 1983. Alien trees, shrubs, and creepers invading indigenous vegetation in Hluhluwe-Umfolozi Game Reserve Complex in Natal. Bothalia 14:949-959.

Macdonald. I. A. W. 1984. An analysis of the role of the Hluhluwe-Umfolozi Game reserves complex in the conservation of the avifauna of Natal. Proc. V. PanAfr. orn. Congr.:601-637. 
Macdonald, I. A. W., and P. J. Birkenstock. 1979. The implications of past vegetation changes for the avifauna of the central game reserves complex in Zululand.

Workshop meeting on vegetation dynamics in the central complex,Zululand.

Macdonald, I. A. W., and P. J. Birkenstock. 1980. Birds of the Hluhluwe-Umfolozi Game reserve Complex. Lammergeyer 29:1-56.

Martin, G. H. G. 1983. Bushmeat in Nigeria as a natural resource with environmental implications. Environmental Conservation 10:125-134.

Meffe, G. K., and C. R. Carroll 1997. Principles of conservation biology, 2nd edition. Sinauer Associates, Sundeland, Massachusetts.

Mills, M. S. L. 2003. Bird community response to savanna fires: should managers be concerned? South African Journal of Science 34:1-11.

Ntiamoa-Baidu, Y. 1997. Wildlife and food security in Africa.

Opdam, P., G. Rijsdijk, and F. Hustings. 1985. Bird communities in small woods in an agricultural landscape: effects of area and isolation. Biological Conservation 34:333-1250.

Owen-Smith, N. 1980. A quantitative assessment of the avifauna of the Umfolozi Thorn Savanna. Lammergeyer 30:4960.

Ralph, C. J. 1985. Habitat association patterns of forest and steppe birds of northern patagonia, Argentina. The Condor 87:471-483.

Robbins, C. S., D. K. Dawson, and B. A. Dowell. 1989. Habitat area requirements of breeding forest birds of the middle Atlantic sites. Wildlife Monographs 103.

Roth, R. R. 1976. Spatial heterogeneity and bird species diversity. Ecology $57: 773-$ 782.

Samson, F. B., and F. L. Knopf. 1994. Prairie conservation in North America. Bioscience 44:418-421.

Skowno, A. L., J. J. Midgley, W. J. Bond, and D. Balfour. 1999. Secondary succession in Acacianilotica (L.) savanna in the Hluhluwe Game Reserve, South Africa. Plant Ecology $145: 1-9$.

Soule, M. E. 1980. Thresholds for survival: maintaining fitness and evolutionary potential. Pages 151-170 in B. A. Wilcox, editor. Conservation biology: an evolutionary-ecological perspective. Sinauer Associates, Sunderland, Massachusetts, USA. 
Tarboton, W. 2001. Nests and Eggs of Southern African Birds. Struik Publishers, Cape Town.

Trollope, W. S. W., H. C. Biggs, A. L. F. Potgieter, and N. Zambatis. 1987. A structured vs a wilderness approach to burning in the Kruger National Park in South Africa. Pages 574575 in N. E. West, editor. Rangelands in a sustainable biosphere. Society for Range Management, Denver.

Vickery. P. D., J. R. Herkert, F. L. Knopf, J. Ruth, and C. E. Keller. 2000. Grassland birds: an overview of threats and recommended management strategies in I. Niles, editor. Strategies for bird conservation: the Partners in Flight planning process. Proceeding of the \#rd Partners in Flight workshop.

Vickery, P. D., M. L. Hunter Jr, and S. M. Melvin. 1994. Effects of habitat area on the distribution of grassland birds in Maine. Conservation Biology 8.

Vincent, J. 1970. The history of Umfolozi Game Reserve, Zululand, as it relates to management. Lammergeyer 11:7-49.

Watson, H. K., and I. A. W. Macdonald. 1983a. Conservation Management Implications of Vegetation Changes in the Hluhluwe- Umfolozi Game Reserve from 1937-1975.9.

Watson, H. K., and I. A. W. Macdonald. 1983b. Vegetation changes in the HluhluweUmfolozi Game Reserve Complex from 1937 to 1975. Bothalia 14:265-269.

Whateley, A., and R. N. Porter. 1983. The woody vegetation communities of the Hluhluwe-Corridor-Umfolozi Reserve Complex. Bothalia $14: 745-758$.

Wiens, J. A. 1969. An approach to the study of ecological relationships among grassland birds. Ornithological Monographs 8:1-93.

Wiens, J. A., and J. T. Rotenberry. 1981. Habitat associations and community structure of birds in shrubsteppe environments. Ecological Monographs 51:2141.

Willson, M. F. 1974. Avian Community organization and habitat structure. Ecology 55:1017-1029.

Wilson, M. V., and A. Schmida. 1984. Measuring Beta Diversity with presenceabsence data. Journal of Ecology $72: 1055-1064$.

Winterbottom. J. M. 1974. The zoogeography of South African avifauna. Annuals of the South African Museum 66:109-149. 
Woinarski, J. C. Z. 1999. Fire and Australian Birds: A review. Australia's Biodiversity-responses to fire: Plants, birds and invertebrates. 


\section{Appendix}

Appendix A: Bird species list

\begin{tabular}{|c|c|}
\hline Scientific name & Common name $^{\star}$ \\
\hline Scopus umbretta & Hamerkop \\
\hline Ciconia ciconia & White Stork \\
\hline Ciconia abdimii & Abdim's Stork \\
\hline Ciconia episcopus & Woolly-necked Stork \\
\hline Geronticus calvus & Southern Bald Ibis \\
\hline Bostrychia hagedash & Hadeda Ibis \\
\hline Alopochen aegyptiacus & Egyptian Goose \\
\hline Saqittarius serpentarius & Secretarybird \\
\hline Milvus aeqvptius & Yellow-billed Kite \\
\hline Buteo vulpinus & Steppe Buzzard \\
\hline Buteo rufofuscus & Jackal Buzzard \\
\hline Circus ranivorus & African Marsh-Harrier \\
\hline Circus macrourus & Pallid Harrier \\
\hline Falco rupicoloides & Greater Kestrel \\
\hline Guttera pucherani & Crested Guineafowl \\
\hline Pternistes natalensis & Natal Francolin \\
\hline Coturnix adansonii & Blue Quail \\
\hline Numida meleaqris & Helmeted Guineafowl \\
\hline Turnix svivatica & Small Buttonquail \\
\hline Balearica requlorum & Grev Crowned Crane \\
\hline Crex crex & Corn Crake \\
\hline Neotis denhami & Denham's Bustard \\
\hline Neotis ludwigii & Ludwig's Bustard \\
\hline Eupodotis melanoqaster & Black-bellied Bustard \\
\hline Charadruis tricollaris & Three-banded Plover \\
\hline Vanellus coronatus & Crowned Lapwing \\
\hline Vanellus lugubris & Senegal Lapwing \\
\hline Burhinus capensis & Spotted Thick-knee \\
\hline Cursorius temminckii & Temminck's Courser \\
\hline Streptopelia capicola & Cape Turtle-dove \\
\hline Turtur chalcospilos & Emerald-spotted Wood-Dove \\
\hline Treron calva & African Green-Pigeon \\
\hline Musophaga porphyreolopha & Purple-crested Turaco \\
\hline Curculus solitanius & Red-chested Cuckoo \\
\hline Oxylophus jacobinus & Jacobin Cuckoo \\
\hline Chrysococcyx klaas & Klass's Cuckoo \\
\hline Centropus arillii & Black Coucal \\
\hline Centropus burchelli & Burchell's Coucal \\
\hline Strix woodfordii & African Wood-Owl \\
\hline Asio capensis & Marsh Owl \\
\hline Caprimulqus pectoralis & Fiery-necked Niqhtiar \\
\hline Colius striatus & Speckled Mousebird \\
\hline Urocolius indicus & Red-faced Mousebird \\
\hline Halcyon albiventris & Brown-hooded Kingfisher \\
\hline Halcyon chelicuti & Striped Kingfisher \\
\hline Merops bullockoides & White-fronted Bee-eater \\
\hline Merops pusillus & Little Bee-eater \\
\hline Coracias garrulus & European Roller \\
\hline
\end{tabular}


Appendix A cont.: Bird species list

\begin{tabular}{|c|c|}
\hline Scientific name & Common name ${ }^{*}$ \\
\hline Coracias caudata & Lilacbreasted Roller \\
\hline Upupa africana & African Hoopoe \\
\hline Phoeniculus purpureus & Green Wood-Hoopoe \\
\hline Rhinopomastus cynomelas & Common Scimitarbill \\
\hline Tockus leucomelas & Southern Yellow-billed Hornbill \\
\hline Tockus alboterminatus & Crowned Hornbill \\
\hline Bucorvus leadbeateri & Southern Ground-hornbill \\
\hline Lybius torquatus & Black-collared Barbet \\
\hline Tricholaema leucomelas & Acacia Pied Barbet \\
\hline Pogoniulus pusillus & Red-fronted Tinkerbird \\
\hline Trachyphonus vaillantii & Crested Barbet \\
\hline Indicator indicator & Greater Honevauide \\
\hline Campethera abingoni & Golden-tailed Woodpecker \\
\hline Dendropicos fuscescens & Cardinal Woodpacker \\
\hline Jynx ruficollis & Red-throated Wryneck \\
\hline Mirafra africana & Rufous-naped Lark \\
\hline Mirafra rufocinnamomea & Flappet Lark \\
\hline Mirafra sabota & Sabota Lark \\
\hline Calandrella cinerea & Red-capped Lark \\
\hline Ereopterix leucotis & Chestnut-backed Sparrowlark \\
\hline Hirundo rustica & Barn Swallow \\
\hline Pseudhirundo qriseopyga & Grev-rumped Swallow \\
\hline Campephaqa flava & Black Cuckooshrike \\
\hline Dicrurus adsimilis & Fork-tailed Drongo \\
\hline Oriolus larvatus & Black-headed Oriole \\
\hline Corvus albus & Pied Crow \\
\hline Conus albicollis & White-necked Raven \\
\hline Parus niger & Southern Black Tit \\
\hline Anthoscopus caroli & Grey Penduline-Tit \\
\hline Pycnonotus tricolor & Dark-capped Bulbul \\
\hline Andropadus importunus & Sombre Greenbul \\
\hline Nicator qularis & Eastern Nicator \\
\hline Turdus libonyanus & Kurrichane Thrush \\
\hline Monticola explorator & Sentinel Rock-Thrush \\
\hline Oenanthe pileata & Capped Wheatear \\
\hline Saxicola torquata & African Stonechat \\
\hline Cossvoha natalensis & Red-capped Robin-Chat \\
\hline Cercotrichas teucophrys & White-browed Scrub-robin \\
\hline Schoenicola brevirostris & Broad-tailed Warbler \\
\hline Apalis flavida & Yellow-breasted Apalis \\
\hline Apalis ruddi & Rudd's Apalis \\
\hline Sylvietta rufescens & Lona-billed Crombec \\
\hline Eremomela icteropvqialis & Yellow-bellied Eremomela \\
\hline Camaroptera brachvura & Green-backed Camaroptera \\
\hline Cisticola juncidis & Zitting Cisticola \\
\hline Cisticola chinianus & Rattling Cisticola \\
\hline Cisticola natalensis & Croakina Cisticola \\
\hline Cisticola aberrans & Lazy Cisticola \\
\hline Prinia subflava & Tawny-flanked Prinia \\
\hline Melaenornis pammelaina & Southern Black Flycatcher \\
\hline
\end{tabular}


Appendix A cont.: Bird species list

\begin{tabular}{|c|c|}
\hline Scientific name & Common name \\
\hline Bradornis pallidus & Pale Flvcatcher \\
\hline Siqelus silens & Fiscal Flvcatcher \\
\hline Batis molitor & Chinspot Batis \\
\hline Terpsiphone vinidis & African Paradise-Flycatcher \\
\hline Anthus cinnamomeus & African Pipit \\
\hline Anthus similis & Lona-billed Pipit \\
\hline Anthus leucophrys & Plain-backed Pipit \\
\hline Anthus caffer & Bushveld Pipit \\
\hline Macronynx croceus & Yellow-throated Longclaw \\
\hline Lanius collaris & Common Fiscal \\
\hline Lanius collurio & Red-backed Shrike \\
\hline Convinella melanoleuca & Magpie Shrike \\
\hline Laniarius ferruaineus & Southern Boubou \\
\hline Dryoscopus cubla & Black-backed Puffback \\
\hline Nilaus afer & Brubru \\
\hline Tchaqra seneqala & Black-crowned Tchagra \\
\hline Tchaqra australis & Brown-crowned Tchagra \\
\hline Telophorus sulfureopectus & Orange-breasted Bush Shrike \\
\hline Malaconotus blanchoti & Grey-headed Bush-Shrike \\
\hline Cretophora cinerea & Wattled Starling \\
\hline Cinnvricinclus leucogaster & Violet-backed Starling \\
\hline Lamprotomis nitens & Cape glossy Starling \\
\hline Onvchoqnathus morio & Red-winged Starling \\
\hline Cinnyris mariquensis & Marico Sunbird \\
\hline Cinnyris talatala & White-bellied Sunbird \\
\hline Chalcomitra seneqalensis & Scarlet-chested Sunbird \\
\hline hedvdipna collaris & nbird \\
\hline Zosterops virens & e White-eve \\
\hline Passer diffusus & Southern Grey-headed Sparrow \\
\hline Petronia superciliaris & Yellow-throated Petronia \\
\hline Ploceus cucullatus & Village Weaver \\
\hline Ploceus velatus & Southern Masked Weaver \\
\hline Quelea quelea & Red-billed Quelea \\
\hline Euplectes onx & Southern Red Bishop \\
\hline Euplectes axillaris & Fan-tailed Widowbird \\
\hline Euplectes albonotatus & White-winged Widowbird \\
\hline Euplectes ardens & Red-collared Widowbird \\
\hline Phytilia melba & Green-winged Pytilia \\
\hline Laganosticta senegala & Red-billed firefinch \\
\hline Uraeqinthus anqlolensis & Blue Waxbill \\
\hline Estrilda astrild & Common Waxbill \\
\hline Vidua macroura & Pin-tailed Whydah \\
\hline Vidua paradisaea & Long-tailed Paradise-Whydah \\
\hline Vidua chalybeata & Village Indigobird \\
\hline Serinus mozambicus & Yellow-fronted Canary \\
\hline Serinus sulphuratus & Brimstone Canary \\
\hline Emberiza tahapisi & Golden-breasted Bunting \\
\hline
\end{tabular}

